\title{
Performance-Based Analysis of Steel Buildings: Special Concentric Braced Frame
}

\author{
A Thesis \\ presented to \\ the Faculty of California Polytechnic State University \\ San Luis Obispo, California
}

In Partial Fulfillment

of the Requirements for the Degree

Master of Science in Architecture with a Specialization in Architectural Engineering

by

Scott Michael Adams

September 2010 
(C) 2010

Scott Michael Adams

ALL RIGHTS RESERVED 


\section{COMMITTEE MEMBERSHIP}

TITLE:

AUTHOR:

DATE SUMMITTED:

COMMITTEE CHAIR: $\quad$ Kevin Dong, S.E.

COMMITTEE MEMBER: Cole McDaniel, PhD, P.E.

COMMITTEE MEMBER: Chris Poland, S.E.

COMMITTEE MEMBER: $\quad$ Robert Pekelnicky, S.E.
Performance-Based Analysis of Steel Buildings: Special

Concentric Braced Frames

Scott Adams

September 2010 


\begin{abstract}
Performance-Based Analysis of Steel Buildings: Special Concentric Braced Frame Scott Michael Adams
\end{abstract}

The performance-based analysis methods and evaluation criteria in ASCE 41-06 were used to evaluate a special concentric braced frame building based on the design standards in ASCE 7-05. A rectangular, six-story office building was evaluated using linear static, linear dynamic, nonlinear static, and nonlinear dynamic procedures. The results showed that the linear procedures underestimated damage compared to the nonlinear procedures, with the building performing to Life Safety for the linear procedures, and the nonlinear procedures indicating component damage beyond the intended Life Safety limit for the 2/3 maximum considered earthquake (MCE) hazard. This trend continued to the maximum considered earthquake hazard as well, under which the overall building performance for the linear procedures did not reach the Collapse Prevention level, which occurred in the nonlinear procedures. 


\section{ACKNOWLEDGMENTS}

I wish to acknowledge and thank those people that contributed to this thesis:

Chris Poland and Robert Pekelnicky of Degenkolb who proposed this project, and without whom none of this would have happened,

Kevin Dong who provided guidance and whose busy schedule provided me with an autonomy I benefited greatly from,

Ansgar Neuenhofer for his help procuring and modifying the ground motions,

and Matt Williams for sharing ideas and finding solutions to half my problems before I even knew they existed. 


\section{TABLE OF CONTENTS}

LIST OF TABLES ....................................................................................................... vii

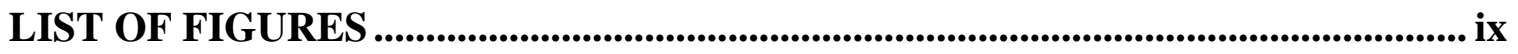

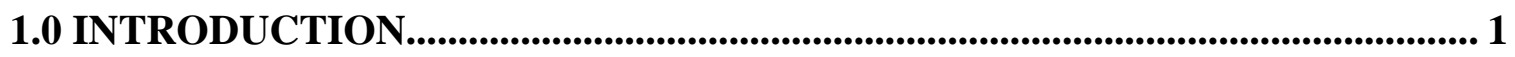

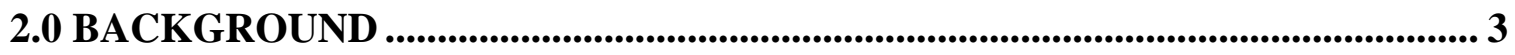

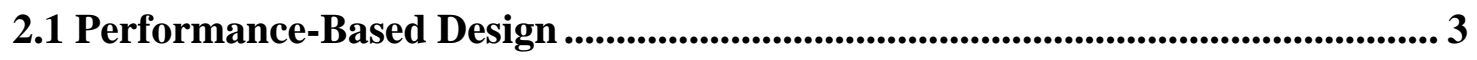

2.2 Linear Static Procedure ............................................................................. 4

2.3 Linear Dynamic Procedure........................................................................ 4

2.4 Nonlinear Static Procedure.......................................................................... 5

2.5 Nonlinear Dynamic Procedure ...............................................................6 6

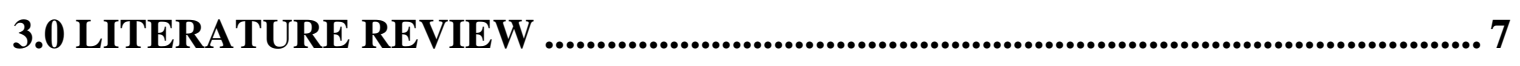

4.0 BUILDING DESIGN AND COMPUTER MODELING ................................... 9

4.1 Building Design ..................................................................................... 10

4.2 Computer Modeling Parameters ................................................................... 14

4.3 Verification of Computer Models......................................................................... 16

5.0 ANAL YSIS OF BSE-1 HAZZARD LEVEL ................................................... 18

5.1 Linear Static Procedure ............................................................................ 19

5.2 Linear Dynamic Procedure....................................................................... 22

5.3 Nonlinear Static Procedure ........................................................................................ 24

5.4 Nonlinear Dynamic Procedure ................................................................ 32

6.0 ANALYSIS OF BSE-2 HAZARD LEVEL ..................................................... 38

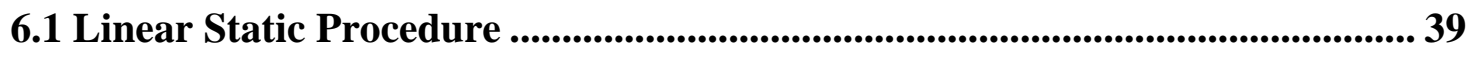

6.2 Linear Dynamic Procedure.......................................................................................... 42

6.3 Nonlinear Static Procedure..................................................................................... 44

6.4 Nonlinear Dynamic Procedure ................................................................... 49

7.0 COMPARISON OF ANALYSIS PROCEDURES .......................................... 53

7.1 BSE-1 Analysis Comparisons ......................................................................... 53

7.1.1 Comparison of the Four Primary Analysis Procedures................................. 53

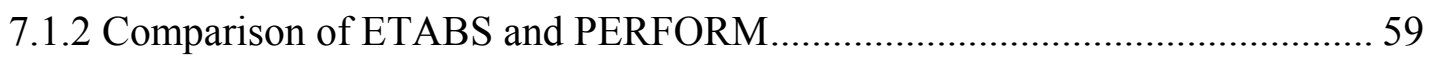

7.2 BSE-2 Analysis Comparisons ......................................................................66 6

7.2.1 Comparison of the Four Primary Analysis Procedures................................... 66

7.2.2 Comparison of ETABS and PERFORM................................................. 71

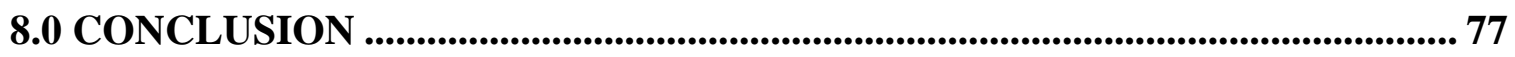

8.1 Building Performance.............................................................................................. 77 
8.2 Areas of Future Study ..............................................................................................8 81

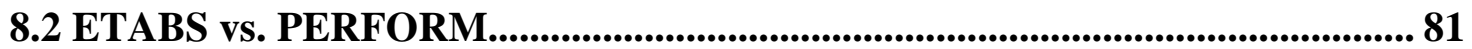

8.3 Comparison to Special Moment Frame Analysis............................................. 82

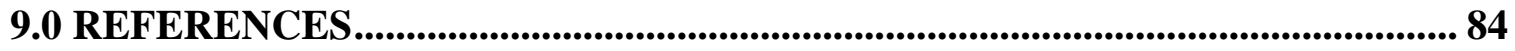

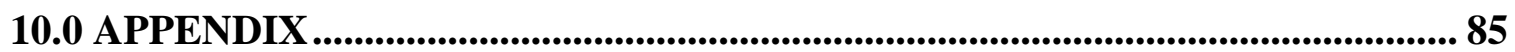

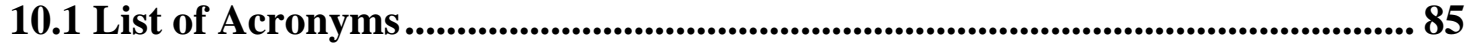




\section{LIST OF TABLES}

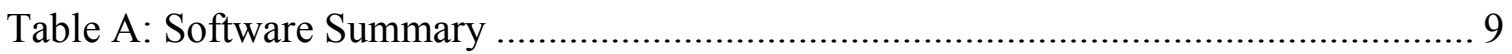

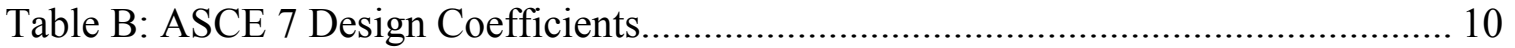

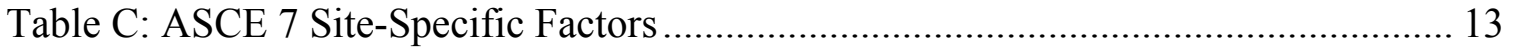

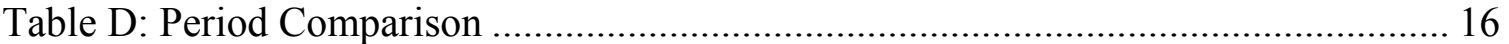

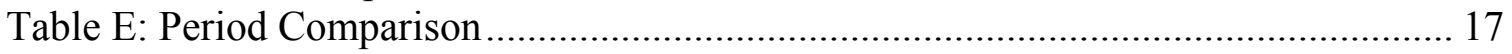

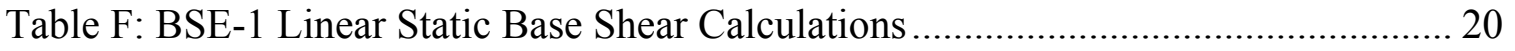

Table G: BSE-1 Nonlinear Static Target Displacement Calculation.............................. 24

Table H: BSE-2 Linear Static Base Shear Calculations ............................................ 39

Table I: BSE-2 Nonlinear Static Target Displacement Calculation ............................... 44

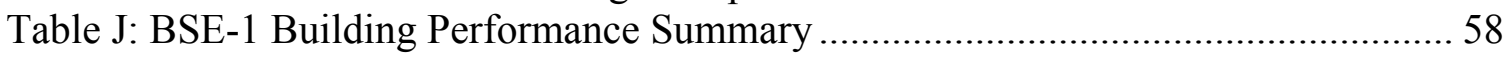

Table K: BSE-1 Roof Displacement Comparison .................................................... 59

Table L: BSE-2 Building Performance Summary ................................................... 71

Table M: Summary of Building Performance for All Analyses .................................. 77 


\section{LIST OF FIGURES}

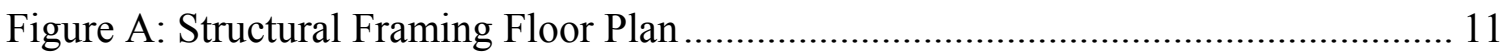

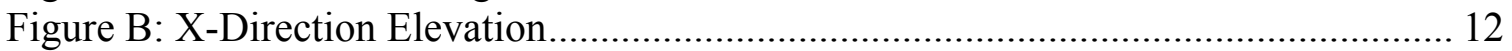

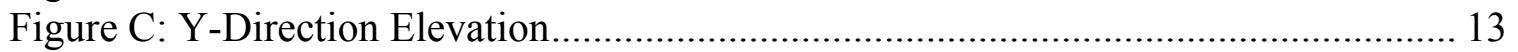

Figure D: ASCE 41-06 Nonlinear Force-Displacement Curve ……………………....... 15

Figure E: BSE-1 Site-Specific Response Spectrum................................................... 19

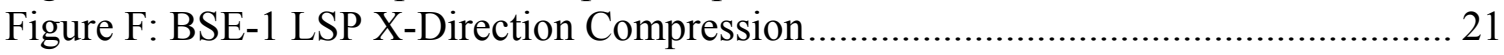

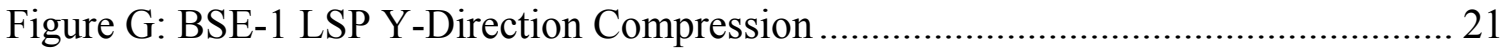

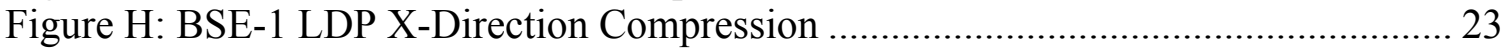

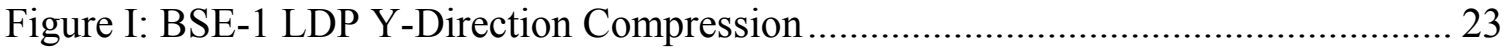

Figure J: BSE-1 X-Direction Force-Displacement Curve ............................................. 26

Figure K: BSE-1 Y-Direction Force-Displacement Curve ................................................ 27

Figure L: BSE-1 NSP PERFORM Triangular Loading X-Direction Compression .......... 29

Figure M: BSE-1 NSP PERFORM Triangular Loading Y-Direction Compression ......... 29

Figure N: BSE-1 NSP PERFORM Uniform Loading X-Direction Compression............. 30

Figure O: BSE-1 NSP PERFORM Uniform Loading Y-Direction Compression............. 30

Figure P: Seven Ground Accelerations..................................................................... 33

Figure Q: BSE-1 Response Spectrum Matching …………………………………….... 34

Figure R: BSE-1 NDP X-Direction Compression …………....................................... 36

Figure S: BSE-1 NDP Y-Direction Compression........................................................ 36

Figure T: BSE-2 Site-Specific Response Spectrum....................................................... 39

Figure U: BSE-2 LSP X-Direction Compression .......................................................... 41

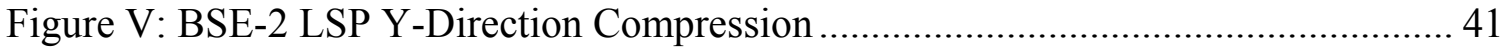

Figure W: BSE-2 LDP X-Direction Compression..................................................... 43

Figure X: BSE-2 LDP Y-Direction Compression …………......................................... 43

Figure Y: BSE-2 X-Direction Force-Displacement Curve ............................................... 45

Figure Z: BSE-2 Y-Direction Force-Displacement Curve ................................................ 46

Figure AA: BSE-2 NSP PERFORM Triangular Loading X-Direction Compression...... 47

Figure BB: BSE-2 NSP PERFORM Triangular Loading Y-Direction Compression ...... 47

Figure CC: BSE-2 NSP PERFORM Uniform Loading X-Direction Compression ......... 48

Figure DD: BSE-2 NSP PERFORM Uniform Loading Y-Direction Compression .......... 48

Figure EE: BSE-2 NDP X-Direction Compression ...................................................... 51

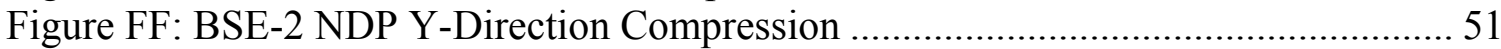

Figure GG: BSE-1 X-Direction Compression Comparison of All Procedures ................. 54

Figure HH: BSE-1 Y-Direction Compression Comparison of All Procedures ................. 54

Figure II: BSE-1 X-Direction Tension Comparison of All Procedures.............................. 55

Figure JJ: BSE-1 Y-Direction Tension Comparison of All Procedures ............................. 55

Figure KK: BSE-1 X-Direction Story Drift Comparison of All Procedures ..................... 56

Figure LL: BSE-1 Y-Direction Story Drift Comparison of All Procedures ...................... 56

Figure MM: BSE-1 NSP X-Direction Pushover Curve Comparison ................................ 60

Figure NN: BSE-1 NSP Y-Direction Pushover Curve Comparison.................................. 60 
Figure OO: BSE-1 NSP X-Direction Compression Comparison ................................ 61

Figure PP: BSE-1 NSP Y-Direction Compression Comparison.................................... 61

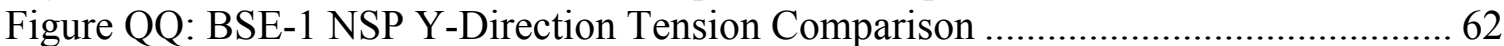

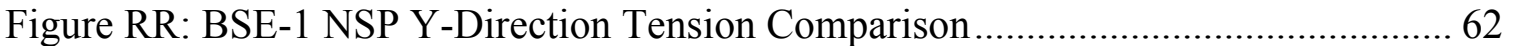

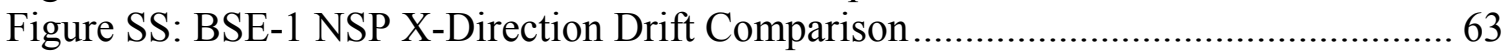

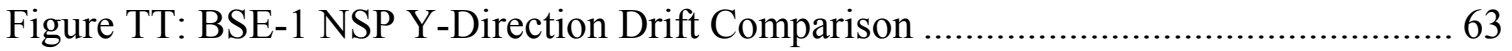

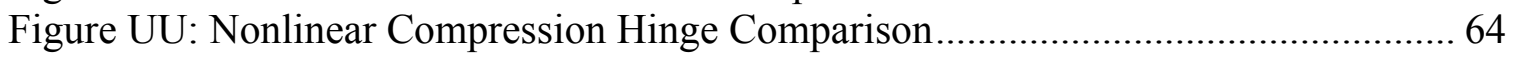

Figure VV: BSE-2 X-Direction Compression Comparison of All Procedures ................ 67

Figure WW: BSE-2 Y-Direction Compression Comparison of All Procedures............... 67

Figure XX: BSE-2 X-Direction Tension Comparison of All Procedures......................... 68

Figure YY: BSE-2 Y-Direction Tension Comparison of All Procedures......................... 68

Figure ZZ: BSE-2 X-Direction Story Drift Comparison of All Procedures ..................... 69

Figure AAA: BSE-2 Y-Direction Story Drift Comparison of All Procedures ................. 69

Figure BBB: BSE-2 NSP X-Direction Pushover Curve Comparison ............................ 72

Figure CCC: BSE-2 NSP Y-Direction Pushover Curve Comparison ............................. 72

Figure DDD: BSE-2 NSP X-Direction Compression Comparison ............................. 73

Figure EEE: BSE-2 NSP Y-Direction Compression Comparison.................................. 73

Figure FFF: BSE-2 NSP X-Direction Tension Comparison........................................ 74

Figure GGG: BSE-2 NSP Y-Direction Tension Comparison...................................... 74

Figure HHH: BSE-2 NSP X-Direction Drift Comparison............................................. 75

Figure III: BSE-2 NSP Y-Direction Drift Comparison ............................................. 75 


\subsection{INTRODUCTION}

The purpose of this thesis is to assess the performance of buildings designed using standards created by the American Society of Civil Engineers (ASCE). To this end, a lateral force resistance system designed to the seismic loads specified by ASCE 7-05 has been evaluated using the four performance-based analysis methods detailed in ASCE 4106:

- Linear static procedure

- Linear dynamic procedure

- Nonlinear static procedure

- Nonlinear dynamic procedure

The evaluation was completed using a six-story, rectangular, special concentrically braced, steel frame building located in San Francisco, CA.

The ASCE 7-05 seismic provisions utilize a linear static or dynamic analysis to derive the design forces for a structure, which is not always accurate when compared to actual earthquake loads. The writers of ASCE 41-06 believe that the limits on permissible building response from the linear analyses will provide excess conservatism in the nonlinear models (ASCE 41-06). However, it is uncertain how a product of ASCE 7-05 linear design will perform under the more rigorous nonlinear analysis methods provided in ASCE 41-06.

Also of interest is a comparison of the results from each of the four ASCE 41-06 analysis methods. The linear analysis methods take less time and computational effort than the nonlinear methods, but it is not clear if the nonlinear methods produce significantly more accurate results for this type of structure. 
The target performance levels presented in ASCE 41-06 will also be investigated. The design intent of ASCE7-05 is for structures to perform to the Life Safety limits for the design earthquake, and to Collapse Prevention for the maximum considered earthquake. However, it is uncertain if all building types will actually meet these goals for each analysis procedure. 


\subsection{BACKGROUND}

Performance-based design is gaining popularity as a means of limiting excessive building damage and maintaining building function after a seismic event. Performancebased design utilizes performance objectives to determine acceptable levels of damage for a given earthquake hazard. These performance objectives can vary from limiting story drift to minimizing component damage. The objectives provided by ASCE 41-06 evaluate individual structural component damage, which the user can then relate to a performance level for the building as a whole. Predicting the level of damage a building

will experience is an important factor in providing life safety, and mitigating the financial impact of repairing structures after an earthquake.

\subsection{Performance-Based Design}

Early work on Performance-based design (PBD) was conducted by the Applied Technology Council (ATC), the Structural Engineers Association of California (SEAOC), and the Federal Emergency Management Agency (FEMA). The origins of performance-based design can be traced to three separate documents: SEAOCs "Vision 2000: Performance-Based Seismic Engineering of Buildings," ATC 40, and FEMA 273/274 (Ghobarah 2001). Published in 1995, Vision 2000 called for performance-based procedures to be used in the design of new construction, though the only legally binding document was FEMA 273/274, published in 1997, which would later be standardized as ASCE 41-06 (Hamburger 2008). ASCE 41-06 provides analysis methods and acceptance criteria to predict the performance level of a building. 


\subsection{Linear Static Procedure}

The linear static procedure (LSP) calls for buildings to be modeled with linearly elastic stiffness and equivalent viscous damping values consistent with components responding near yield level. A lateral force is used to calculate internal forces and system displacements resulting from the design earthquake. The magnitude of the lateral force is intended to result in design displacements that approximate the maximum displacements expected during the design earthquake. However, at these displacements, the resulting internal forces in the lateral resisting system will typically be larger than those that would actually occur if nonlinearity had been included. The internal forces in the lateral resisting system are evaluated by comparing them to an acceptable force level. The acceptance criteria include modification factors to account for the anticipated inelastic response of the actual structure (ASCE 41-06).

\subsection{Linear Dynamic Procedure}

The linear dynamic procedure (LDP) employs a modal spectral analysis that uses linear elastic response spectra that are not modified to account for the anticipated nonlinear response of the real structure. The computer modeling for the LDP is the same as with the LSP. As was the case with the LSP, it is expected that the resulting model displacements will approximate the maximum displacements on the structure from the design earthquake. Once again, the consequence of matching the expected displacements is that it results in member forces that exceed the forces that would be obtained from a building that experiences strength and stiffness loss at yield, so modification factors are used to account for the expected inelastic behavior. 
ASCE 41-06 prohibits either of the linear procedures from being used if the building being investigated possesses a structural irregularity. Such irregularities include: in-plane discontinuity, out-of-plane discontinuity, a weak story irregularity, or a torsional strength irregularity (ASCE 41-06).

\subsection{Nonlinear Static Procedure}

The nonlinear static procedure (NSP) requires a computational model that incorporates the nonlinear load-deformation characteristics of the individual components. This model is subjected to monotonically increasing lateral loads representing inertial earthquake forces until a target displacement is exceeded or a failure mechanism develops. The target displacement is intended to be the maximum displacement likely to be experienced by the building during the design earthquake. If an appropriate lateral load pattern is used, the structural member forces predicted by the model should be a reasonable approximation of the actual earthquake forces.

The NSP is only permitted to be used on structures with certain characteristics. The strength ratio, $\mathrm{R}$, must be less than the maximum allowable ratio, as defined by ASCE 41-06 Chapter 3. If the strength ratio exceeds the maximum, the structure experiences significant nonlinear degradation, and a nonlinear dynamic analysis is required. Also, the higher mode effects must not be significant, as determined by comparing the story shears generated using only the first mode to the story shears generated with enough modes to produce $90 \%$ mass participation. If higher mode effects are significant, the NSP may be permitted if an LDP is also performed (ASCE 41-06). 


\subsection{Nonlinear Dynamic Procedure}

The nonlinear dynamic procedure (NDP), like the NSP, requires a computational model that incorporates the nonlinear load-deformation characteristics of the individual components. The model is then subjected to earthquake shaking represented by ground motion time-histories. The ground motion time-histories should be specific to the building site. The resulting internal forces predicted by the model do not need to be modified since the nonlinear response is explicitly modeled, and the displacements can be directly compared to the acceptance criteria. A minimum of seven ground motion analyses are required before the results of the individual time-histories may be averaged to produce the final analysis results (ASCE 41-06). 


\subsection{LITERATURE REVIEW}

The forces and load combinations for the initial building design were based on ASCE 7-05. The seismic design criteria in chapter 11 and 12 of this document provided the equations and design coefficients necessary to calculate the design base shear. ASCE 7-05 refers to AISC 341-05 for steel detailing provisions in order to use the specified response modification factor.

ASCE 41-06 provided the basis for the analysis procedures. The load equations and modeling requirements were obtained from chapter 3 , and the acceptance criteria for the linear and nonlinear procedures were obtained from chapter 5 .

"FEMA 351: Recommended Seismic Evaluation and Upgrade Criteria for Existing Welded Steel Moment-Frame Buildings" provides modeling information for moment resisting connections. The document provided the equation for modeling the spring stiffness of shear tabs.

"FEMA 440: Improvement of Nonlinear Static Seismic Analysis Procedures" provides insight on nonlinear static analyses, and in particular, discusses the relative accuracy of triangular load patterns versus uniform load patterns in a pushover analysis.

The relative accuracy of the load patterns is the basis for why this analysis only considers the triangular load pattern when evaluating the nonlinear static procedure.

In "Performance-Based Design in Earthquake Engineering: State of Development," Ghobarah provides a history of performance-based design, as well as explanations and examples of performance objectives, and design evaluation. This 
information is used in the background section to provide context for performance based design.

Hamburger writes about the future applications of performance-based design in "Development of Next-Generation Performance-Based Structural Design Criteria." He discusses using performance-based design in new construction, and provides a short history of the development of PBD. As with Ghoharah, this information was used to provide a context for performance based design in the background section. 


\subsection{BUILDING DESIGN AND COMPUTER MODELING}

The building used for this study was designed to the standards presented by the American Society of Civil Engineers (ASCE) and the American Institute of Steel Construction (AISC). The standards used in the design were ASCE 7-05, the AISC Steel Construction Manual, and the AISC Seismic Design Manual. As noted previously, the building design resulting from these standards was then evaluated using the four analysis methods presented in ASCE 41-06. The software program ETABS Nonlinear version 9.5, developed by Computers and Structures, Inc. (CSI), was used to develop the computational model for the linear static, linear dynamic, and nonlinear static analysis. The program PERFORM 3D version 4, also developed by CSI, was used to develop a computational model for a comparative nonlinear static analysis, as well as the nonlinear dynamic analysis. The software used for each analysis is summarized in the Table A below.

\begin{tabular}{||c||c||}
\hline ETABS & PERFORM 3D \\
\hline \hline Linear Static & Nonlinear Static \\
\hline Linear Dynamic & Nonlinear Dynamic \\
\hline Nonlinear Static & \\
\hline
\end{tabular}

Table A: Software Summary

Each analysis was performed using earthquake hazards scaled to both the Maximum Considered Earthquake (MCE), as well as 2/3 MCE. ASCE 41-06 refers to these hazards as a Basic Safety Earthquake (BSE). For this study, the BSE-1 is equivalent to the $2 / 3 \mathrm{MCE}$, and the BSE-2 is equivalent to the full MCE. 


\subsection{Building Design}

The building used for this study is a six-story, steel framed structure. The building rises 83 feet above grade and includes a two-story basement. In plan, the sides span 150 feet by 180 feet divided into 30-foot square bays as shown in Figure A on the following page. The typical floor height is 12.5 feet with a 20.5 -foot-tall first story as shown in Figures B and C on pages 11 and 12. The seismic design weight totals 17,145 kips. The lateral force resisting system utilizes special concentric braces in a chevron configuration, with four brace systems in each principal direction. The corresponding ASCE 7-05 design coefficients are shown in Table B below.

\begin{tabular}{||c|c||}
\hline $\mathrm{R}=$ & 6.0 \\
\hline$\Omega_{0}=$ & 2.0 \\
\hline $\mathrm{C}_{\mathrm{d}}=$ & 5.0 \\
\hline \hline $\mathrm{I}=$ & 1.0 \\
\hline
\end{tabular}

\section{Table B: ASCE 7 Design Coefficients}

The braces are HSS tube sections, while the beams and columns are wide flange sections. The member sizes of the lateral force resisting system are included in the diagrams on the following pages. The floors are comprised of 6.25 inch corrugated steel decking with a lightweight concrete fill. The exterior cladding is precast concrete panels at the upper floors, with a glass curtain wall at the ground level.

The principal plan directions, $\mathrm{X}$ and $\mathrm{Y}$, are specified on the floor plan in Figure A on the following page. The corresponding elevations are shown in Figures B and C, respectively. These directions are referenced for the results in sections 5.0 and 6.0. Braces that are referred to as "in the x-direction" are the braces that provide lateral 
resistance to a load applied parallel to the $\mathrm{x}$-axis. The same principle applies to braces "in the y-direction."

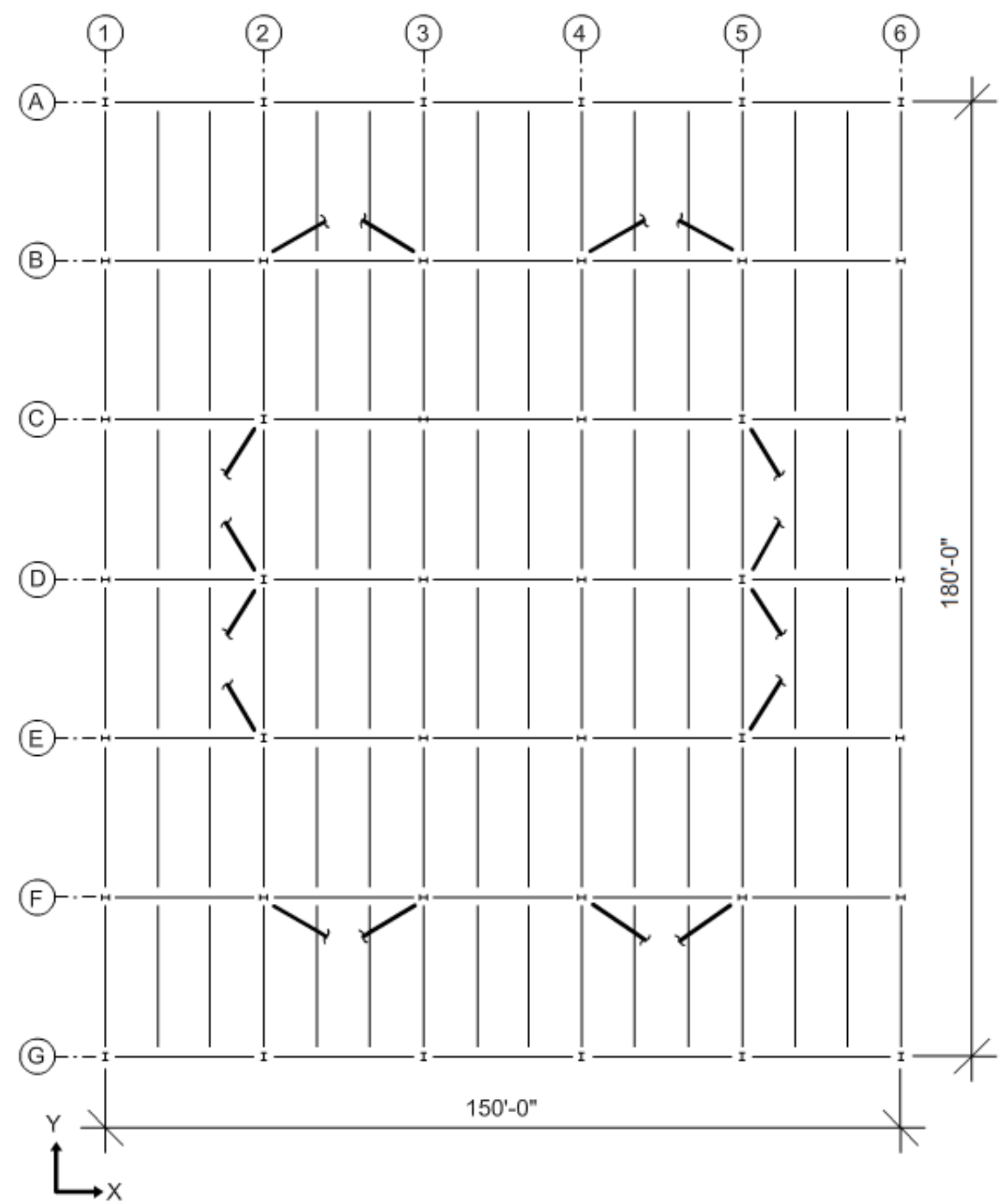

Figure A: Structural Framing Floor Plan

Performance-Based Analysis of Steel Buildings: Special Concentric Braced Frame 


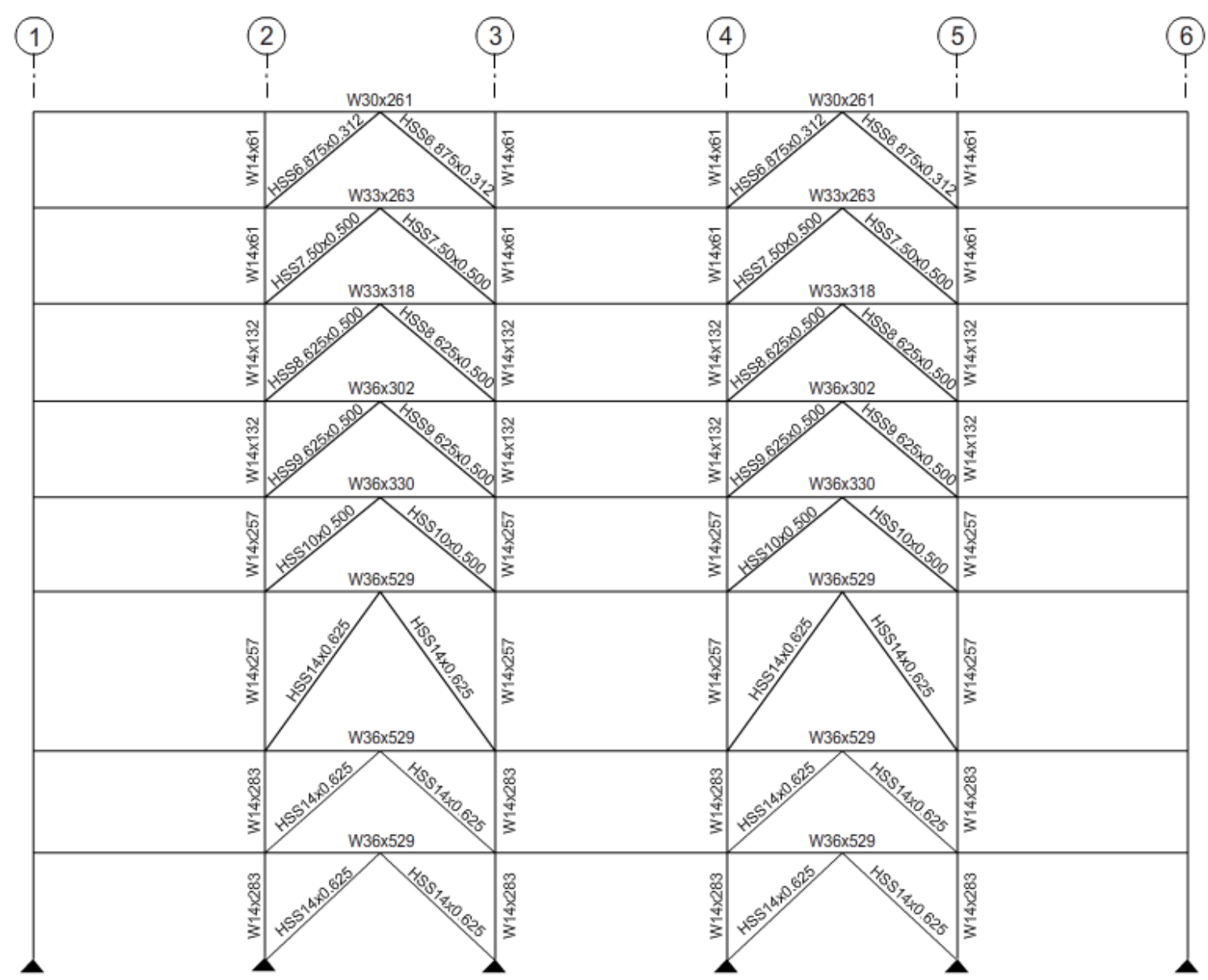

Figure B: X-Direction Elevation 


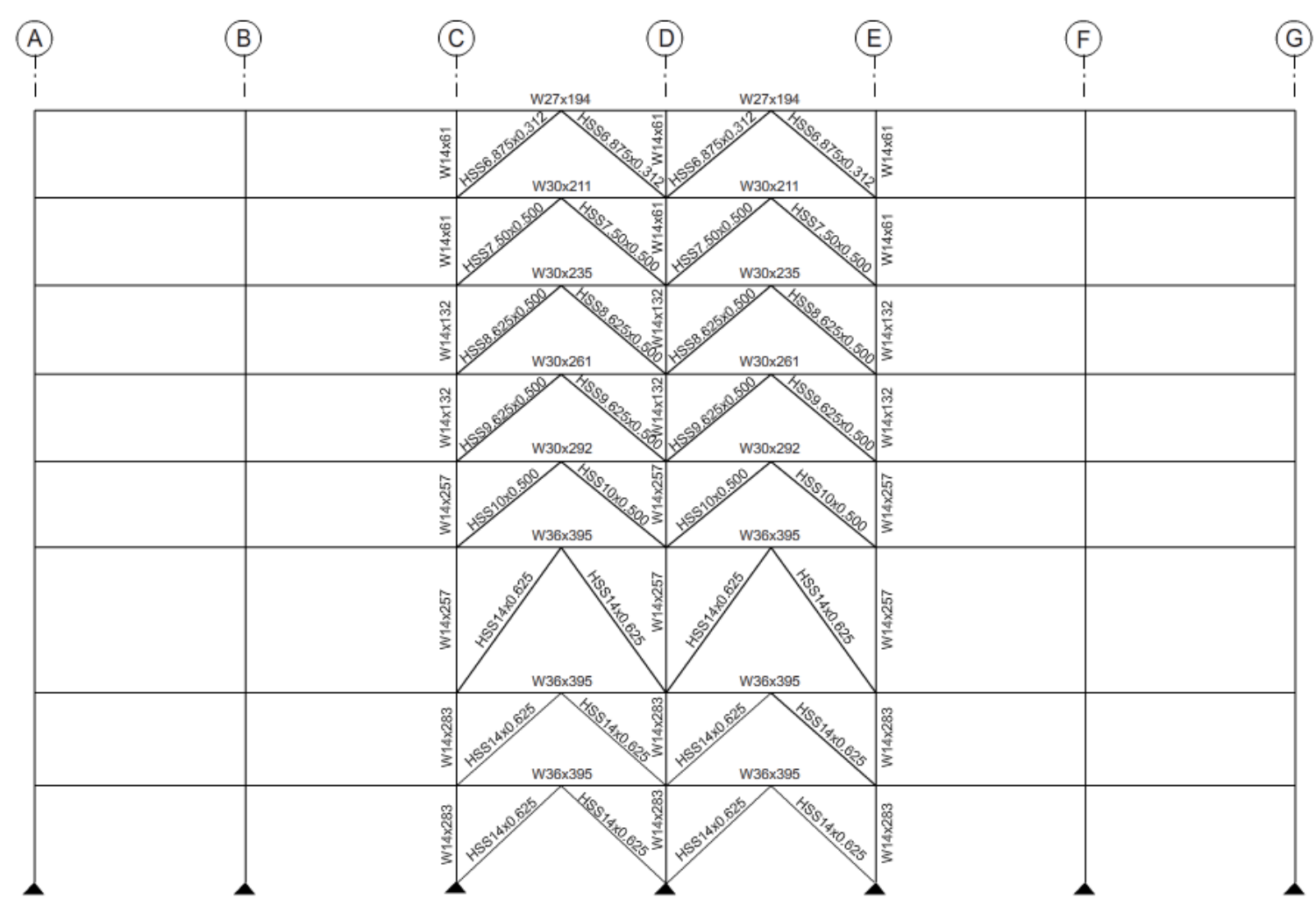

Figure C: Y-Direction Elevation

The structure has an office occupancy and is located in San Francisco, California. An assumed 5\% damping was used to determine the site-specific ground acceleration values for the ASCE 7-05 design, as well as the ASCE 41-06 procedures. The site factors are shown in Table $\mathrm{C}$ below.

\begin{tabular}{||l|r|l||}
\hline $\mathrm{S}_{\mathrm{S}}=$ & 1.5 & $\mathrm{~g}$ \\
\hline $\mathrm{S}_{1}=$ & 0.65 & $\mathrm{~g}$ \\
\hline \hline $\mathrm{F}_{\mathrm{a}}=$ & 1 & \\
\hline $\mathrm{F}_{\mathrm{v}}=$ & 1.5 & \\
\hline
\end{tabular}

\section{Table C: ASCE 7 Site-Specific Factors}

After the initial design, the ETABS model indicated a building period greater than 1.0 second, so the upper limit period coefficient was used to find the ASCE 7-05 base 
shear as specified in ASCE 7-05 section 12.8.2. The modified design period is 0.77 seconds after applying the maximum $\mathrm{C}_{\mathrm{u}}$ factor of 1.4 to the initial design period of 0.55 seconds. For the design base shear, the $\mathrm{C}_{\mathrm{S}}$ factor applied to the seismic weight is 0.141 , and the resulting ASCE 7-05 design base shear is 2,412 kips. To prevent a soft story irregularity, the sizes of the braces on the first floor are larger than the base shear alone would dictate. The higher capacity of the braces impacts the results, which are shown in the following sections.

\subsection{Computer Modeling Parameters}

The braces and beams in the braced frames were modeled with moment connections to include the increased stiffness effects of the gusset plates. The connecting drag elements were also modeled with moment connections. Rigid end offsets were not included to create parity between the ETABS and PERFORM models. All other beamto-column connections were modeled using FEMA 351 Eq. 6-1 for the bolted connection spring stiffness, shown on the following page.

$$
K_{\Theta}=28000\left(d_{b g}-5.6\right),
$$

where: $K_{\odot}$ is Spring stiffness (k-inches/radian), $d_{b g}$ is Depth of the bolt group (inches)

The foundations were modeled as pinned connections at the base of the columns. The diaphragms were modeled as rigid with loads placed at the center of mass plus $5 \%$ eccentricity, per analysis requirements. No mass was included in the basement floors or shear walls because it would have minimal impact on the super-structure, and decreased computer analysis time. The brace design is based on an effective length determined by 
the center line distances of the beams and columns. The element force-displacement curves were calculated using the values in Table 5-7 in ASCE 41-06. The ASCE 41-06 force-displacement curve is shown in Figure D on the following page for reference. The actual hinge diagrams can be found in the appendix.

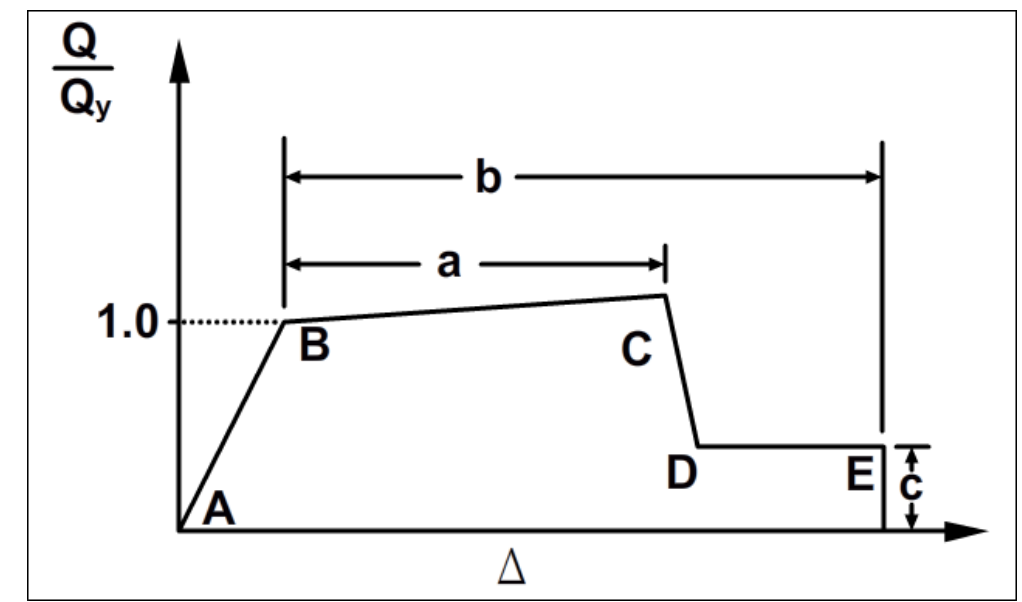

Figure D: ASCE 41-06 Nonlinear Force-Displacement Curve

Source: ASCE 41-06

The negative slope of the post-yield degradation (line CD) was taken as 75\% of the elastic slope for each member. This slope was large enough to prevent convergence errors during the nonlinear analyses, while maintaining a step size large enough to make the analysis time practical.

In ETABS, the braces were modeled using pipe sections. The hinges were placed at the center of the braces, with the yield load and displacement values determined by the ASCE 41-06 values, rather than the ETABS calculated value.

In PERFORM, the braces were modeled using inelastic bar elements with yield strain values based on the full center-line length of the members. ASCE 41-06 specifies the effective length of chevron braces to be taken as the total length of the brace, 
including the gusset plates, for out-of-plane bending. The center-line length was used because the inelastic bar elements cannot include rigid-end zones, and the difference in the effective length did not significantly change the capacities, which is discussed more in the conclusion. The columns in the braced frames were modeled as a semi-rigid axial hinge, with two axially rigid members on each side. This was done because PERFORM $3 \mathrm{D}$ analyses the column components as elements in series, which has the potential to reduce the stiffness if the non-hinge elements are not axially rigid.

\subsection{Verification of Computer Models}

The ETABS and PERFORM models were similar in their dynamic properties.

For both models, the first mode was in the x-direction, and the second mode was in the ydirection. The mass participation ratios for each program are shown in Table D below.

\begin{tabular}{||c|c|c||}
\hline \multicolumn{3}{|c|}{ Mass Participation Ratios (\%) } \\
\hline \hline Mode & ETABS & PERFORM \\
\hline \hline First (X-Direction) & 82.5 & 83.3 \\
\hline Second (Y-Direction) & 83.6 & 83.5 \\
\hline \hline
\end{tabular}

Table D: Period Comparison

Over $99.5 \%$ mass participation was achieved using 12 total modes for both computational models. Over $95 \%$ of the mass was captured in both directions with 5 modes in ETABS, and with 4 modes in PERFORM.

The period calculations were checked against the Rayleigh method for approximating the period of the structure. This equation is included in ASCE 41-06 as Eq. C3-2, and is shown on the following page for reference. The calculation was performed using the ETABS static displacements under the ASCE 7-05 design load. 


$$
T=2 \pi \sqrt{\frac{\sum_{i=1}^{n} w_{i} \delta_{i}^{2}}{g \sum_{i=1}^{n} f_{i} \delta_{i}}},
$$

where: $T$ is fundamental period of structure (seconds), $w$ is seismic weight at floor $i$ (kips),

$\delta$ is elastic deflection at floor $i$ (inches), $g$ is gravity (inches/sec/sec), $f$ is seismic force at floor $i$ (kips), $n$ is number of stories

The results of this calculation are shown in the following table. The first mode period values for the three methods are summarized in Table E below.

\begin{tabular}{||c|c||}
\hline \multicolumn{2}{|c|}{ X-Direction } \\
\hline \hline Method & Period (sec.) \\
\hline \hline ETABS & 1.090 \\
\hline PERFORM & 1.078 \\
\hline Rayleigh & 1.075 \\
\hline
\end{tabular}

\begin{tabular}{||c|c||}
\hline \multicolumn{2}{|c|}{ Y-Direction } \\
\hline \hline Method & Period (sec.) \\
\hline \hline ETABS & 1.009 \\
\hline PERFORM & 1.006 \\
\hline Rayleigh & 0.995 \\
\hline
\end{tabular}

Table E: Period Comparison

The periods from the software and Rayleigh calculations were similar enough for each direction that the models were deemed acceptable. 


\subsection{ANALYSIS OF BSE-1 HAZZARD LEVEL}

The American Society of Civil Engineers (ASCE) 41-06 standard provides a means of evaluating the performance of individual components of the seismic resisting system, from which an overall building performance may be based. The implicit design goal of ASCE 7-05 is for structures to achieve a Life Safety performance for the Basic Safety Earthquake 1 (BSE-1) hazard.

For the linear procedures, the performance evaluation process compares a demand-capacity ratios (DCR) to an $m$-factor associated with a specific performance level. An m-factor is a unitless value derived from physical testing and the judgment of the FEMA 273 committee that represents the damage limit for a member to be considered within a performance level. A performance level is achieved if the DCR for the member is less than the $m$-factor at that performance level.

For the nonlinear procedures, performance is evaluated by comparing the inelastic displacement of an element to an acceptable level of deformation for a given performance level. For this thesis, the inelastic displacements from the analyses have been divided by the hand-calculated yield displacement of the element to produce a unitless DCR similar to the linear procedures. The acceptance criteria have also been divided by the yield displacement to create an inelastic equivalent to the $m$-factors. This conversion was done to provide consistency in the assessment of the linear and nonlinear results.

The site-specific response spectrum used for the BSE-1 is the same spectrum used for the ASCE 7-05 design, which is taken as 2/3 of the maximum considered earthquake 
(MCE). The ground accelerations and site coefficients are shown in Section 4.1, Table C. The resulting BSE-1 site-specific response spectrum is shown in Figure E below.

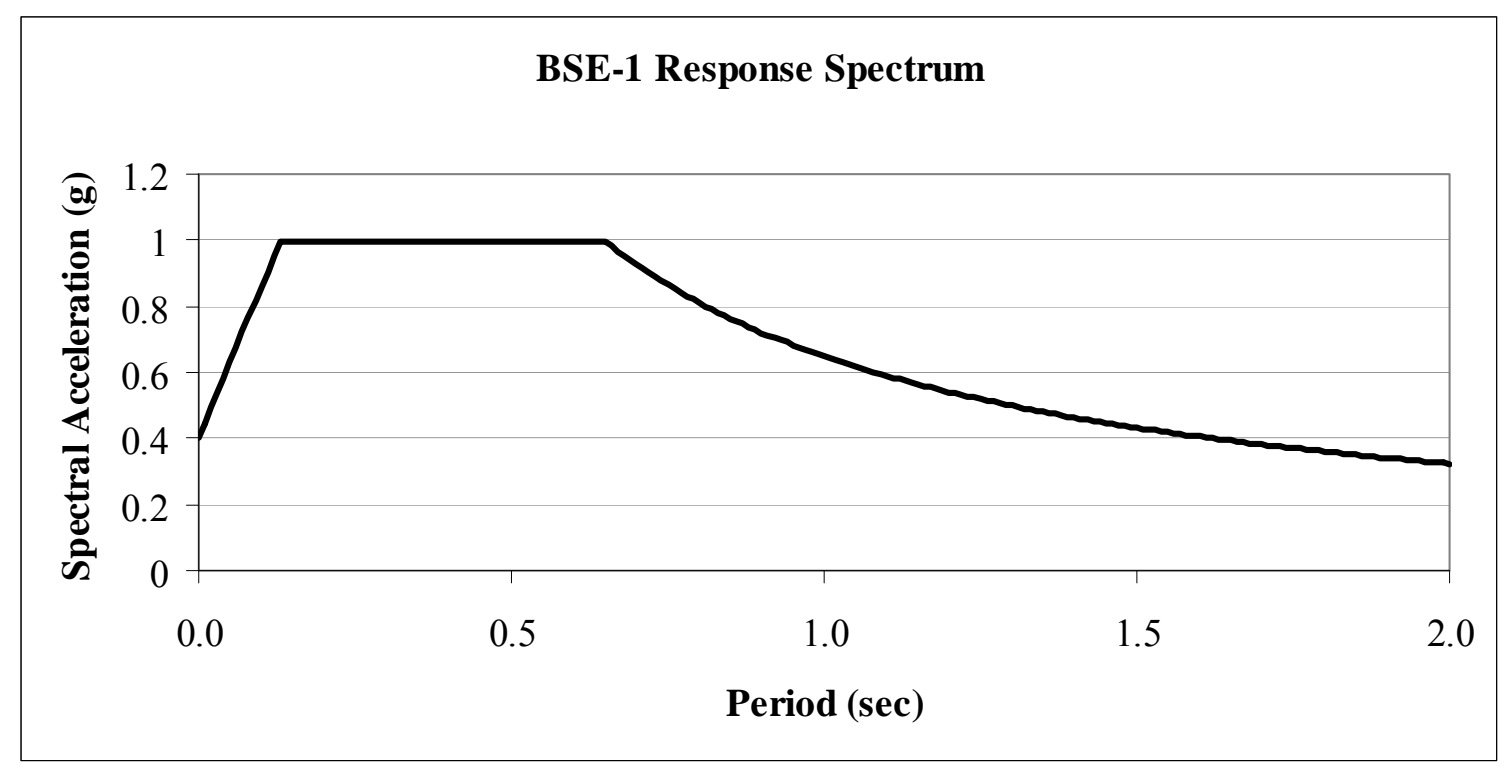

Figure E: BSE-1 Site-Specific Response Spectrum

The accelerations used for all four of the BSE-1 analyses were taken from this spectrum. At a period of 1.10 seconds in the $\mathrm{x}$-direction, the resulting spectral acceleration is $0.590 \mathrm{~g}$; and in the y-direction, a period of 1.01 seconds results in an acceleration of $0.642 \mathrm{~g}$.

\subsection{Linear Static Procedure}

The base shear for the linear static procedure was calculated using Eq. 3-9 in ASCE 41-06, shown below.

$$
V=C_{1} C_{2} C_{m} S_{a} W
$$

where: $C_{1}$ is factor to relate expected inelastic displacements to elastic response, $C_{2}$ is factor to represent cyclic degradation and strength deterioration, $C_{m}$ is effective mass factor, $S_{a}$ is spectral acceleration at building site at the fundamental period $(\mathrm{g})$, $W$ is seismic weight of structure (kips)

Performance-Based Analysis of Steel Buildings: Special Concentric Braced Frame 
The values used in the calculations, and the resulting base shears for the $\mathrm{x}$ and $\mathrm{y}$-directions are summarized in Table $\mathrm{F}$ on the following page.

\begin{tabular}{||l|r|l||}
\hline \multicolumn{3}{|c|}{ X-Direction } \\
\hline \hline $\mathrm{C}_{1}=$ & 1.005 & \\
\hline $\mathrm{C}_{2}=$ & 1.000 & \\
\hline $\mathrm{C}_{\mathrm{m}}=$ & 1.0 & \\
\hline $\mathrm{S}_{\mathrm{a}}=$ & 0.590 & $\mathrm{~g}$ \\
\hline $\mathrm{W}=$ & 17,145 & $\mathrm{k}$ \\
\hline $\mathrm{V}_{\mathbf{x}}=$ & $\mathbf{1 0 , 1 6 4}$ & $\mathbf{k}$ \\
\hline
\end{tabular}

\begin{tabular}{||l|r|l||}
\hline \multicolumn{3}{|c|}{ Y-Direction } \\
\hline \hline $\mathrm{C}_{1}=$ & 1.009 & \\
\hline $\mathrm{C}_{2}=$ & 1.000 & \\
\hline $\mathrm{C}_{\mathrm{m}}=$ & 1.0 & \\
\hline $\mathrm{S}_{\mathrm{a}}=$ & 0.642 & $\mathrm{~g}$ \\
\hline $\mathrm{W}=$ & 17,145 & $\mathrm{k}$ \\
\hline $\mathbf{V}_{\mathbf{y}}=$ & $\mathbf{1 1 , 1 0 9}$ & $\mathbf{k}$ \\
\hline
\end{tabular}

Table F: BSE-1 Linear Static Base Shear Calculations

The analysis results on the following page show the demand-capacity ratios for the compression braces. Figure F shows the results for the x-direction, and Figure G shows the results for the y-direction. The tension braces have higher capacities and larger acceptance values, and consequently do not govern the analysis. For comparison purposes, tension brace results for both linear procedures are summarized in Figures $\mathrm{HH}$ and II in section 7.1.1. The graphs include the performance level associated with each DCR to convey the overall performance of the brace. The maximum values for the Life Safety and Collapse Prevention performance levels differ from floor to floor because the acceptance values are based on the slenderness of the braces. The columns and beams are not included because the demands in those members remain below yield after the forces are reduced to account for the capacity of the braces.

Due to the required 5\% mass eccentricity, the braces on each side of the building receive a different force. For this reason, the graphs include the maximum DCR occurring in any brace at each floor, and an average of the highest DCRs in all braces at each floor. 


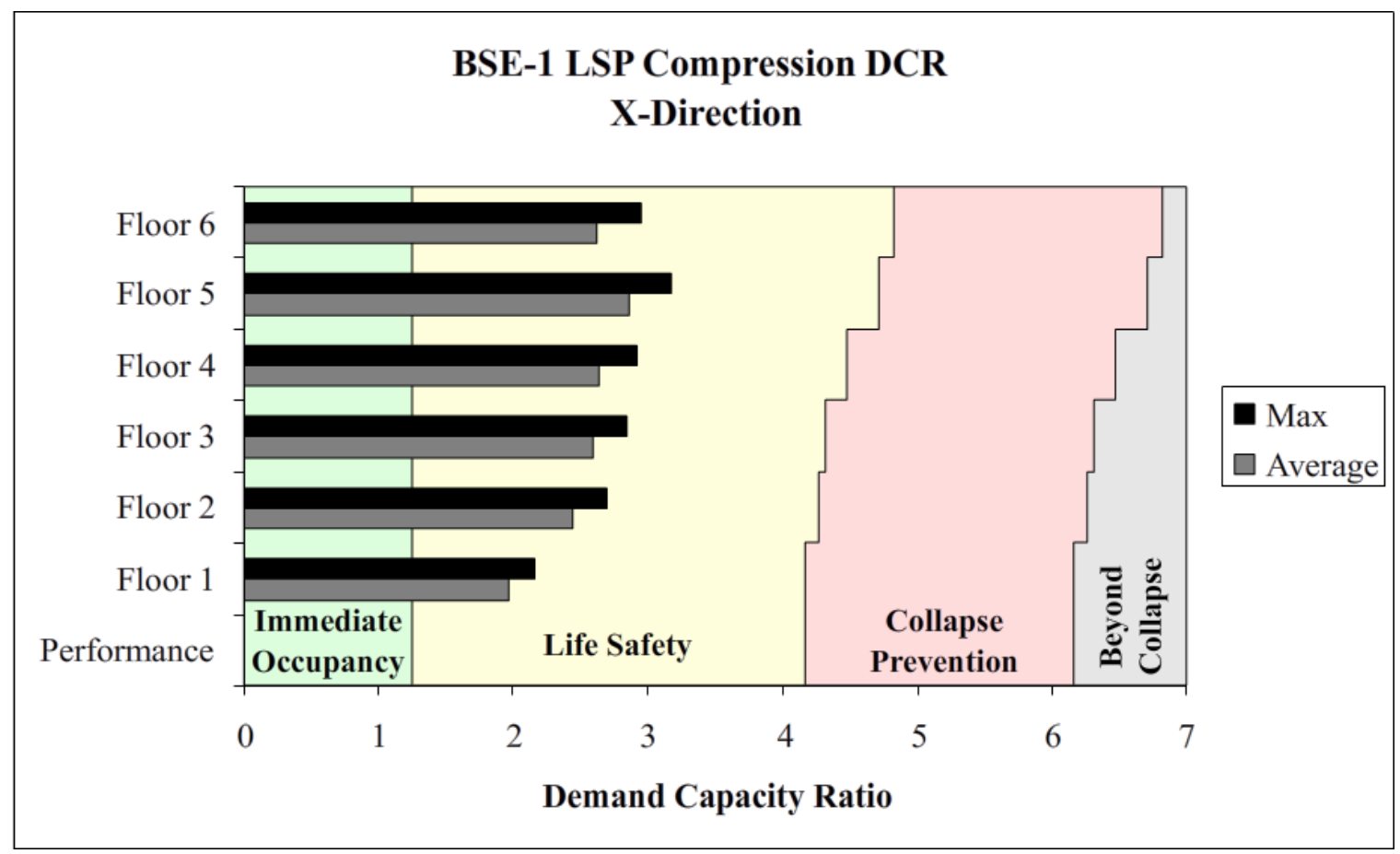

Figure F: BSE-1 LSP X-Direction Compression

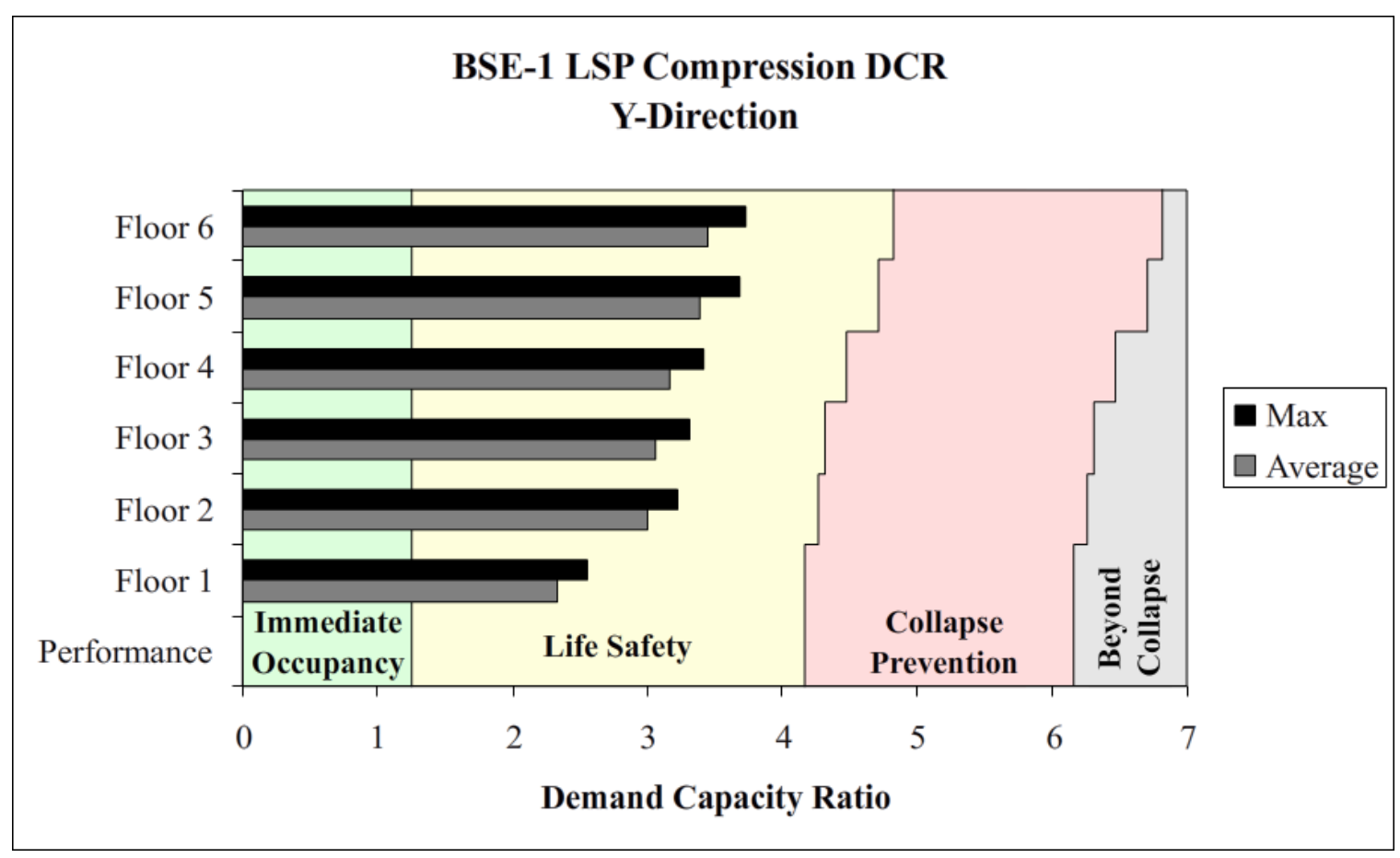

Figure G: BSE-1 LSP Y-Direction Compression

Performance-Based Analysis of Steel Buildings: Special Concentric Braced Frame 
The graphs show that all compression braces perform to a level of Life Safety. Therefore, the overall performance of the building is considered to be Life Safety.

\subsection{Linear Dynamic Procedure}

The linear dynamic procedure was based on the BSE-1 site-specific response spectrum that was shown in Figure E. The acceleration in the x-direction is $0.590 \mathrm{~g}$. for a period of 1.10 seconds, and the acceleration in the $\mathrm{y}$-direction is $0.642 \mathrm{~g}$. for a period of 1.01 seconds.

The analysis results are shown in the graphs on the following pages. The compression brace demand-capacity ratios for the $\mathrm{x}$ - and $\mathrm{y}$-directions are shown in Figure $\mathrm{H}$ and Figure I, respectively. The demand-capacity ratios for tension braces do not govern the analysis, but they are included in Figures $\mathrm{HH}$ and II in section 7.1.1 for comparison purposes. As with the linear static procedure, the graphs include the performance level associated with each DCR to convey the overall performance of the brace. The columns and beams are not included because the demands remain below yield after the forces are reduced to account for the capacity of the braces.

Due to the required 5\% mass eccentricity, the braces on each side of the building receive a different force. For this reason, the graphs include the maximum DCR occurring in any brace at each floor, and an average of the critical DCRs in all braces at each floor.

The LDP DCRs are less than those of the LSP because the base shears generated by the LDP were $87 \%$ of the base shears determined in the LSP. This was caused by the effect of higher building modes, and is discussed more in the conclusion in section 8 .

Performance-Based Analysis of Steel Buildings: Special Concentric Braced Frame 


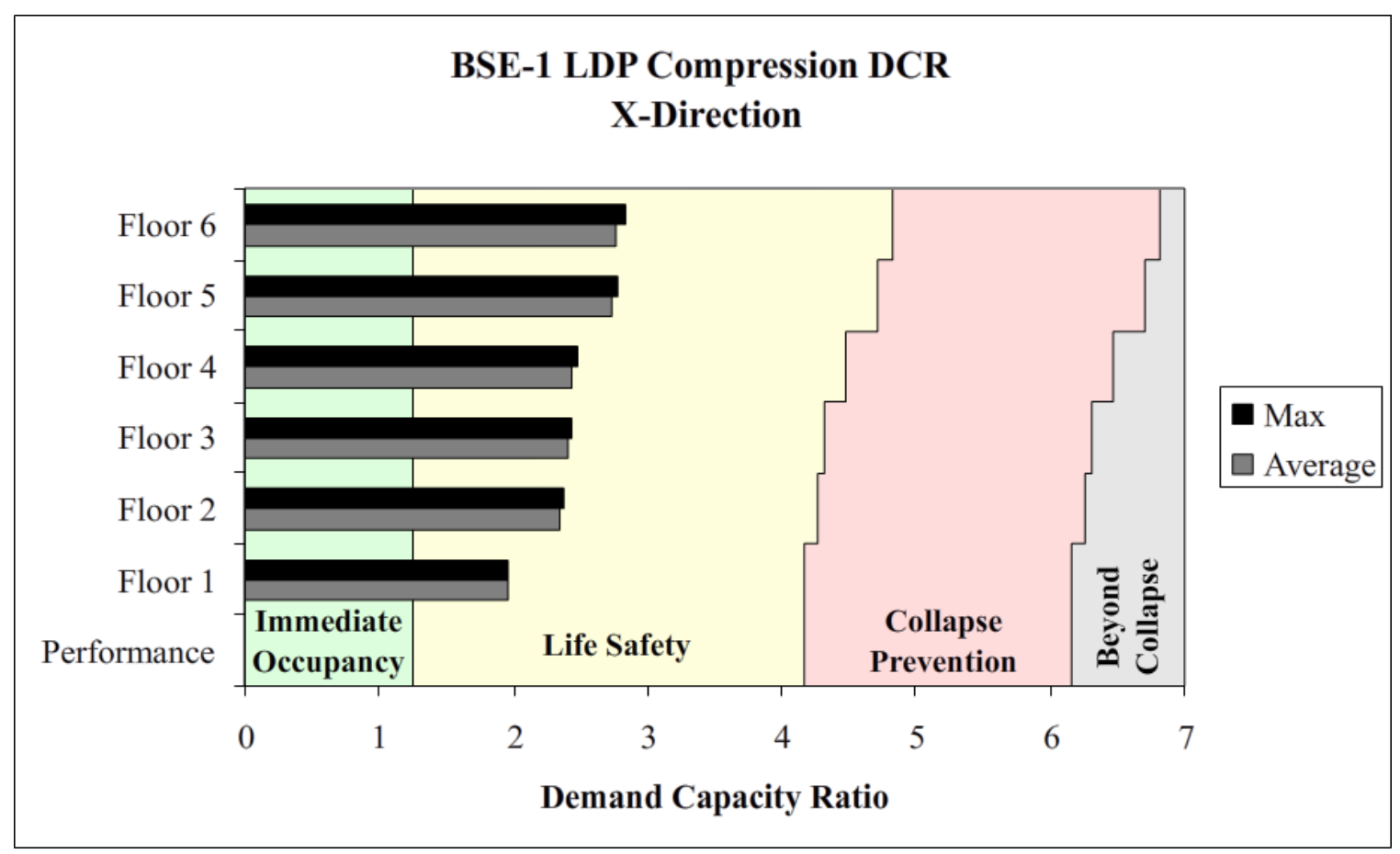

Figure H: BSE-1 LDP X-Direction Compression

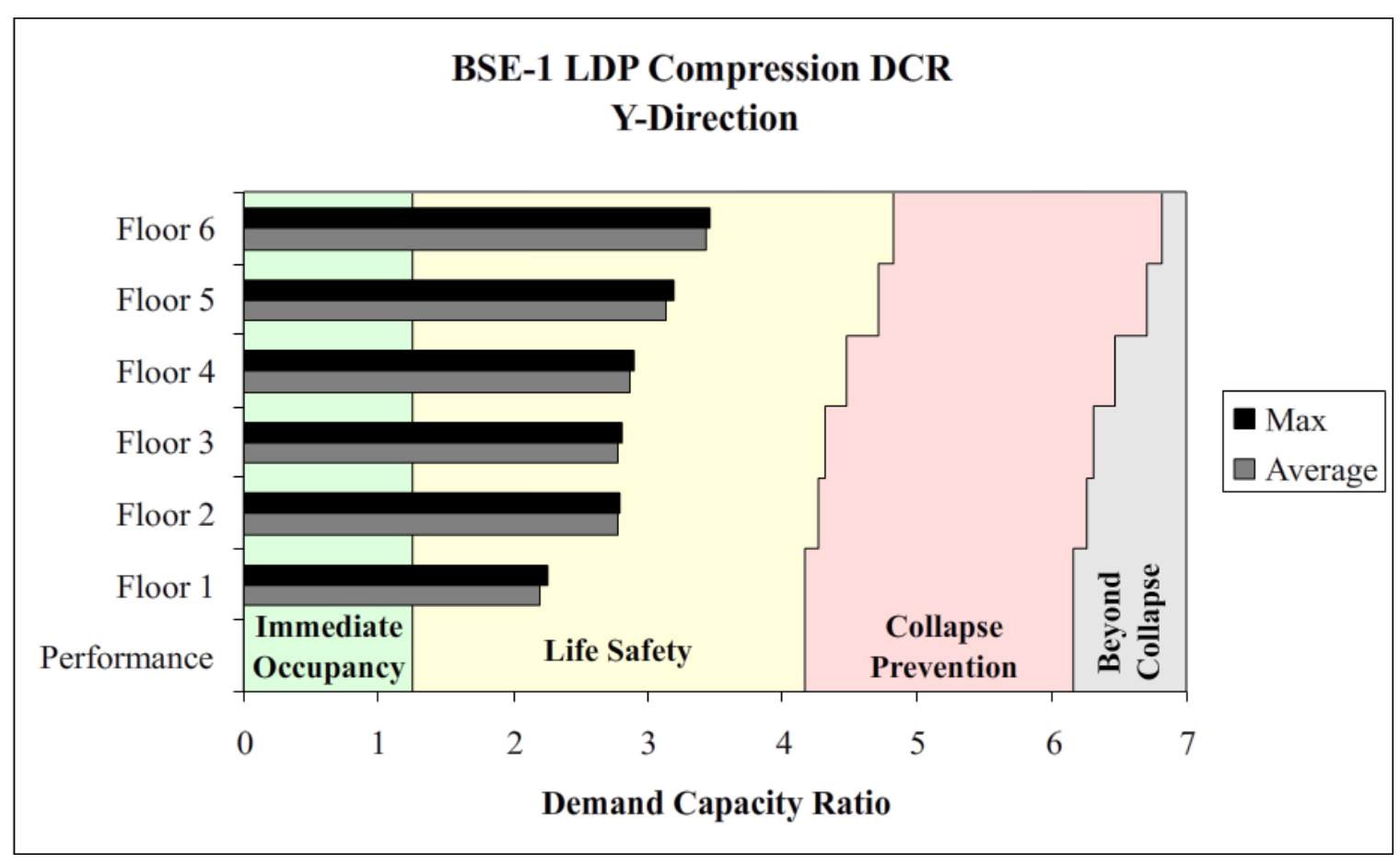

Figure I: BSE-1 LDP Y-Direction Compression

Performance-Based Analysis of Steel Buildings: Special Concentric Braced Frame 
The results of the linear dynamic procedure are very similar to the linear static procedure. The tension and compression braces both performed to a middle range of Life Safety, therefore the overall building performance can be classified as Life Safety.

\subsection{Nonlinear Static Procedure}

The nonlinear static procedure (NSP) applies an increasing load to the building until the roof reaches a predetermined target displacement. The target displacement for the nonlinear static procedure was calculated using Eq. 3-14 in ASCE 41-06, shown below.

$$
\delta_{t}=C_{0} C_{1} C_{2} S_{a} \frac{T_{e}^{2}}{4 \pi^{2}} g,
$$

where: $C_{0}$ is factor to relate spectral displacement of a single-degree of freedom system to the roof displacement of a multi-degree of freedom system, $C_{1}$ is factor to relate expected maximum inelastic displacements to linear elastic displacements. For periods greater than $1.0 \mathrm{sec}, \mathrm{C}_{1}=1.0$, $C_{2}$ is factor to represent cyclic degradation and strength deterioration, for periods greater than $0.7 \mathrm{sec}, \mathrm{C}_{2}=1.0$,

$S_{a}$ is spectral acceleration at building site at the fundamental period $(\mathrm{g})$, $T_{e}$ is effective fundamental period of the building ( $\mathrm{sec}$ ), and $g$ is acceleration of gravity (in/sec/sec)

The values used in the displacement calculation are shown in Table G below.

The building was pushed to these targets using both triangular and uniform load patterns.

\begin{tabular}{||l|r|l||}
\hline \multicolumn{3}{|c||}{ X-Direction } \\
\hline \hline $\mathrm{C}_{0}=$ & 1.3 & \\
\hline $\mathrm{C}_{1}=$ & 1.0 & \\
\hline $\mathrm{C}_{2}=$ & 1.0 & \\
\hline $\mathrm{S}_{\mathrm{a}}=$ & 0.590 & $\mathrm{~g}$ \\
\hline $\mathrm{T}_{\mathrm{e}}=$ & 1.10 & sec. \\
\hline $\boldsymbol{\delta}_{\mathbf{t x}}=$ & $\mathbf{9 . 0 8}$ & in. \\
\hline \hline
\end{tabular}

\begin{tabular}{|l|r|l||}
\hline \multicolumn{3}{|c|}{ Y-Direction } \\
\hline \hline $\mathrm{C}_{0}=$ & 1.3 & \\
\hline $\mathrm{C}_{1}=$ & 1.0 & \\
\hline $\mathrm{C}_{2}=$ & 1.0 & \\
\hline $\mathrm{S}_{\mathrm{a}}=$ & 0.642 & $\mathrm{~g}$ \\
\hline $\mathrm{T}_{\mathrm{e}}=$ & 1.01 & sec. \\
\hline $\boldsymbol{\delta}_{\mathbf{t y}}=$ & $\mathbf{8 . 3 3}$ & in. \\
\hline
\end{tabular}

Table G: BSE-1 Nonlinear Static Target Displacement Calculation

Performance-Based Analysis of Steel Buildings: Special Concentric Braced Frame 
ASCE 41-06 specifies that this procedure push the building to $150 \%$ of the target displacement, this is done because the target displacement is intended to be an average of the displacement values for the design earthquake, and the additional $50 \%$ is intended to account for the higher displacement scatter. The concern in ASCE 41-06 is that "the target displacement may be unconservative for buildings with low strength compared with the elastic spectral demands" (ASCE 41-06). The extra displacement also ensures there is no sudden, unexpected strength loss just beyond the target.

The analysis was conducted using both a triangular load pattern as well as a uniform load pattern; however, the triangular loading will be the primary criteria for ascertaining the performance level for the NSP. FEMA 440 explains that the uniform load pattern is prone to producing larger errors than the triangular loading, and that "a single first-mode vector is sufficient for displacement estimates and for the estimate of response quantities that are not significantly affected by higher modes" (FEMA 440). The first mode in each direction captured $85 \%$ of the mass, so it was determined that the building was not significantly affected by higher modes. The uniform load pattern has been included in this analysis to ensure that the building does not experience any unexpected failures from a higher mode loading.

The same target displacement values are used in both the ETABS and PERFORM analyses. The ETABS results can be found in section 7.1.2. The PERFORM analysis force-displacement curves up to the target displacements are shown below in Figure $\mathrm{J}$ for the $\mathrm{x}$-direction and Figure $\mathrm{K}$ for the $\mathrm{y}$-direction. Due to the required $5 \%$ eccentricity, the 
braces at each floor did not yield simultaneously. The graphs are annotated to reference the major early events.

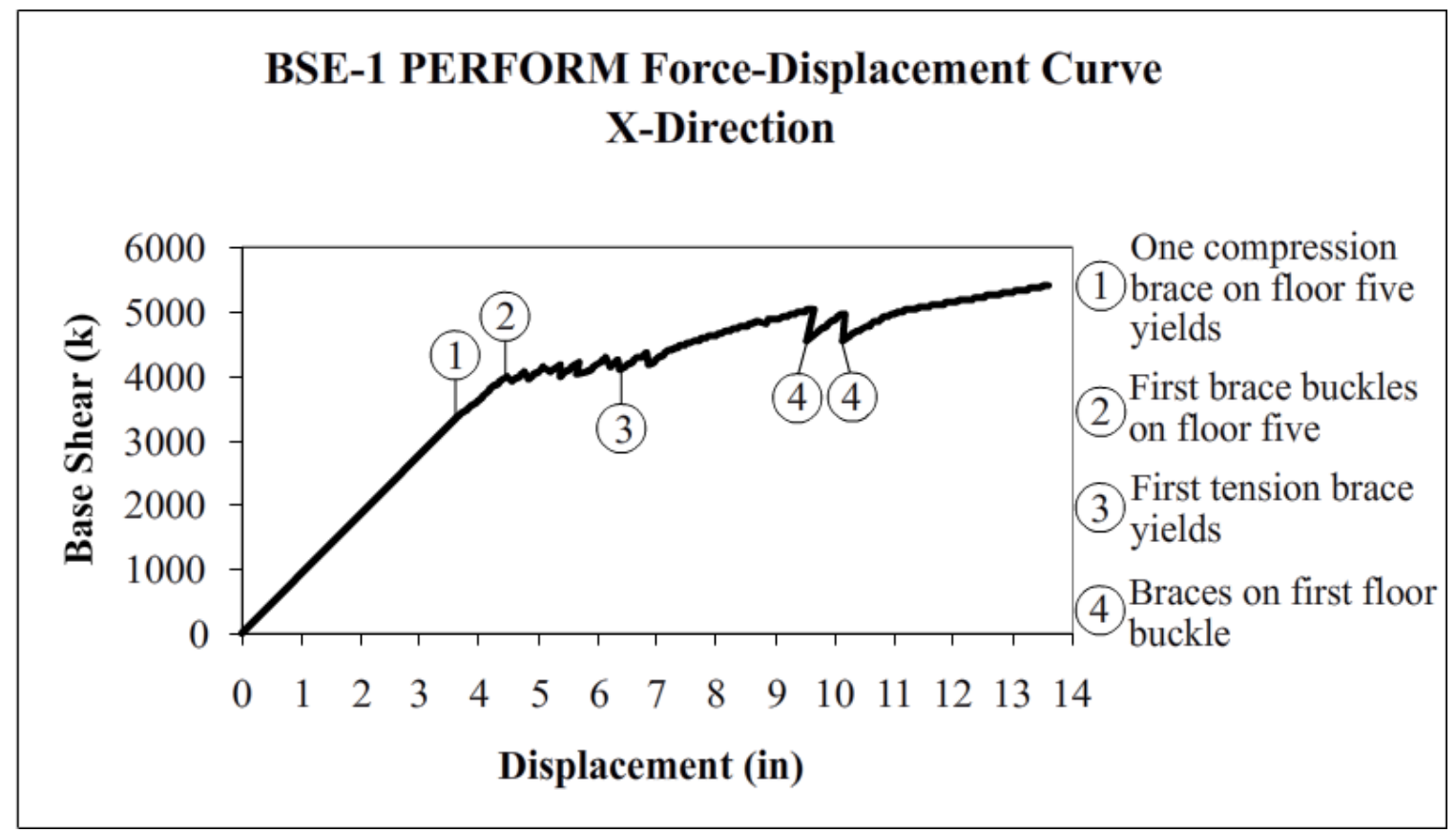

Figure J: BSE-1 X-Direction Force-Displacement Curve

The jagged response of the post-buckling region is caused by the sudden loss of strength that results when a brace buckles. In the x-direction, the first yield occurs in a compression brace on the fifth floor at a force of 3,337 kips and a roof displacement of 3.62 in. Two braces on the fifth floor are the first to buckle at a force of 3,976 kips and a displacement of 4.48 in. The first tension brace yields at a displacement of 6.39 in. and a base shear of 4096 kips. The two large drops in strength result from braces buckling on the first floor. Two first-floor braces buckle on one side of the building at a displacement of 9.52 in. and a base shear of 5014 kips. The remaining two first-floor braces at a displacement of 10.12 in. and a force of 4972 kips. All tension braces on the bottom four 
floors have yielded at a roof displacement of $11.14 \mathrm{in.}$ The beams and columns in the braced frame remain elastic for both the $\mathrm{x}$ - and $\mathrm{y}$-directions.

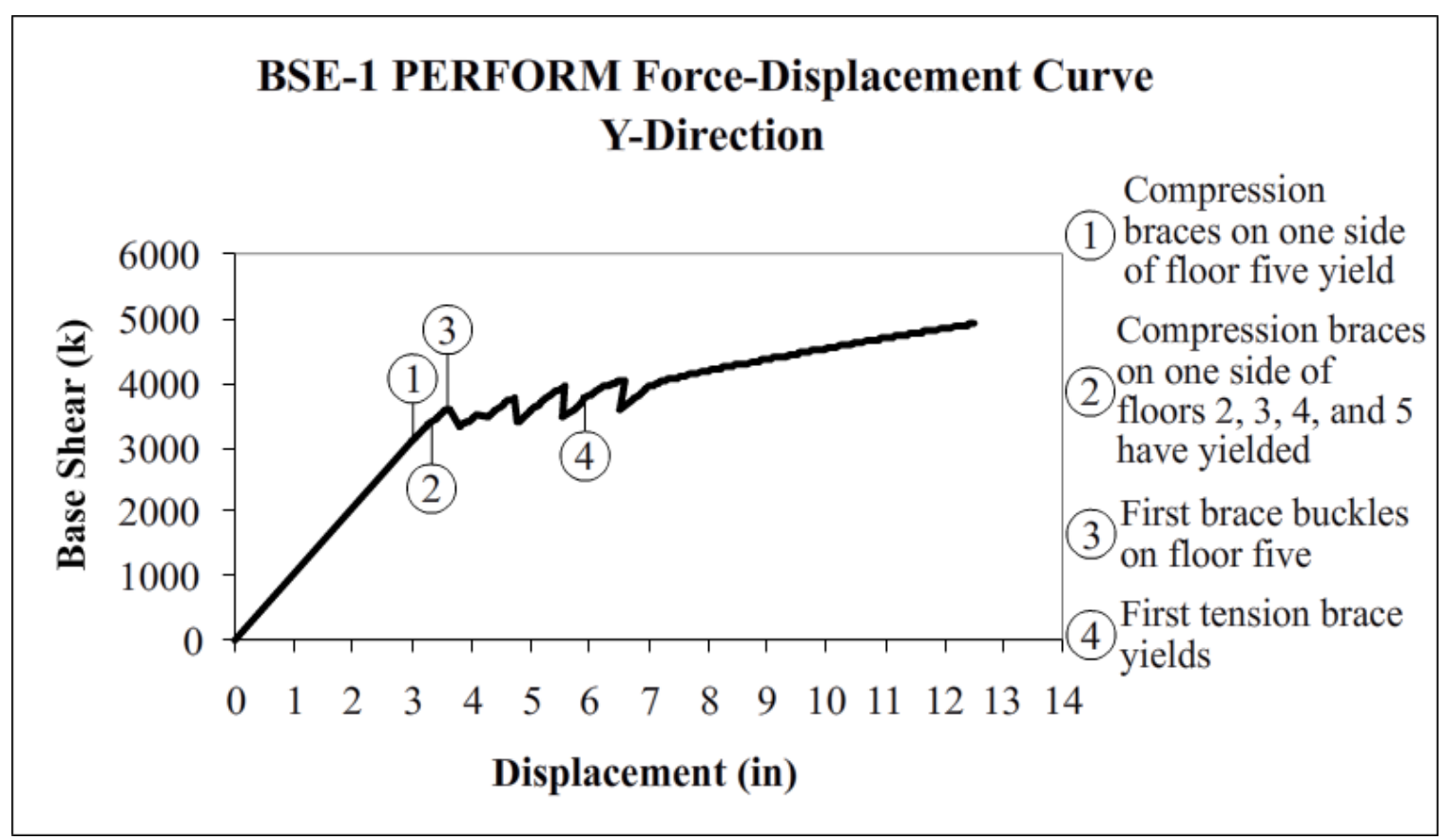

Figure K: BSE-1 Y-Direction Force-Displacement Curve

As with the curve for the $\mathrm{x}$-direction, the jagged response of the post-buckling region is the result of braces bucking and losing strength. The primary difference between the two curves is that the $\mathrm{x}$-direction contains many small drops, while the $\mathrm{y}$ direction has fewer, larger drops in strength. This is caused by most of the braces in the $\mathrm{x}$-direction buckling at separate times, while the braces in the $\mathrm{y}$-direction frequently buckled simultaneously. In the y-direction, the two compression braces on one side of the fifth floor are the first to yield. The yielding occurs at 3,082 kips and a displacement of $2.98 \mathrm{in.}$ A brace on floor five buckles at 3,560 kips and a displacement of $3.60 \mathrm{in}$. The first tension braces to yield are on the third floor, with yielding occurring at a 
displacement of 5.98 in. and a base shear of 3789 kips. All tension braces on the second, third, fourth, and fifth floors have yielded at a roof displacement of $11.37 \mathrm{in}$.

The brace performance is shown in the graphs on the following pages. The nonlinear procedures use a DCR based on plastic displacement, therefore a value of zero on the graph indicates the member did not yield. The 5\% center of mass eccentricity produced forces that were different on each side of the building, so the graphs include the maximum DCR at each level and the average of the critical DCRs at each level.

Figures $\mathrm{L}$ and $\mathrm{M}$ show the PERFORM compression DCRs under a triangular loading pattern. Figures $\mathrm{N}$ and $\mathrm{O}$ show the PERFORM compression DCRs under a uniform loading pattern. The results for the tension braces can be found in section 7.1.1. 


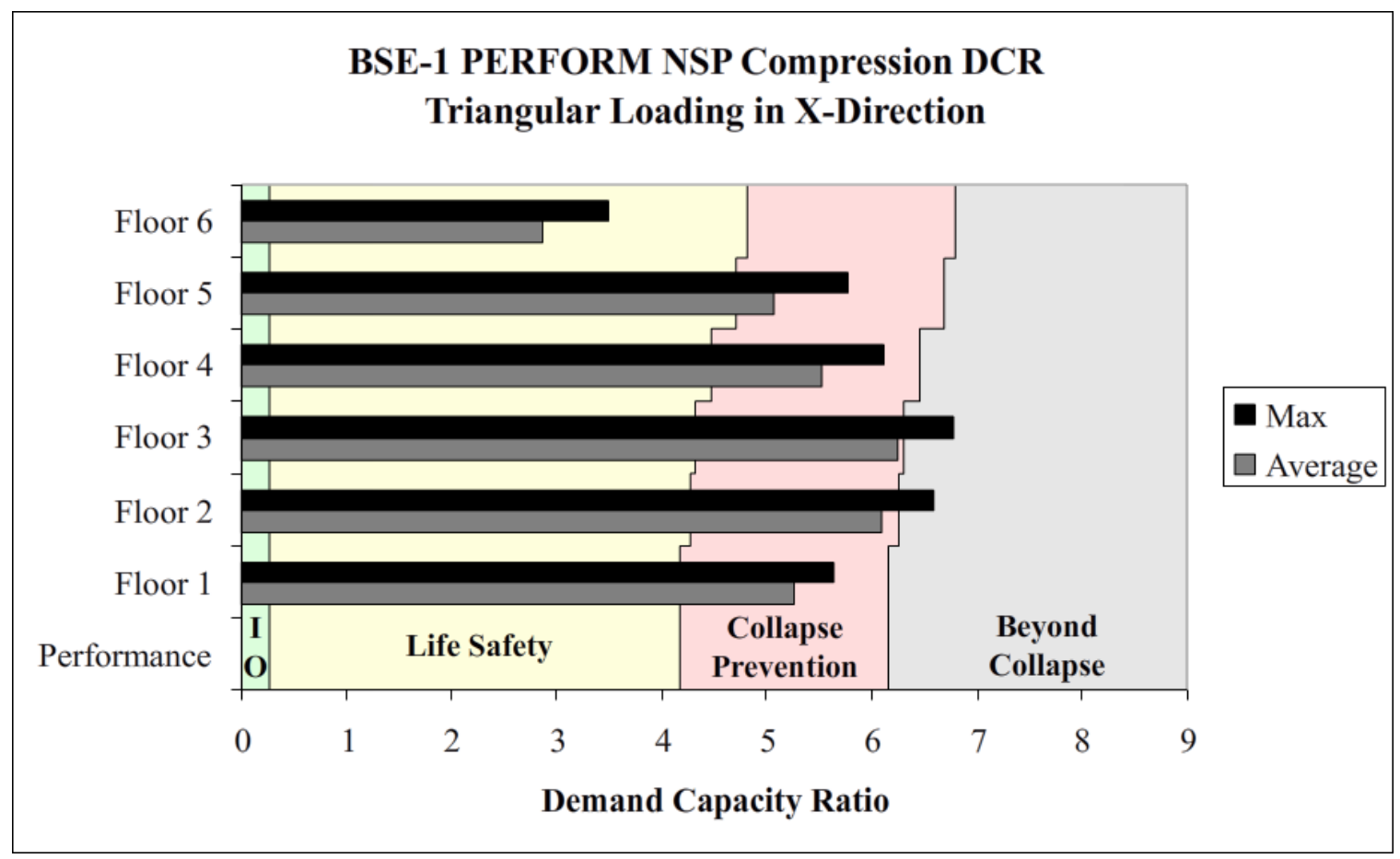

Figure L: BSE-1 NSP PERFORM Triangular Loading X-Direction Compression

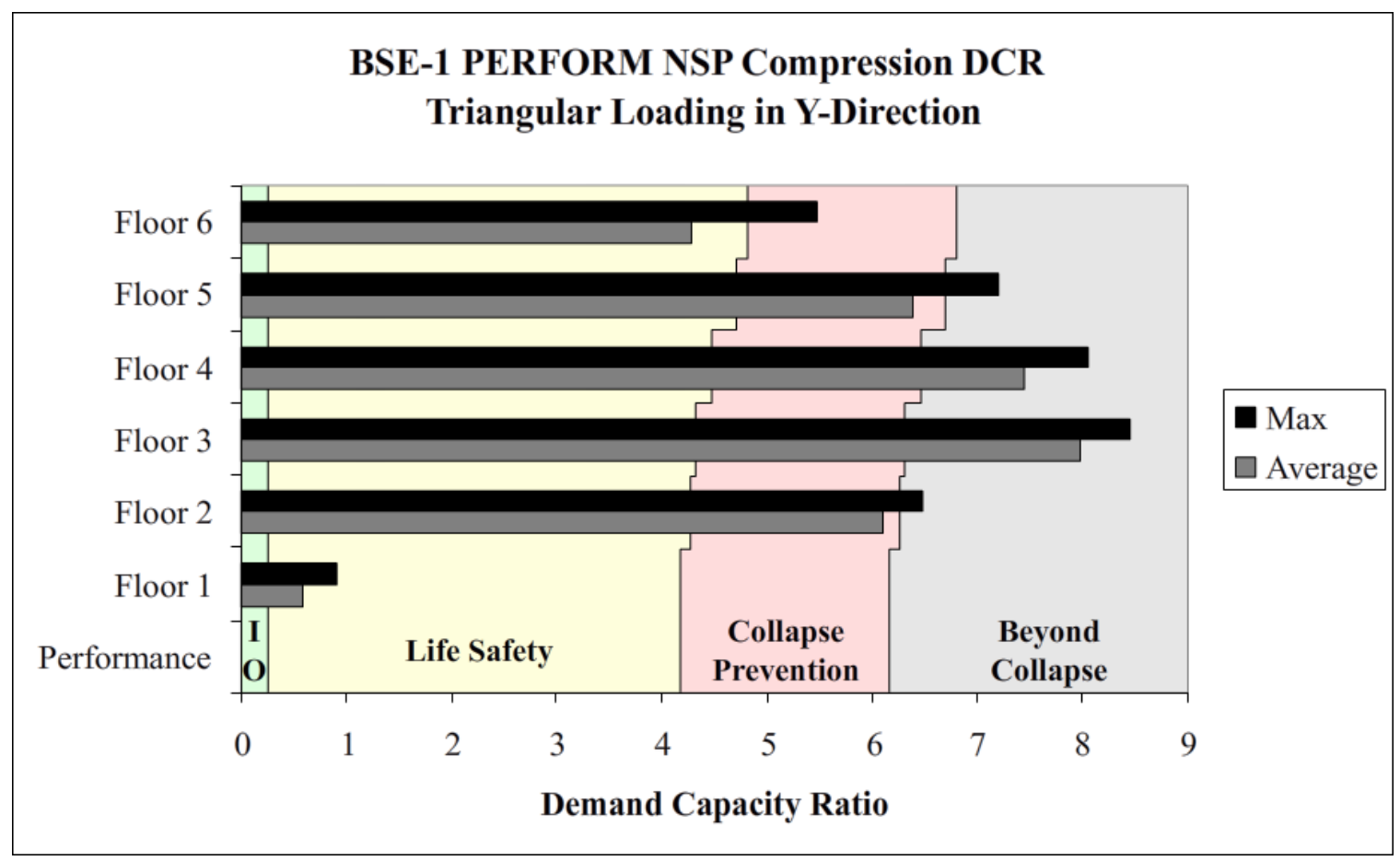

Figure M: BSE-1 NSP PERFORM Triangular Loading Y-Direction Compression

Performance-Based Analysis of Steel Buildings: Special Concentric Braced Frame 


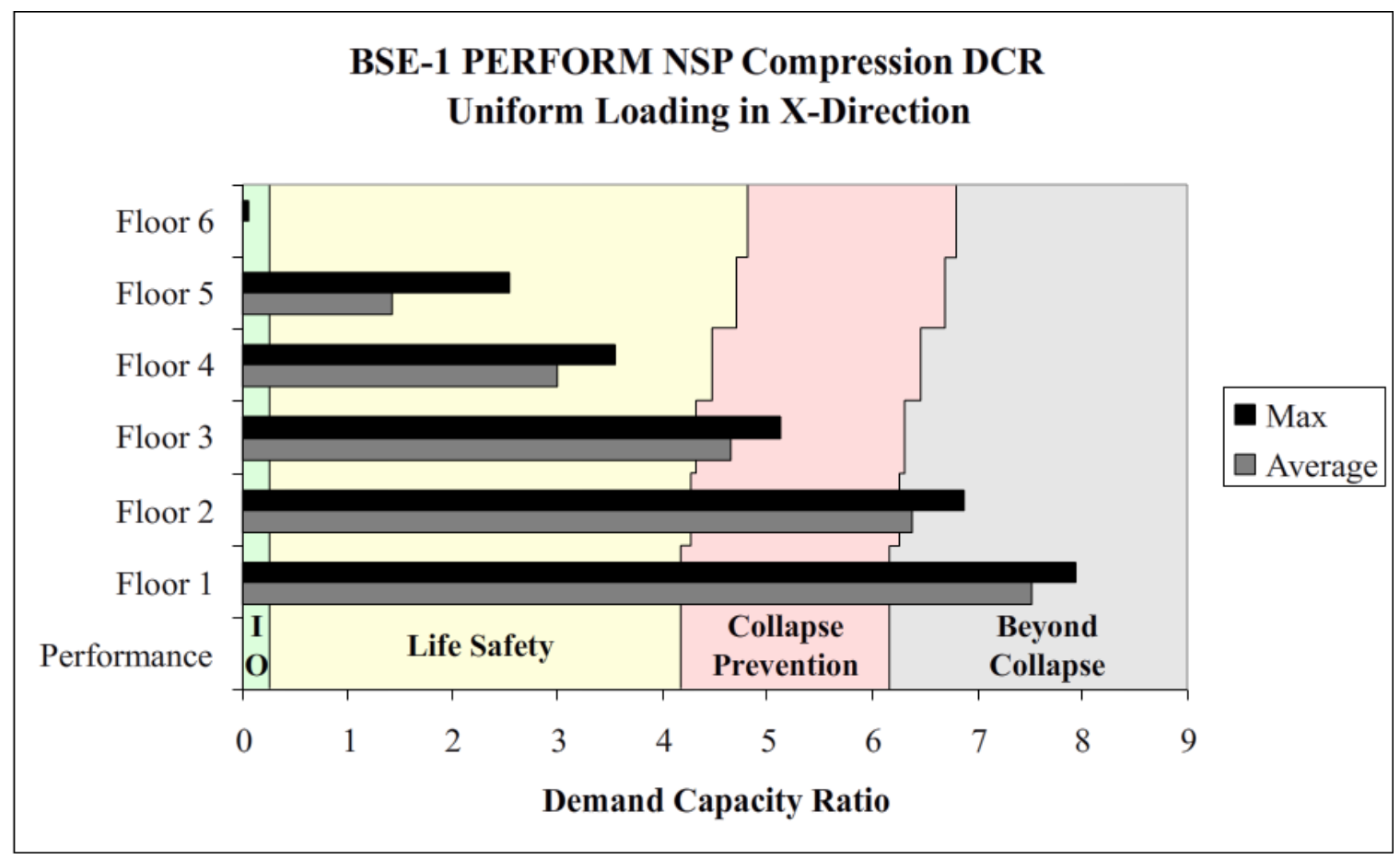

Figure N: BSE-1 NSP PERFORM Uniform Loading X-Direction Compression

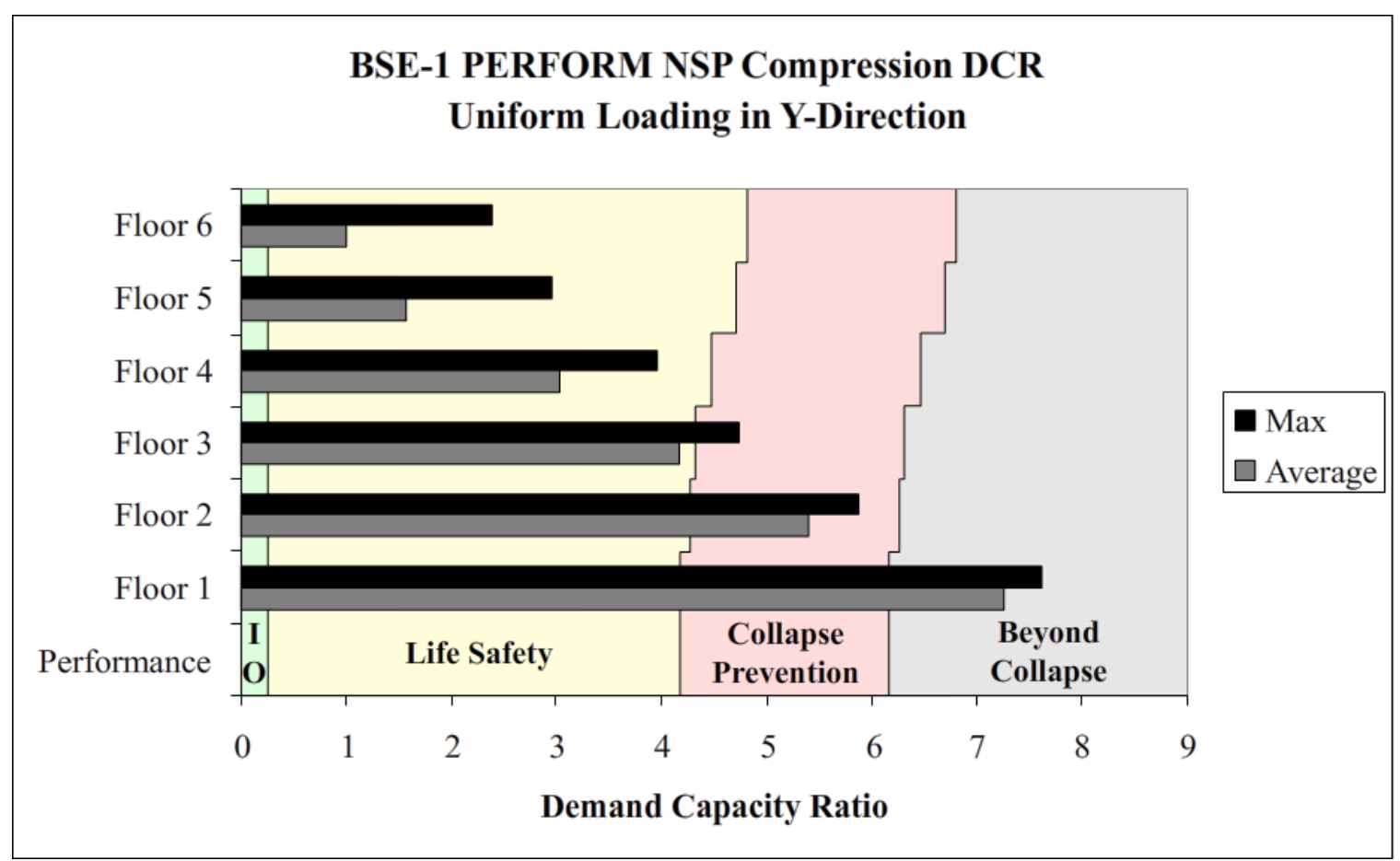

Figure O: BSE-1 NSP PERFORM Uniform Loading Y-Direction Compression

Performance-Based Analysis of Steel Buildings: Special Concentric Braced Frame 
The PERFORM analysis showed that $67 \%$ of the compression braces in the $\mathrm{x}-$ direction under triangular loading performed to Collapse Prevention while 17\% performed beyond the Collapse Prevention limits. In the y-direction, 33\% of the compression braces performed to Collapse Prevention while $42 \%$ performed beyond Collapse Prevention. Under uniform loading, 33\% of the compression braces in the $\mathrm{x}$ direction performed beyond Collapse Prevention, and in the y-direction, $17 \%$ of the braces performed beyond Collapse Prevention. In the x-direction, 17\% performed to Collapse Prevention, and in the y-direction, 25\% performed to Collapse Prevention. In general, the tension braces under both load patterns, and in both directions, performed to Life Safety standards. Considering that the compression braces performed beyond Collapse Prevention, and the performance of the tension braces is Life Safety, the overall building performance is not definitive. The tension braces, as well as the beams and columns, retain some lateral resisting capacity, but the extensive damage in the compression braces means the building could be classified at the Collapse Prevention level, or in what ASCE 41-06 section 1.5.1 calls the "Limited Safety Structural Performance Range.” This is a range of damage between the Life Safety and Collapse Prevention performance levels. As a possibly conservative interpretation, the building has been determined to perform to the Collapse Prevention level.

The uniform loading increased damage on lower floors while reducing damage on the upper floors. This was expected because the increasing uniform load creates larger relative forces on the lower floors, concentrating the damage there. Under triangular loading, the results showed the damage was more evenly spread among all of the floors. 
Once again, these results are included to check for unexpected failure mechanisms, of which none developed, and are not considered in the final performance evaluation.

\subsection{Nonlinear Dynamic Procedure}

ASCE 41-06 section 3.3.2.2.4 requires a minimum of seven time-history analyses in order to use an average of the results. For this investigation, a total of seven ground motions were used, and each was repeated for the $\mathrm{x}$ - and y-directions. The ground motions were provided by a San Francisco structural engineering firm, and are intended to be representative of ground motions at the building site. The ground motions have been spectral matched, and scaled to the site-specific response spectrum. The spectral matching was used to reduce the peaks and valleys inherent in a response spectrum created from unaltered ground motions. As a result, the altered ground motions used in this analysis produce response spectrums that better fit the shape of the site-specific response spectrum used in the previous procedures.

A general overview of the ground accelerations can be seen in Figure $\mathrm{P}$ on the following page. The graphs show each of the ground accelerations carried out to a total time of 80 seconds, and each graph is displayed to a maximum of $1.0 \mathrm{~g}$ and a minimum of $-1.0 \mathrm{~g}$. Larger, more detailed versions of the ground motion graphs are presented in the appendix. 
General Shape of Ground Accelerations Used
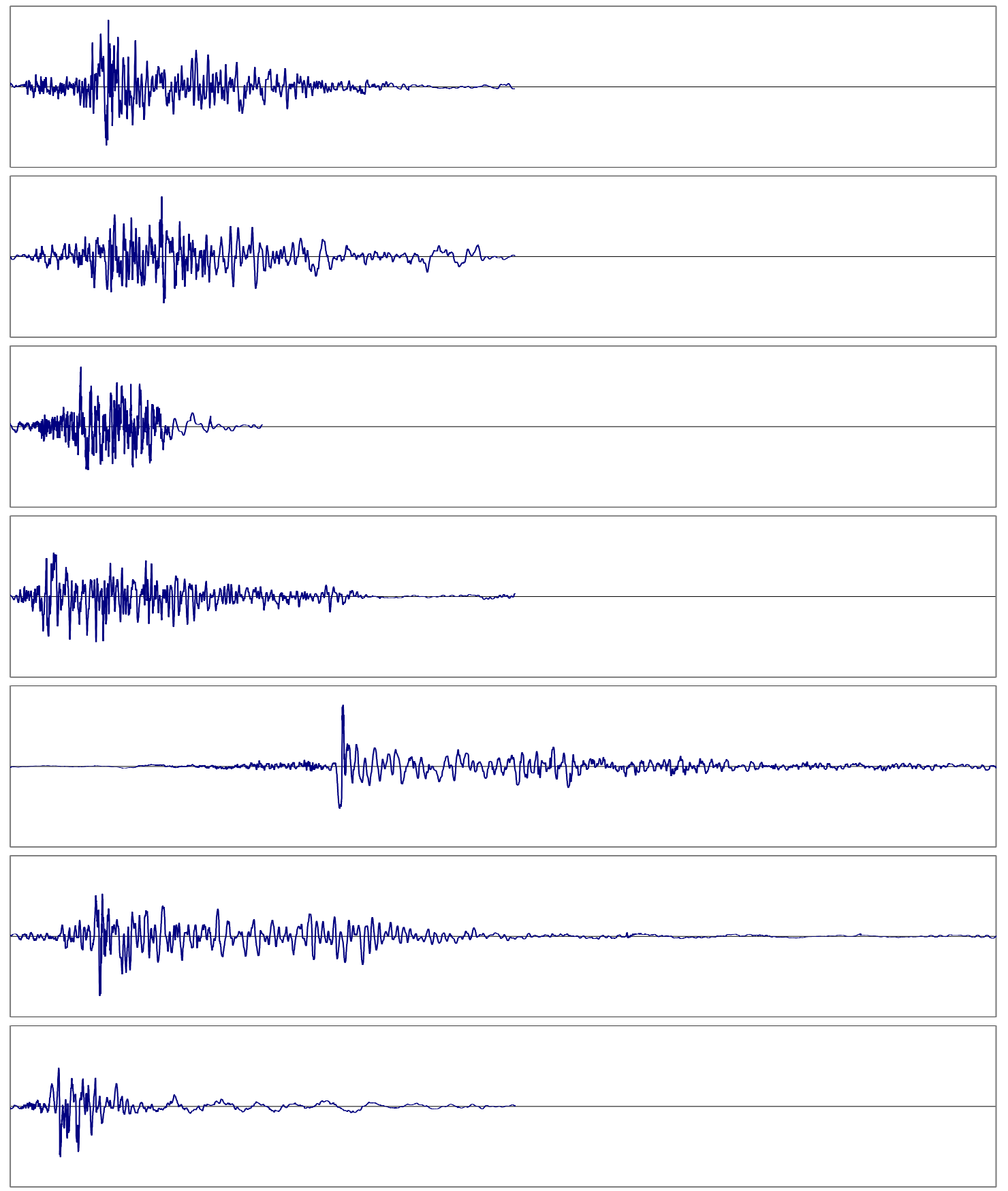

Figure P: Seven Ground Accelerations

Performance-Based Analysis of Steel Buildings: Special Concentric Braced Frame 
The chosen ground motions show a variety of intensities and durations, with the goal of enveloping probable earthquake ground motions for the building site. The resulting spectral matched response spectrums from each ground motion are compared to the design spectrum in Figure Q below.

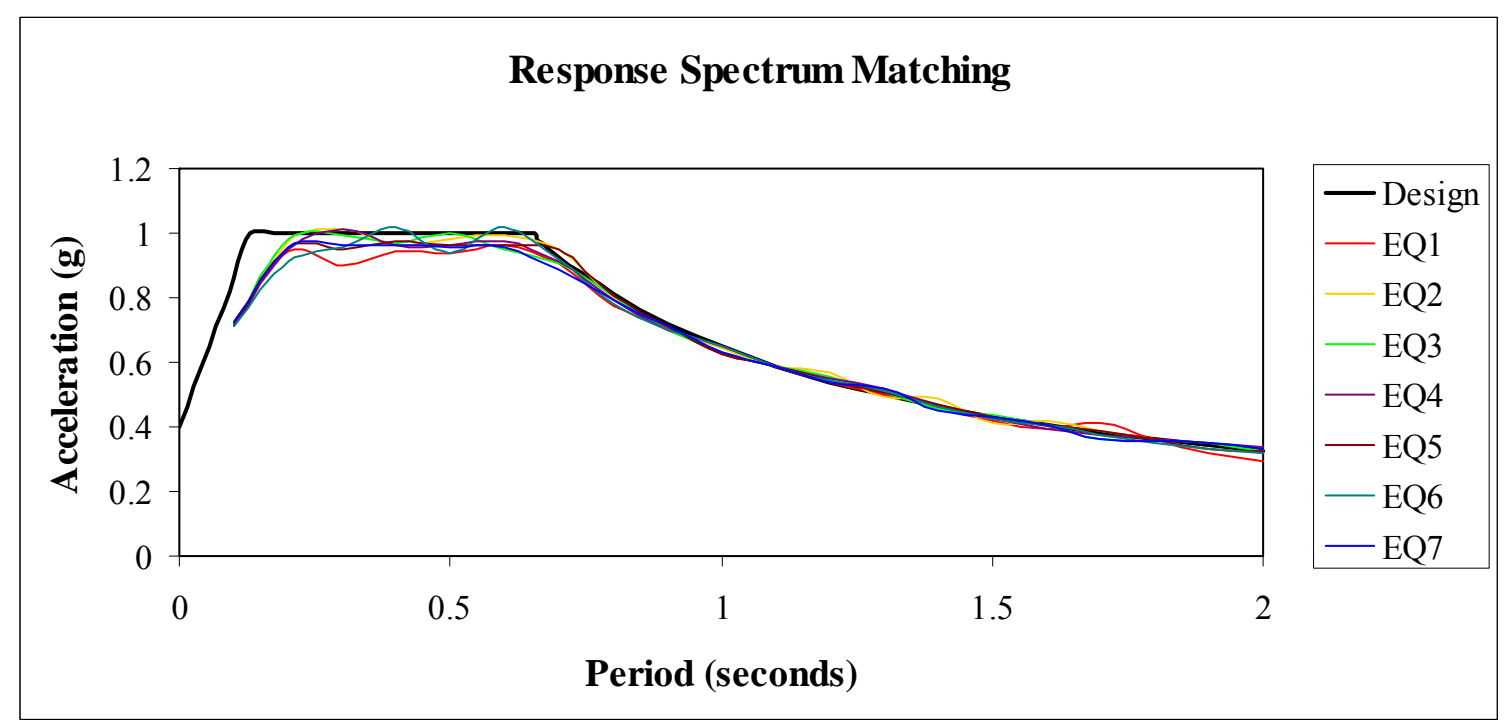

\section{Figure Q: BSE-1 Response Spectrum Matching}

The spectrum from each ground motion is very similar to the design spectrum, especially at the building period of 1.1 seconds, which was the chosen scaling and matching point for the spectrums.

The NDP results are comprised of the average of the seven individual time-history analyses. Each time-history analysis consisted of running a ground motion through the building model and retrieving the maximum and minimum deformations in the nonlinear components. The deformations from each of the analyses were then averaged to produce the final NDP results. For this analysis, the center of mass at each floor was offset by $5 \%$ as specified by ASCE 41-06. 
The graphs on the following pages display the DCRs for the braces. Figures R and $\mathrm{S}$ show the values for the compression forces. The graphs show the results for the brace with the largest DCR, as well as the average DCR of all the braces at each floor. In general, the tension braces performed to Immediate Occupancy or Life Safety if the braces yielded at all. The results for the tension braces can be found in a comparison between the analysis procedures in section 7.1.1. 


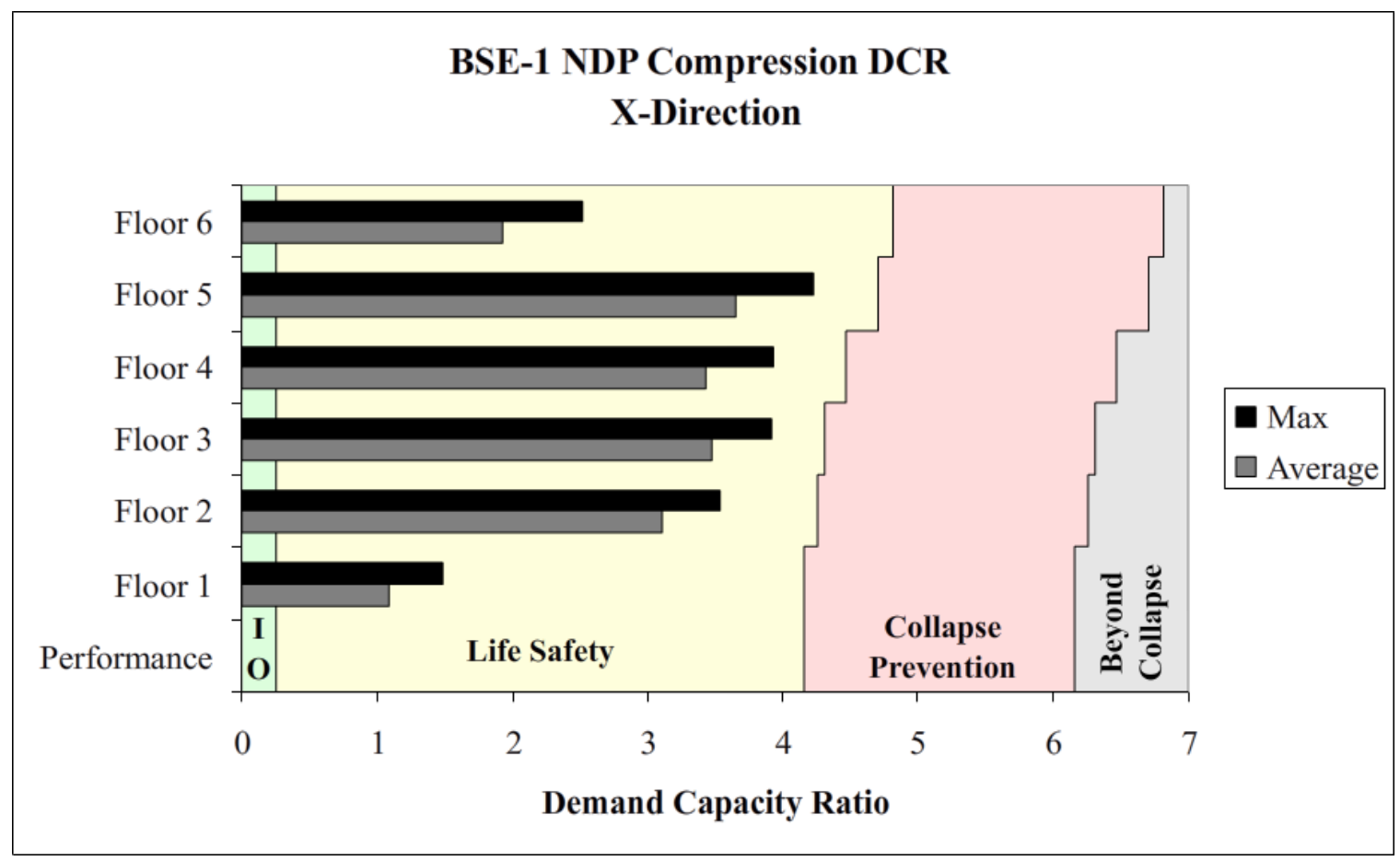

Figure R: BSE-1 NDP X-Direction Compression

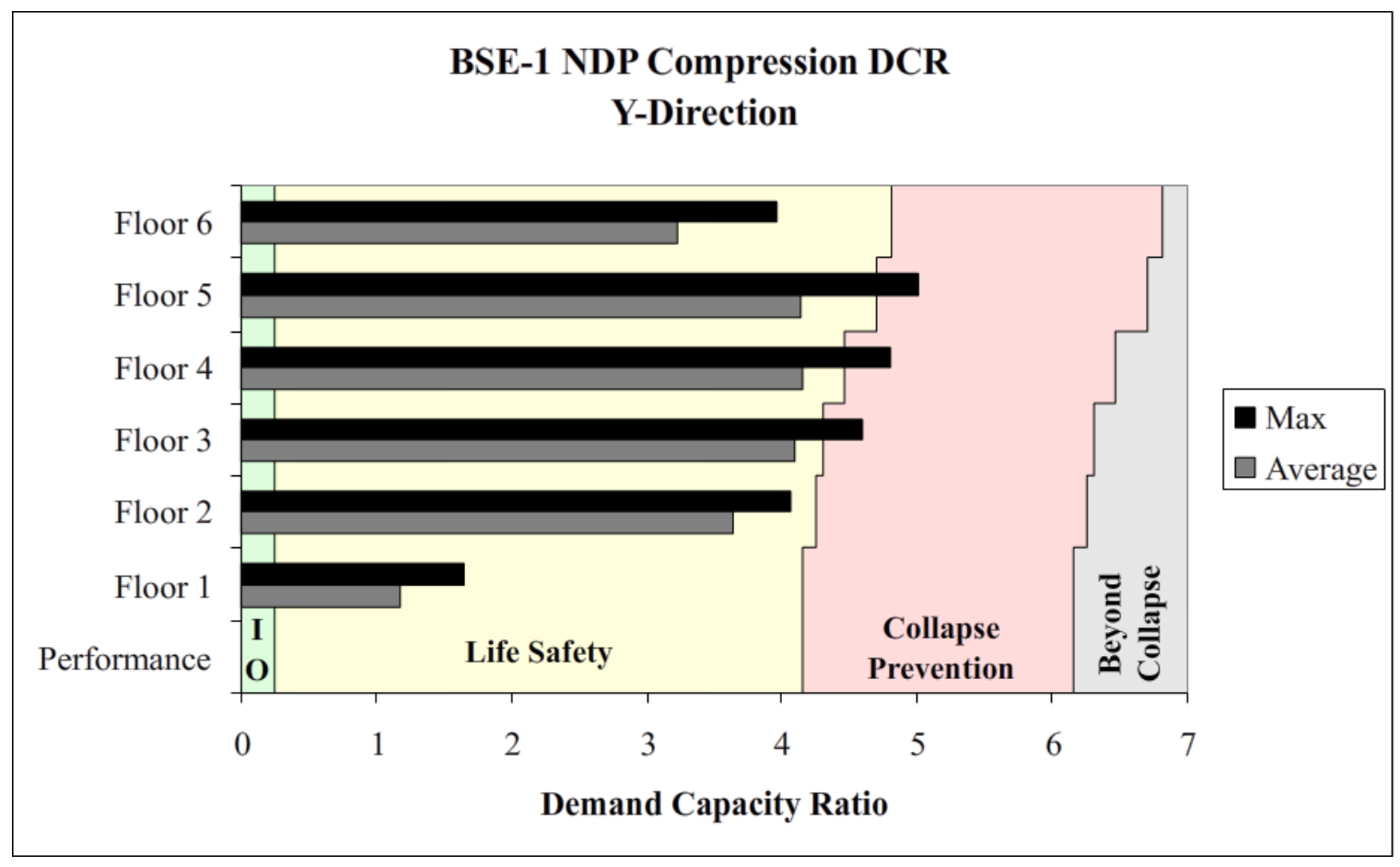

Figure S: BSE-1 NDP Y-Direction Compression

Performance-Based Analysis of Steel Buildings: Special Concentric Braced Frame 
Unlike the static procedures in which loads are applied in one direction and the braces can be distinctively regarded as tension or compression, the dynamic procedure ground motions shake the building side-to-side, which produces tension and compression forces in all braces. For all of the ground motions, the compression deformations for each frame were larger in one brace than the other. This was likely caused by a large pulse in the ground motion causing more damage in the brace acting in compression. For comparability with the other procedures, the average DCRs were determined by taking only the braces that acted in compression during the governing pulse.

The compression DCRs in the $\mathrm{x}$-direction can be considered to perform to Life Safety because all braces performed within the Life Safety limits. In the y-direction, 25\% of the compression braces perform to low levels of Collapse Prevention, and the remaining braces performing to Life Safety. The tension braces all performed to Life Safety in both directions. As with the nonlinear static procedure, the building performed within the Limited Safety Range. However, considering the borderline performance in only one direction, it could be argued that the building performance is a less definitive Life Safety. As the more conservative interpretation, it is argued here that the building performed to the Limited Safety Range for the nonlinear dynamic procedure. 


\subsection{ANALYSIS OF BSE-2 HAZARD LEVEL}

The American Society of Civil Engineers (ASCE) 41-06 standard provides a second earthquake hazard level to investigate, which is the unreduced maximum considered earthquake (MCE). ASCE 41-06 refers to this hazard as the Basic Safety Earthquake 2 (BSE-2). As with the previous analysis, ASCE 41-06 evaluates the performance of individual components of the seismic resisting system, and the engineer determines an overall building performance. The goal of the ASCE 7-05 design is for a building to perform no worse than Collapse Prevention for the BSE-2 level hazard.

The acceptance criteria for this level hazard are the same as the previous level. A demand-capacity ratio (DCR) is still compared to an acceptable value, as determined by ASCE 41-06. More information can be found in section 5.0.

The site-specific response spectrum used for the BSE-2 represents a $2 \%$ probability of exceedance in 50 years. The resulting site-specific response spectrum is shown in Figure $\mathrm{T}$ on the following page. 


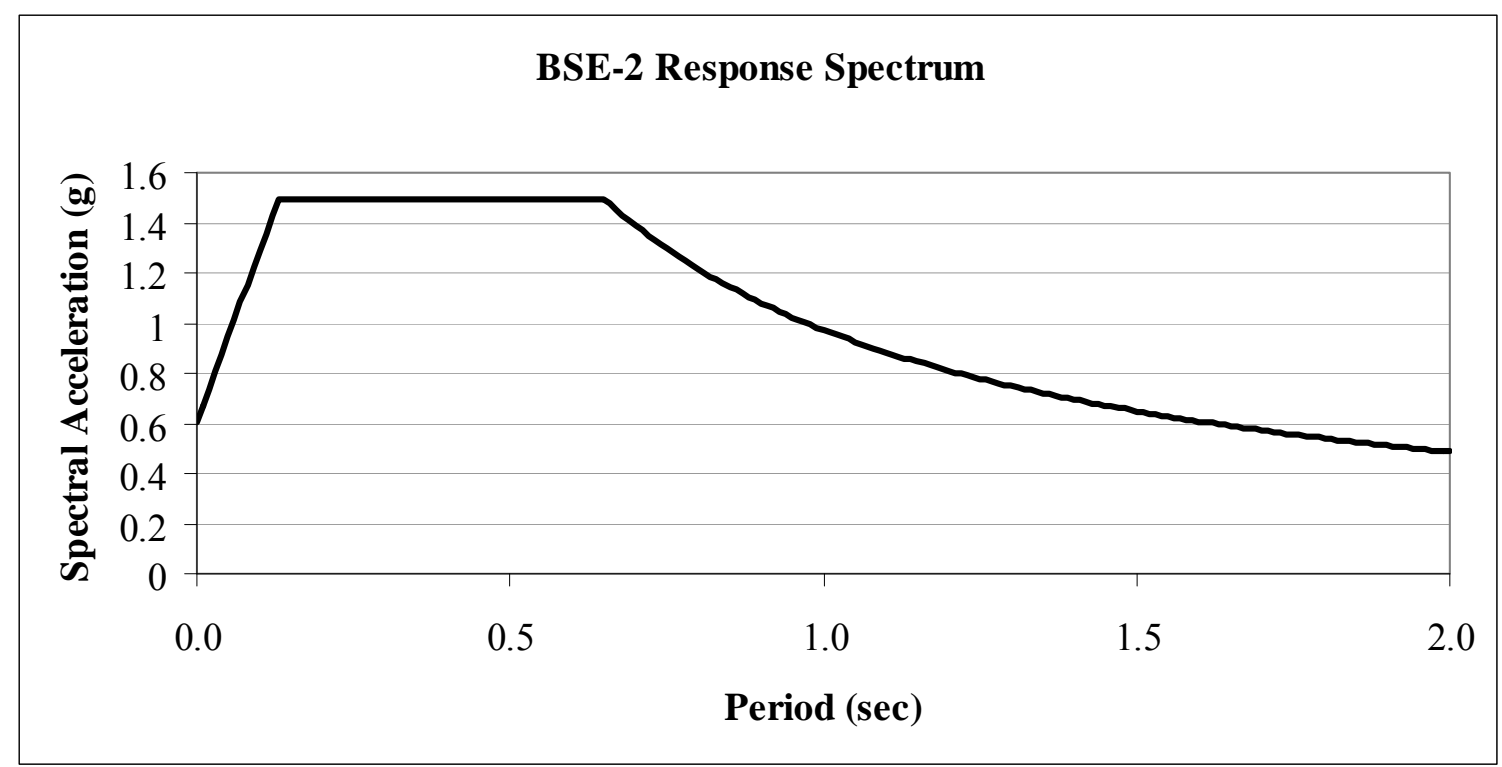

Figure T: BSE-2 Site-Specific Response Spectrum

The accelerations used for all four of the MCE analyses were taken from this spectrum. At a period of 1.10 seconds in the $\mathrm{x}$-direction, the resulting spectral acceleration is $0.884 \mathrm{~g}$, and in the $\mathrm{y}$-direction, a period of 1.01 seconds results in an acceleration of $0.963 \mathrm{~g}$.

\subsection{Linear Static Procedure}

The base shear for the linear static procedure was calculated using Eq. 3 on page 18. The values used in the calculations, and the resulting base shears for the $\mathrm{x}-$ and $\mathrm{y}-$ directions are summarized in Table $\mathrm{H}$ below.

\begin{tabular}{||r|r|l||}
\hline \multicolumn{3}{|c|}{ X-Direction } \\
\hline \hline $\mathrm{C}_{1}=$ & 1.005 & \\
\hline $\mathrm{C}_{2}=$ & 1.000 & \\
\hline $\mathrm{C}_{\mathrm{m}}=$ & 1.0 & \\
\hline $\mathrm{S}_{\mathrm{a}}=$ & 0.884 & $\mathrm{~g}$ \\
\hline $\mathrm{W}=$ & 17,145 & $\mathrm{k}$ \\
\hline $\mathbf{V}_{\mathbf{x}}=$ & $\mathbf{1 5 , 2 4 7}$ & $\mathbf{k}$ \\
\hline
\end{tabular}

\begin{tabular}{||l|r|l||}
\hline \multicolumn{3}{|c||}{ Y-Direction } \\
\hline \hline $\mathrm{C}_{1}=$ & 1.009 & \\
\hline $\mathrm{C}_{2}=$ & 1.000 & \\
\hline $\mathrm{C}_{\mathrm{m}}=$ & 1.0 & \\
\hline $\mathrm{S}_{\mathrm{a}}=$ & 0.963 & $\mathrm{~g}$ \\
\hline $\mathrm{W}=$ & 17,145 & $\mathrm{k}$ \\
\hline $\mathbf{V}_{\mathbf{y}}=$ & $\mathbf{1 6 , 6 6 3}$ & $\mathbf{k}$ \\
\hline \hline
\end{tabular}

Table H: BSE-2 Linear Static Base Shear Calculations

Performance-Based Analysis of Steel Buildings: Special Concentric Braced Frame 
The results for these analyses are formatted in the same manner as the previous hazard level. An explanation of the format can be found in section 5.0 on page 17. Figure $\mathrm{U}$ and Figure $\mathrm{V}$ show the demand-capacity ratios for the compression braces subject to the full static load. The tension results do not govern the analysis, so they are only included for comparison purposes in section 7.2.1. The columns and beams do not yield under the loading; therefore, the results are not included.

As with the previous section, the required 5\% eccentricity results in different forces in each of the braces on each floor, so the graphs include the maximum DCR in any brace at each floor, and the average of the DCRs for all braces at each floor. 


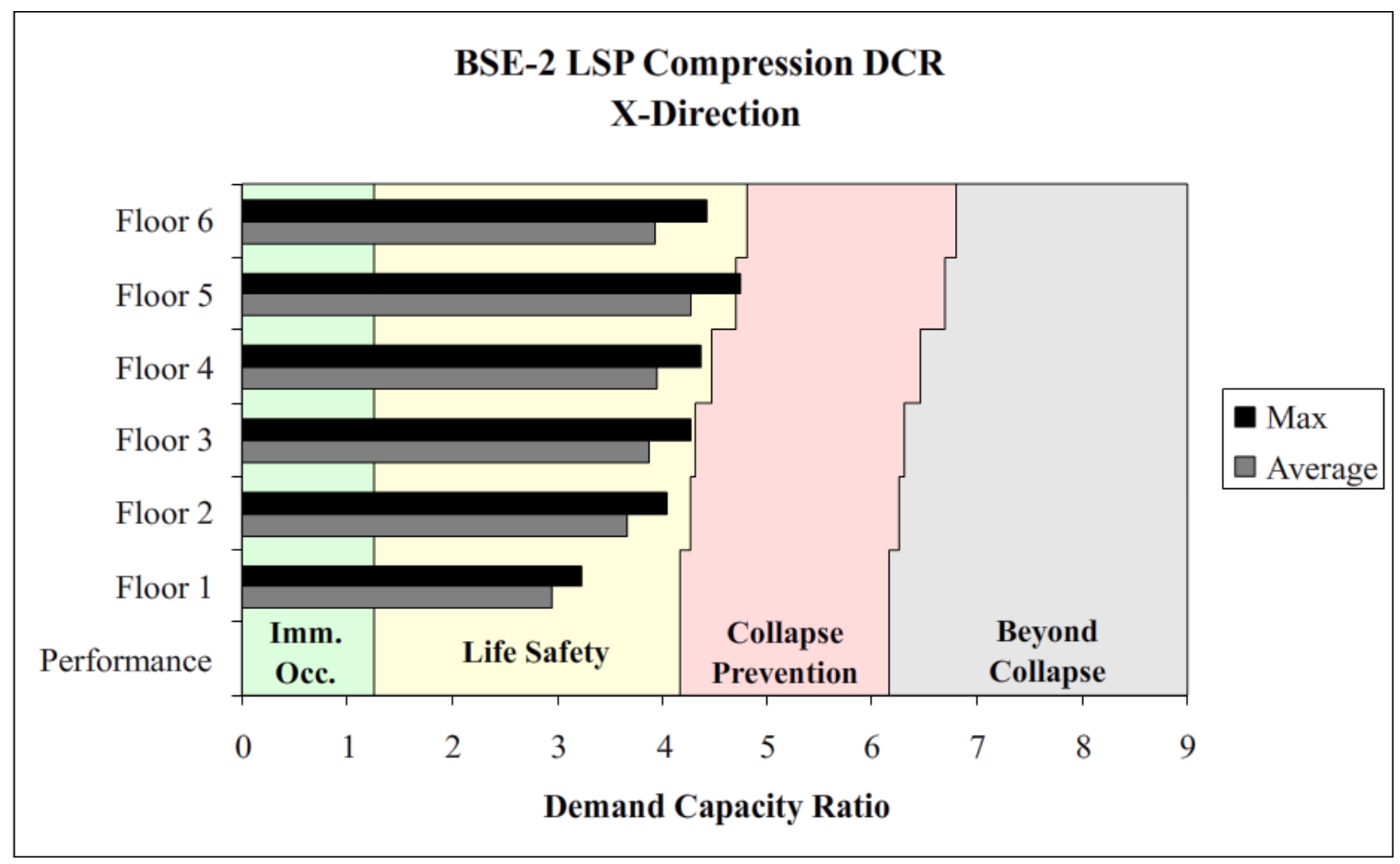

Figure U: BSE-2 LSP X-Direction Compression

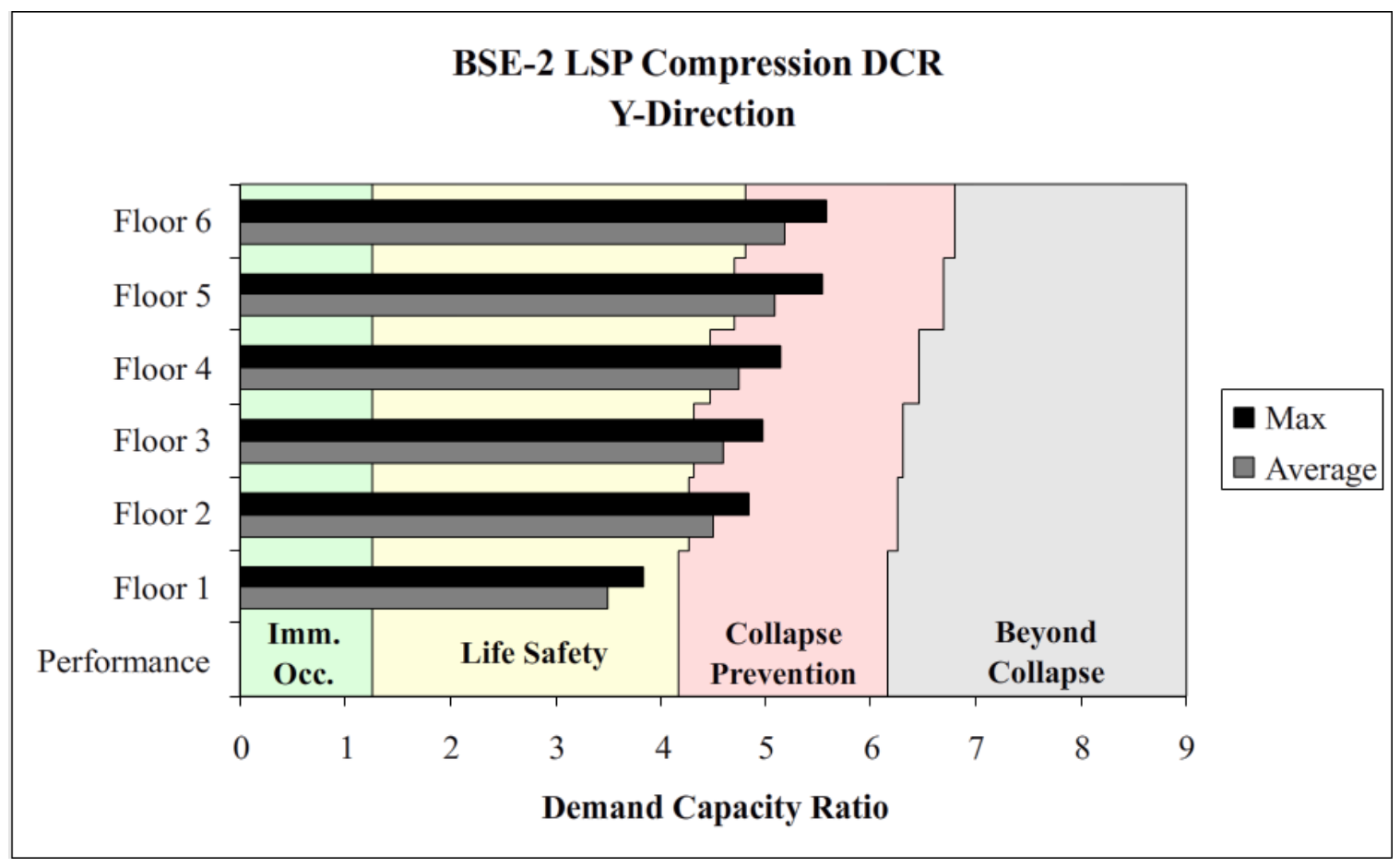

Figure V: BSE-2 LSP Y-Direction Compression

Performance-Based Analysis of Steel Buildings: Special Concentric Braced Frame 
The graphs show that the compression braces in the x-direction generally perform to a level of Life Safety, with one brace on the fifth floor crossing into Collapse Prevention. In the y-direction, all of the braces, with the exception of the first floor, perform well within the Collapse Prevention range. The performances of each direction differ as a result of their respective braced frame configurations. The adjacent braced frames in the y-direction increase the lateral stiffness, and therefore the base shear. This increased force is enough to produce a different performance level between the two directions. Considering the Life Safety performance of the tension braces and the $\mathrm{x}$ direction, it is argued that the building has not sustained enough damage to declare it at a full Collapse Prevention level. Therefore, the building has performed within the Limited Safety Range for the BSE-2 linear static procedure.

\subsection{Linear Dynamic Procedure}

The linear dynamic procedure (LDP) was based on the site-specific response spectrum shown in Figure S. The acceleration values are the same as the values used in the BSE-2 LSP.

The analysis results are shown in the graphs on the following pages. Figure $\mathrm{W}$ and Figure $\mathrm{X}$ show the demand-capacity ratios for the compression braces. The forces in the tension braces do not govern the analysis and have been included for comparison on in section 7.2.1. The graphs are formatted as they were in the previous analyses, and an explanation of the information presented can be found in section 5.0.

The graphs show the maximum DCR of any brace at each floor, as well as the average of the critical DCR of each brace at the floor.

Performance-Based Analysis of Steel Buildings: Special Concentric Braced Frame 


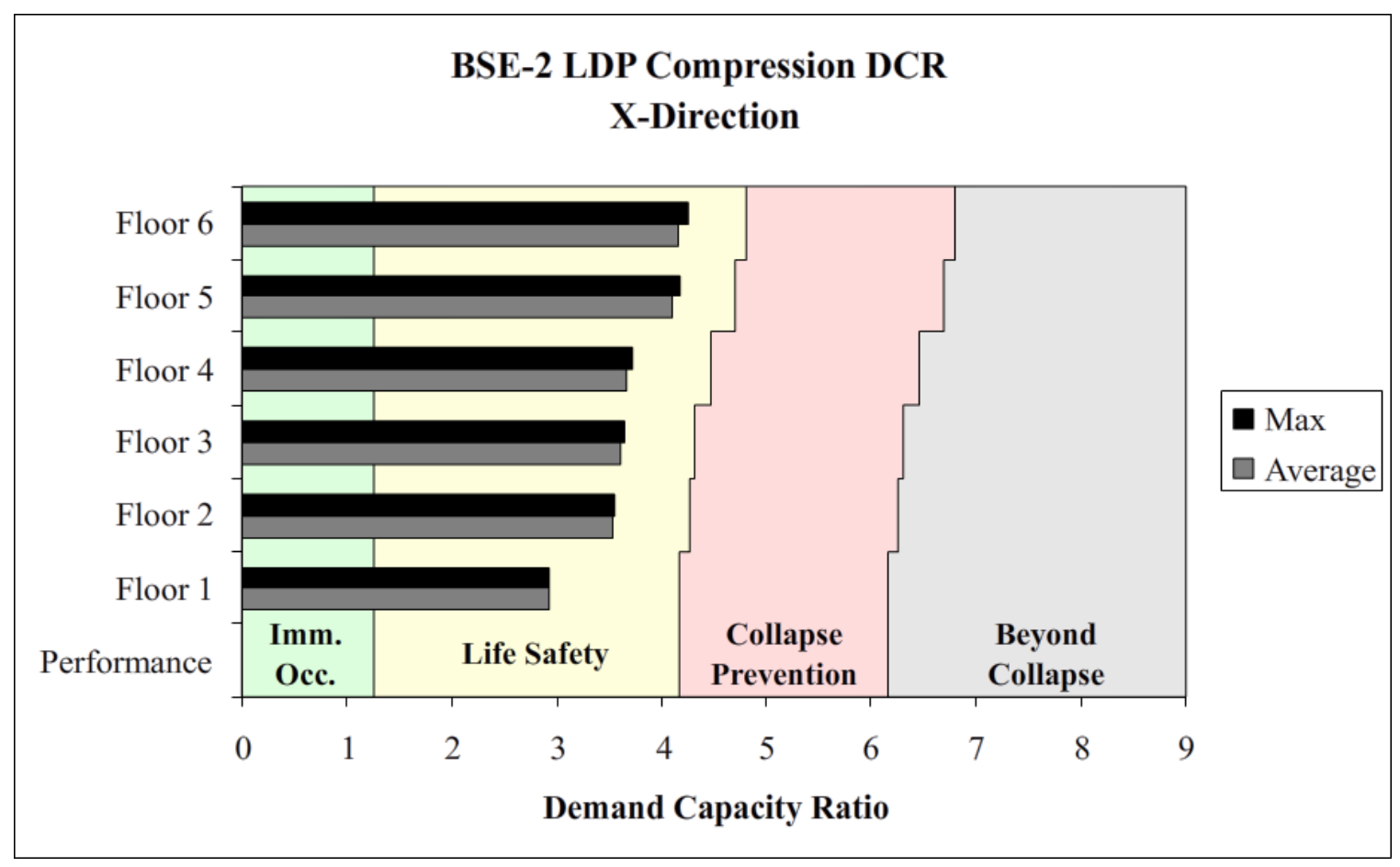

Figure W: BSE-2 LDP X-Direction Compression

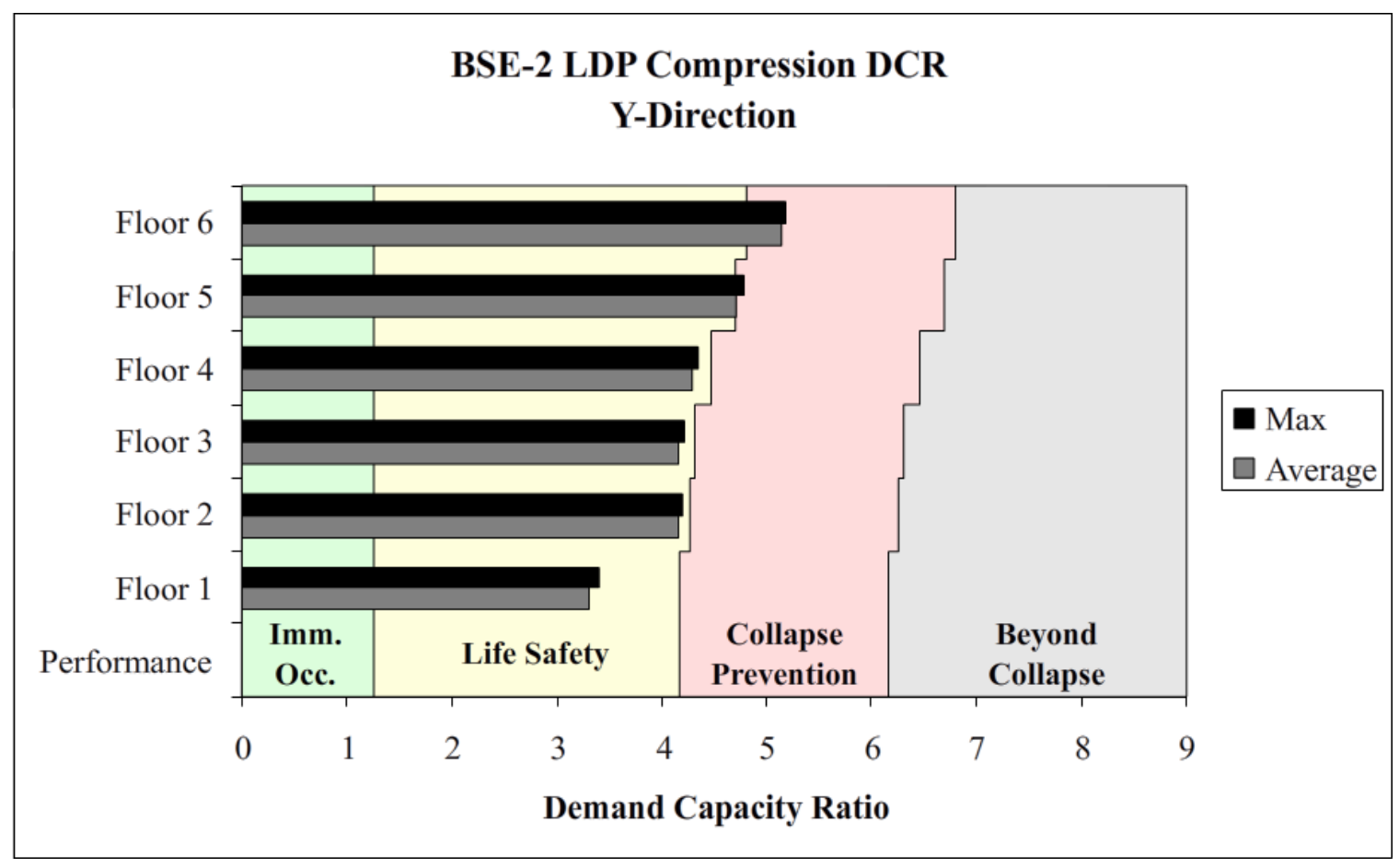

Figure X: BSE-2 LDP Y-Direction Compression

Performance-Based Analysis of Steel Buildings: Special Concentric Braced Frame 
The compression braces in the x-direction all performed within Life Safety. The compression braces in the $\mathrm{y}$-direction show more damage than the $\mathrm{x}$-direction, and $33 \%$ of the braces perform slightly into Collapse Prevention, while the remaining braces perform to Life Safety. The tension braces in both directions perform to Life Safety. The borderline performance of only the top two floors in one direction could allow the building performance to be considered Life Safety. However, as the Life Safety classification is not definitive, the building has performed to the Limited Safety Range for this analysis.

\subsection{Nonlinear Static Procedure}

The nonlinear static procedure (NSP) for the BSE-2 is the same as the BSE-1 analysis, but with a larger target displacement. The target displacement equation can be found in section 5.3 as Eq. 4. The values used in the displacement calculation are shown in Table I below. The building was pushed to these targets using both triangular and uniform load patterns.

\begin{tabular}{||l|r|l||}
\hline \multicolumn{3}{||c|}{ X-Direction } \\
\hline \hline $\mathrm{C}_{0}=$ & 1.3 & \\
\hline $\mathrm{C}_{1}=$ & 1.0 & \\
\hline $\mathrm{C}_{2}=$ & 1.0 & \\
\hline $\mathrm{S}_{\mathrm{a}}=$ & 0.884 & $\mathrm{~g}$ \\
\hline $\mathrm{T}_{\mathrm{e}}=$ & 1.10 & sec. \\
\hline $\boldsymbol{\delta}_{\mathrm{tx}}=$ & $\mathbf{1 3 . 6 1}$ & in. \\
\hline
\end{tabular}

\begin{tabular}{||l|r|l||}
\hline \multicolumn{3}{|c||}{ Y-Direction } \\
\hline \hline $\mathrm{C}_{0}=$ & 1.3 & \\
\hline $\mathrm{C}_{1}=$ & 1.0 & \\
\hline $\mathrm{C}_{2}=$ & 1.0 & \\
\hline $\mathrm{S}_{\mathrm{a}}=$ & 0.963 & $\mathrm{~g}$ \\
\hline $\mathrm{T}_{\mathrm{e}}=$ & 1.01 & sec. \\
\hline $\boldsymbol{\delta}_{\mathrm{ty}}=$ & $\mathbf{1 2 . 5 0}$ & in. \\
\hline \hline
\end{tabular}

Table I: BSE-2 Nonlinear Static Target Displacement Calculation

As explained in section 5.3, the target displacement has been increased $150 \%$ as required by ASCE 41-06. 
The triangular loading will be the governing load profile as explained in section 5.3. The force-displacement curves up to the target displacements are shown below in Figure $\mathrm{Y}$ for the $\mathrm{x}$-direction, and on the following page in Figure $\mathrm{Z}$ for the $\mathrm{y}$-direction.

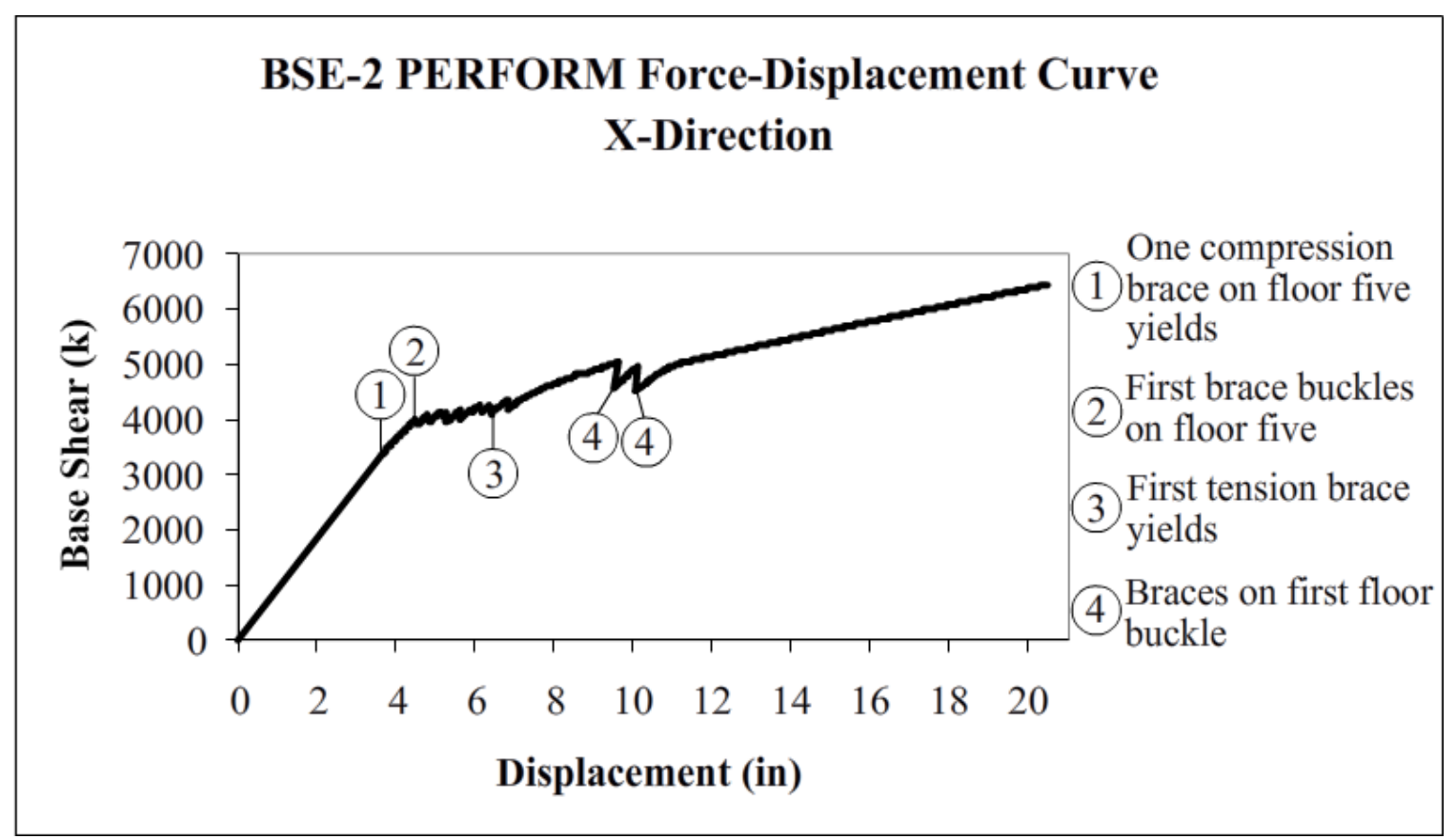

Figure Y: BSE-2 X-Direction Force-Displacement Curve

The $\mathrm{x}$-direction curve is the same as the BSE-1 curve up to that target displacement of 13.62 in. In the post BSE-1 displacement range there is very little activity. The two remaining tension braces on the fifth floor yield at a base shear of 5718 kips and a roof displacement of $15.61 \mathrm{in.}$ Two of the four remaining tension braces on the sixth floor yield at a base shear of 6226 kips and a roof displacement of $18.98 \mathrm{in}$. Two braces on the sixth floor remain un-buckled. The beams and columns in the braced frame remain elastic in both the $\mathrm{x}$ - and $\mathrm{y}$-directions. 


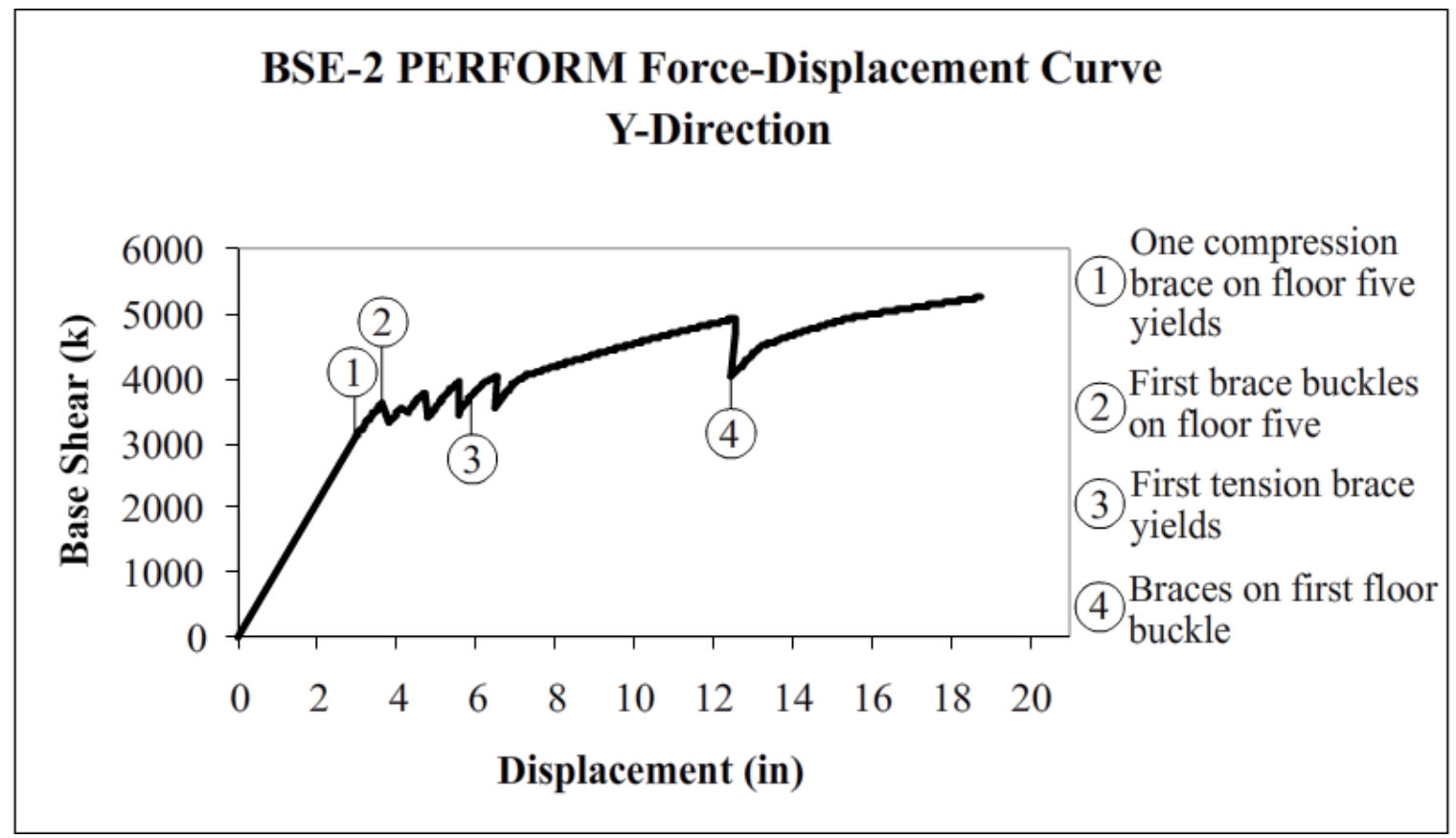

Figure Z: BSE-2 Y-Direction Force-Displacement Curve

The y-direction pushover shows a sudden strength loss after the BSE-1 target displacement. The strength loss is due to all of the compression braces on the first floor buckling simultaneously at a base shear of 4682 kips and a roof displacement of $12.55 \mathrm{in}$. All four tension braces on the first floor have yielded at a displacement of $13.05 \mathrm{in}$. and a base shear of 4405 kips.

The performances of the braces are shown in the graphs on the following pages. The graphs can be read as they were in the previous analyses. As with the previous analyses, the graphs include a maximum DCR at each level and the average of the DCRs at each level. Figures AA and BB show the PERFORM compression braces under a triangular loading pattern. Figures $\mathrm{CC}$ and DD show the PERFORM compression braces under a uniform loading pattern. The ETABS values can be found in section 7.2.2. 


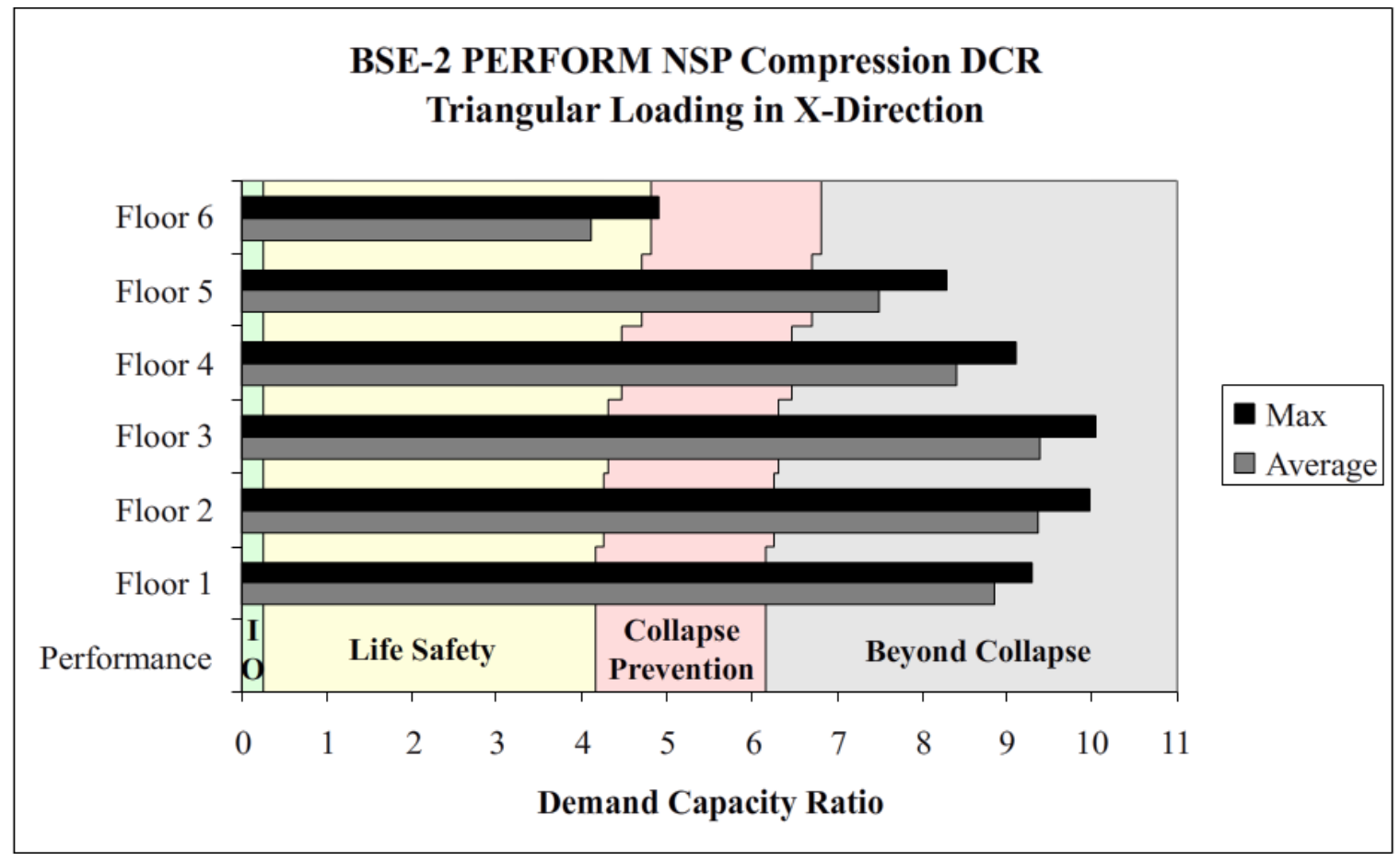

Figure AA: BSE-2 NSP PERFORM Triangular Loading X-Direction Compression

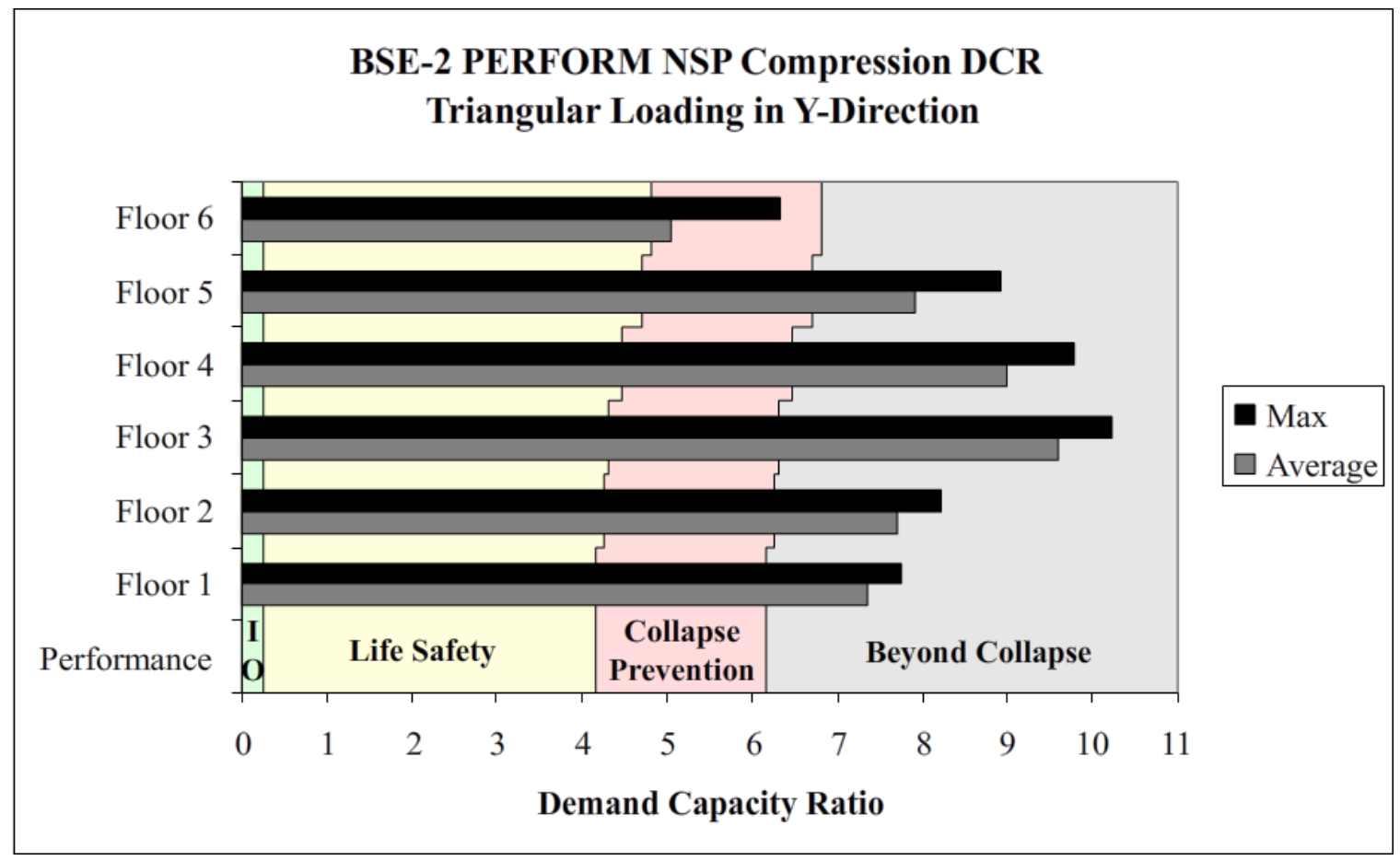

Figure BB: BSE-2 NSP PERFORM Triangular Loading Y-Direction Compression

Performance-Based Analysis of Steel Buildings: Special Concentric Braced Frame 


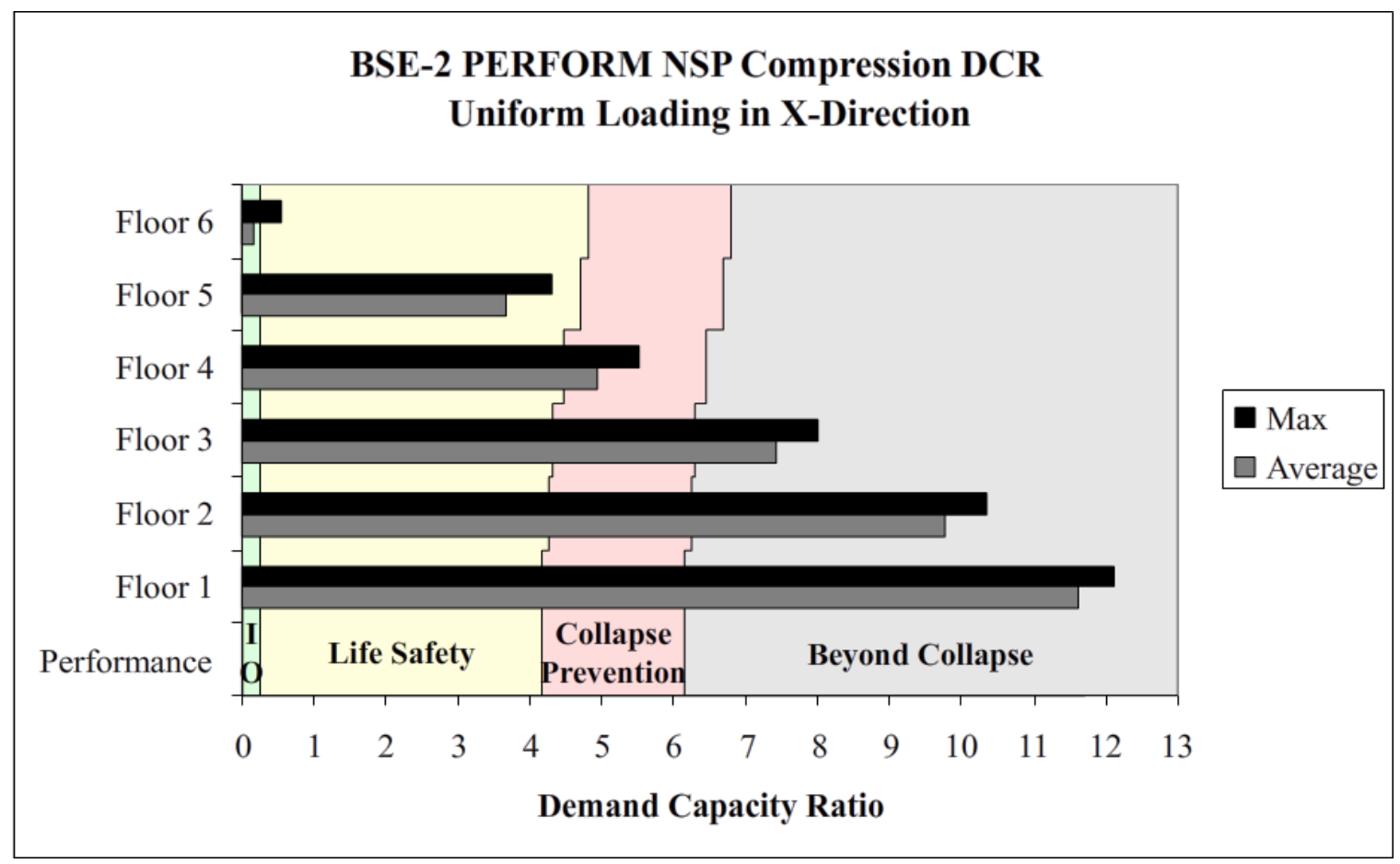

Figure CC: BSE-2 NSP PERFORM Uniform Loading X-Direction Compression

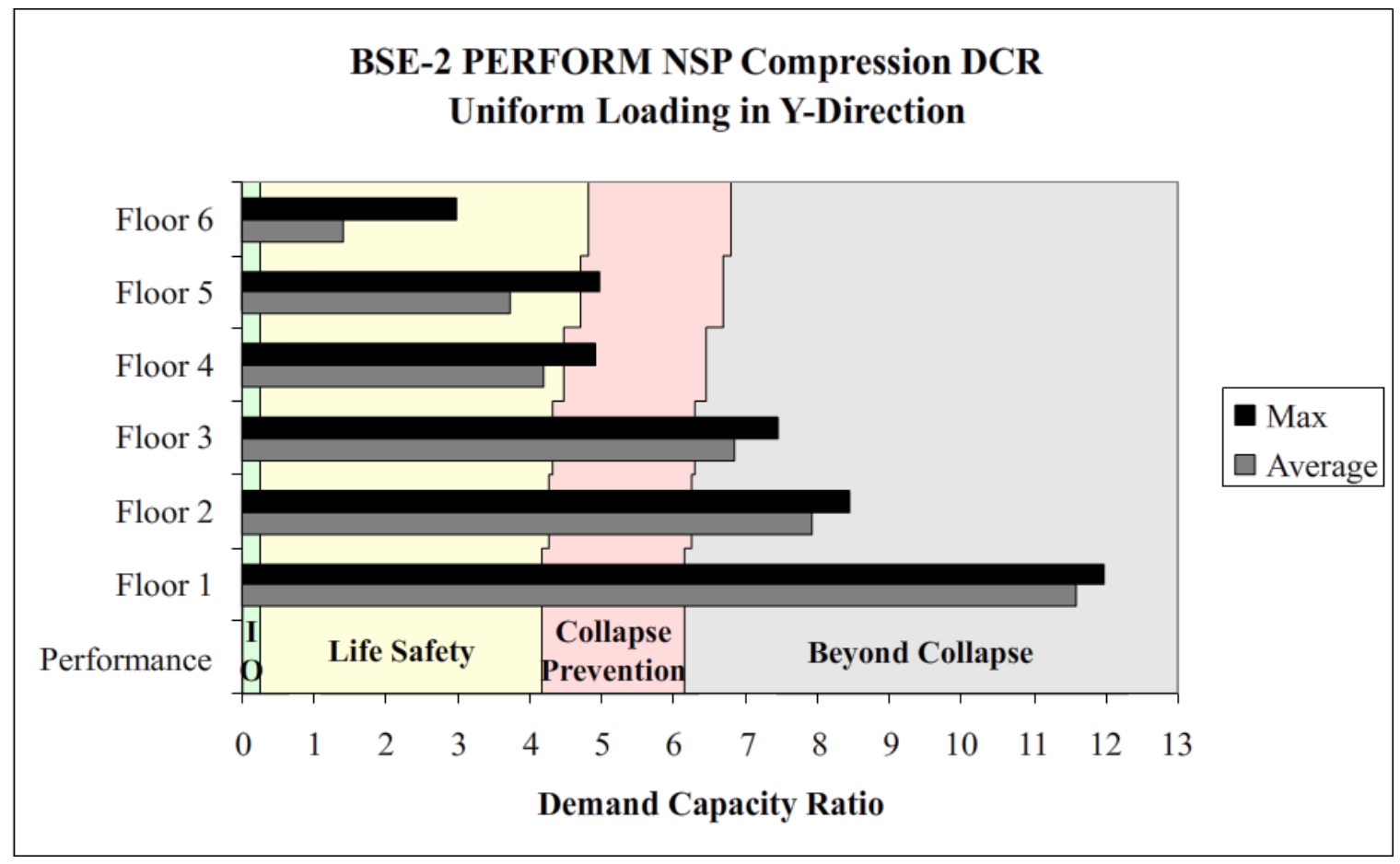

Figure DD: BSE-2 NSP PERFORM Uniform Loading Y-Direction Compression

Performance-Based Analysis of Steel Buildings: Special Concentric Braced Frame 
The analysis showed that $83 \%$ of the compression braces in both directions performed beyond the Collapse Prevention limits under triangular loading. In both directions, the top floor showed the least damage, and performed to Collapse Prevention. The tension braces in both directions performed within the Life Safety limits, and the beams and columns in the braced frames remained elastic. The damage in the compression braces significantly exceeds the Collapse Prevention limits, however, the tension braces are still capable of providing lateral resistance. So while the building as a whole has not yet exceeded Collapse Prevention, the damage to the compression braces means the building is beyond the Limited Safety Range. For this reason, the building performs to the Collapse Prevention level for the BSE-2 nonlinear static procedure.

Under uniform loading, the building performed as expected with the lower floors receiving more damage than under the triangular loading. The damage to the braces on the first floor governed in both directions. In both directions, $50 \%$ of the braces performed beyond the Collapse Prevention limits. Even with the extreme damage on the first floor, the beams and columns remained elastic because they were designed to the capacity of the braces. These results do not indicate any unexpected failures for higher mode participation.

\subsection{Nonlinear Dynamic Procedure}

As explained in section 5.4 of this document, ASCE 41 section 3.3.2.2.4 requires a minimum of seven time-history analyses in order to average the results of the individual time-histories. This average is then considered the final result of the nonlinear dynamic procedure (NDP). An explanation of this is provided in section 5.4. The same ground 
motions from the BSE-1 analysis were scaled up to the BSE-2 response spectrum and used for this procedure. A general overview of the ground accelerations can be seen in figure $\mathrm{HH}$ in section 5.4. Larger, more detailed versions of the ground motion graphs are presented in the appendix.

The graphs on the following pages display the DCRs for the compression braces. The $\mathrm{x}$-direction is shown in Figures EE and the y-direction is shown in Figure FF. The tension braces did not govern the analysis, but have been included for comparison in section 7.2.1. 


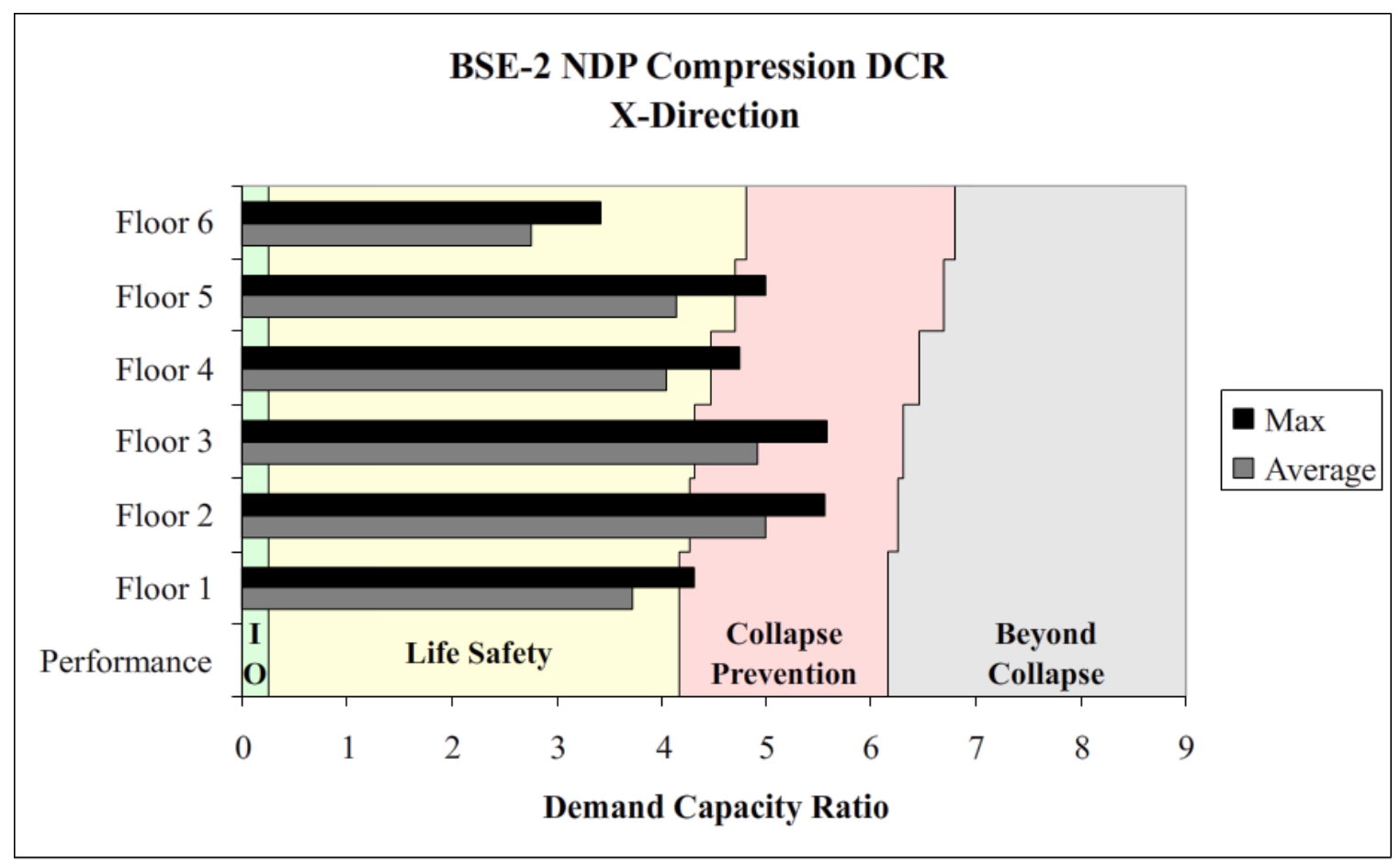

Figure EE: BSE-2 NDP X-Direction Compression

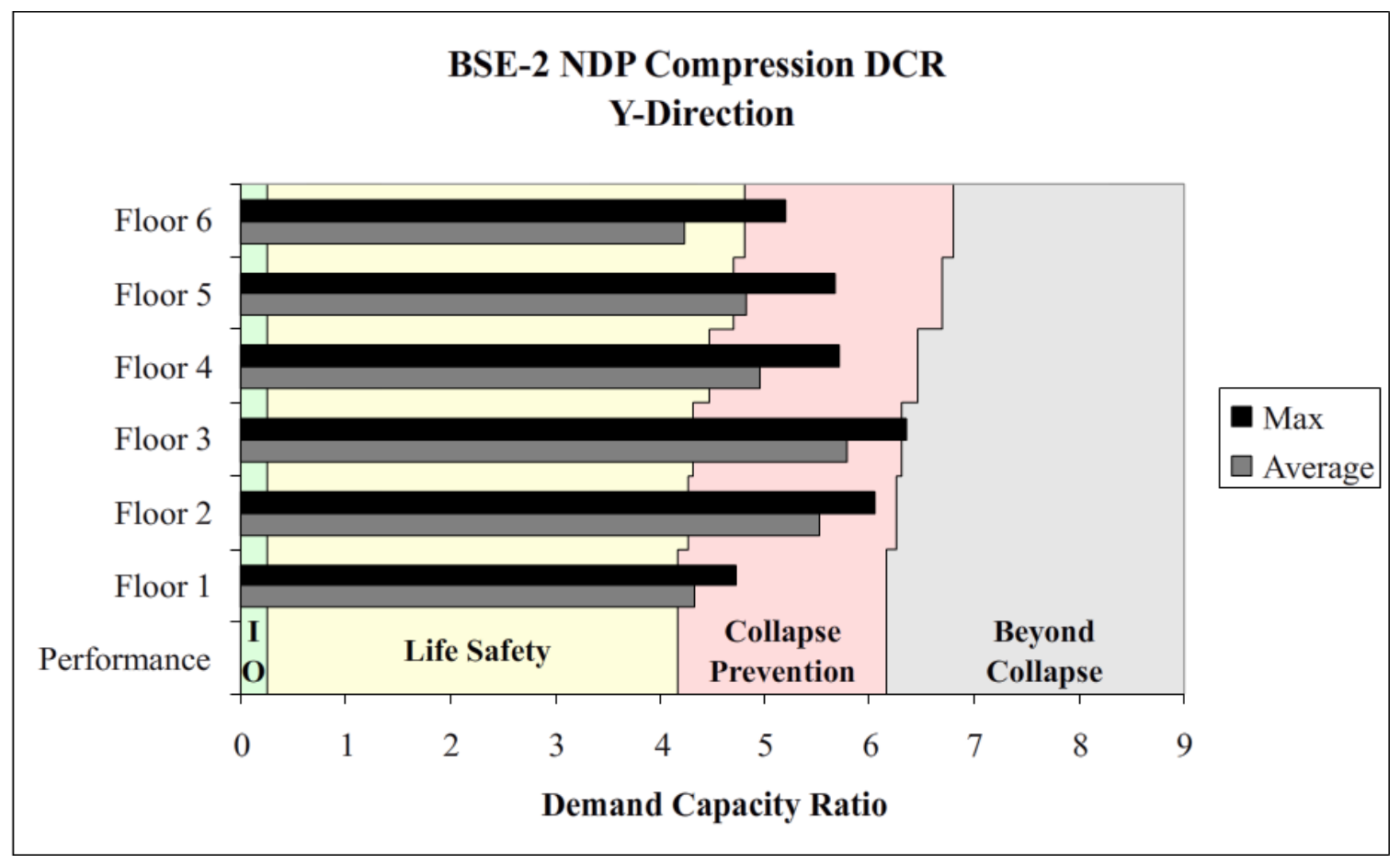

Figure FF: BSE-2 NDP Y-Direction Compression

Performance-Based Analysis of Steel Buildings: Special Concentric Braced Frame 
In the $\mathrm{x}$-direction, $50 \%$ of the braces perform to Collapse Prevention, while the remaining braces perform to Life Safety. In the y-direction, two braces on the third floor slightly perform beyond Collapse Prevention, while the majority of the braces perform to Collapse Prevention. Considering the Life Safety performance of the tension braces, it could be argued that the building is in the Limited Safety Range, however, given the extensive buckling of so many braces, the conservative determination has been made, and the overall building performance has been placed at the Collapse Prevention level for the BSE-2 nonlinear dynamic procedure. 


\subsection{COMPARISON OF ANALYSIS PROCEDURES}

In addition to simply examining the buildings performance in each of the ASCE 41-06 procedures, a direct comparison of each procedure can be made. The linear static procedure (LSP), linear dynamic procedure (LDP), nonlinear static procedure (NSP), and nonlinear dynamic procedure (NDP) vary in their performance, and a comparison can draw attention to the shortcomings of a particular procedure. This section also compares the nonlinear static analyses conducted in ETABS and PERFORM.

\subsection{BSE-1 Analysis Comparisons}

ASCE 7-05 has an implicit design goal of Life Safety for the basic safety earthquake 1 (BSE-1) hazard level. The four primary analysis procedures, as well as the ETABS nonlinear static procedure varied in the degree to which this goal was or was not achieved.

\subsubsection{Comparison of the Four Primary Analysis Procedures}

The graphs on the following pages directly compare the demand-capacity ratios (DCRs) for each analysis procedure to one another. Figures GG and HH show the results for the compression braces in the $\mathrm{x}$ - and $\mathrm{y}$-directions respectively, while Figures II and JJ show the tension results for the $\mathrm{x}$ - and $\mathrm{y}$-directions respectively. Figures KK and LL show a comparison of floor drift for each direction. 


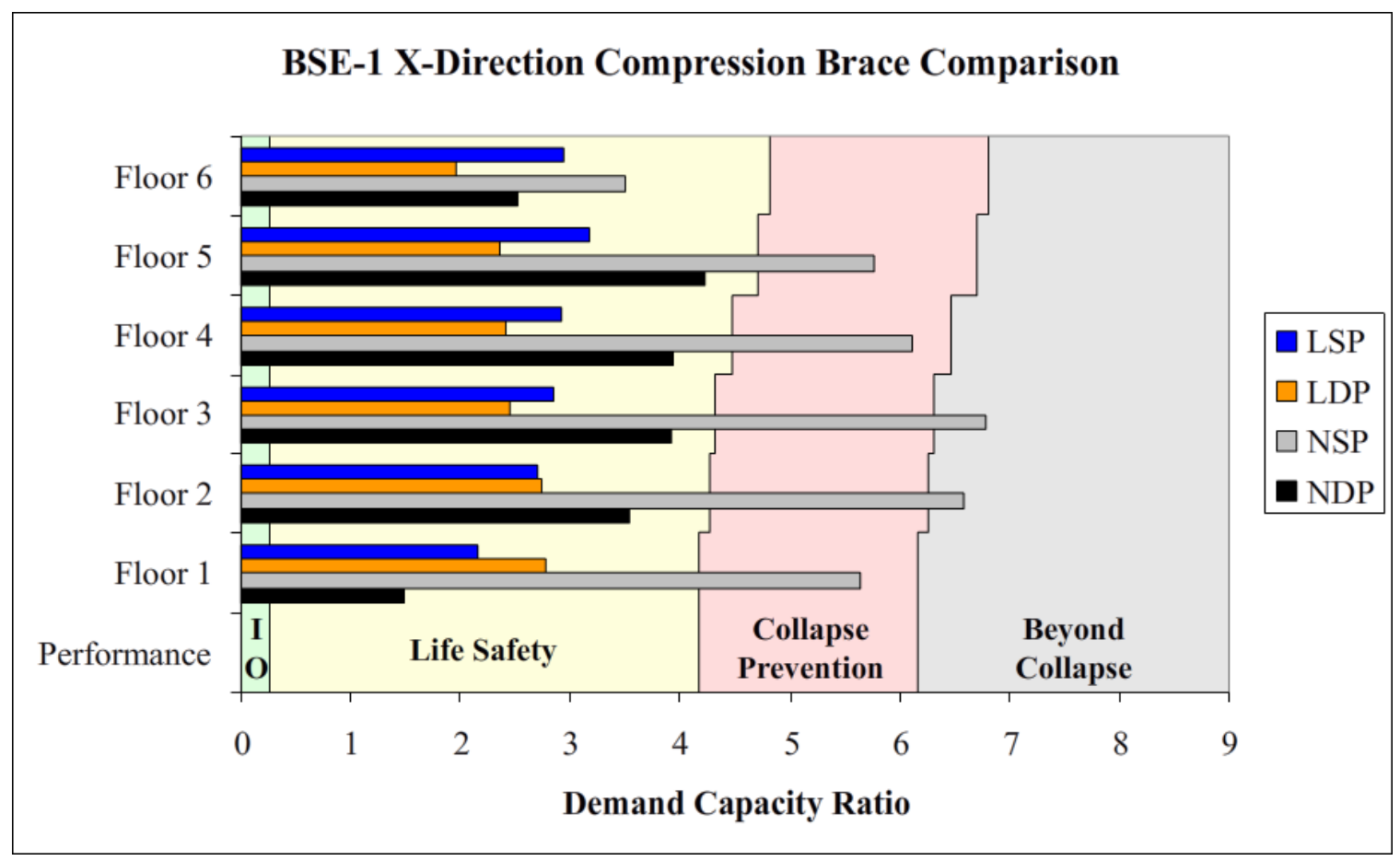

Figure GG: BSE-1 X-Direction Compression Comparison of All Procedures

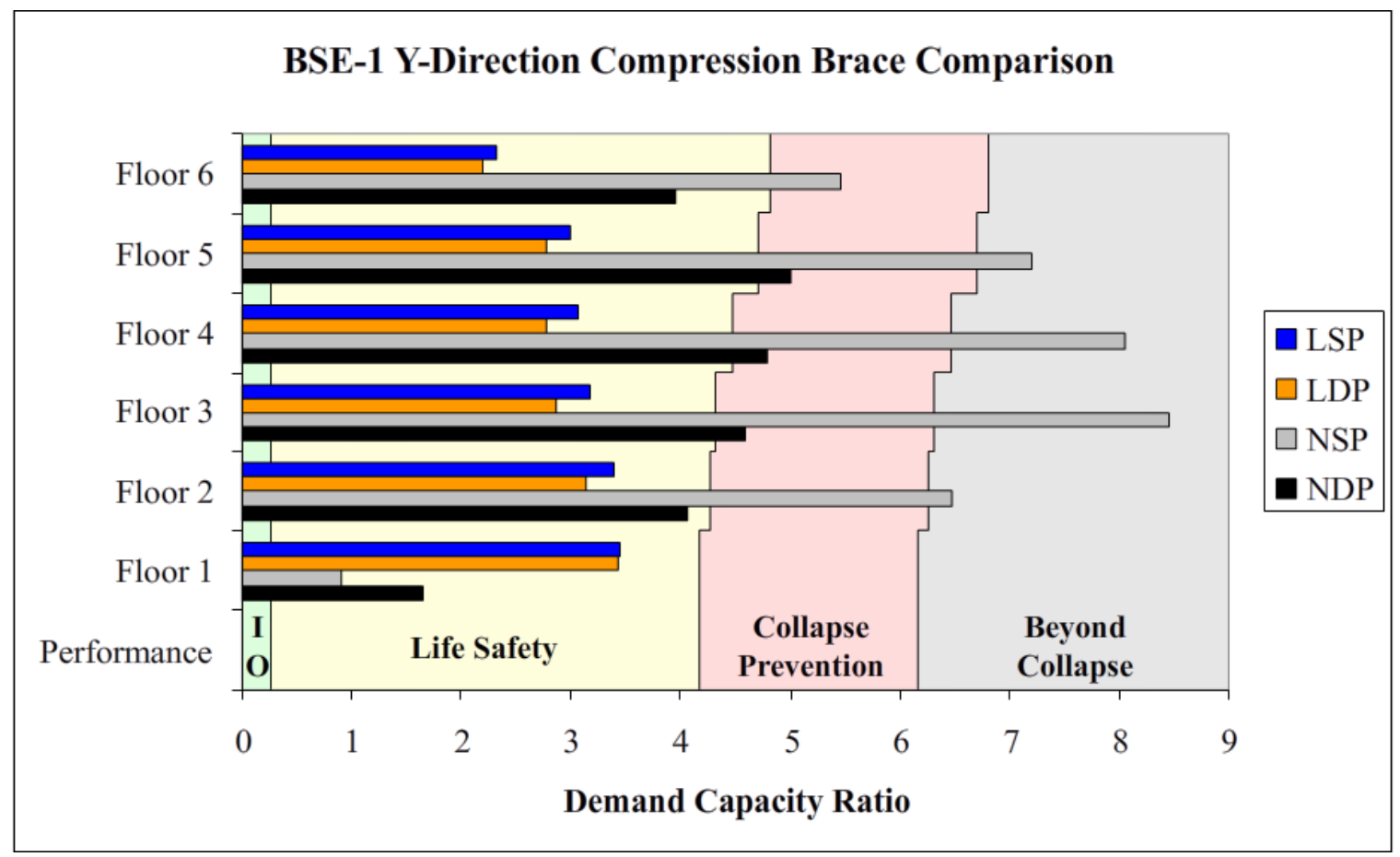

Figure HH: BSE-1 Y-Direction Compression Comparison of All Procedures

Performance-Based Analysis of Steel Buildings: Special Concentric Braced Frame 


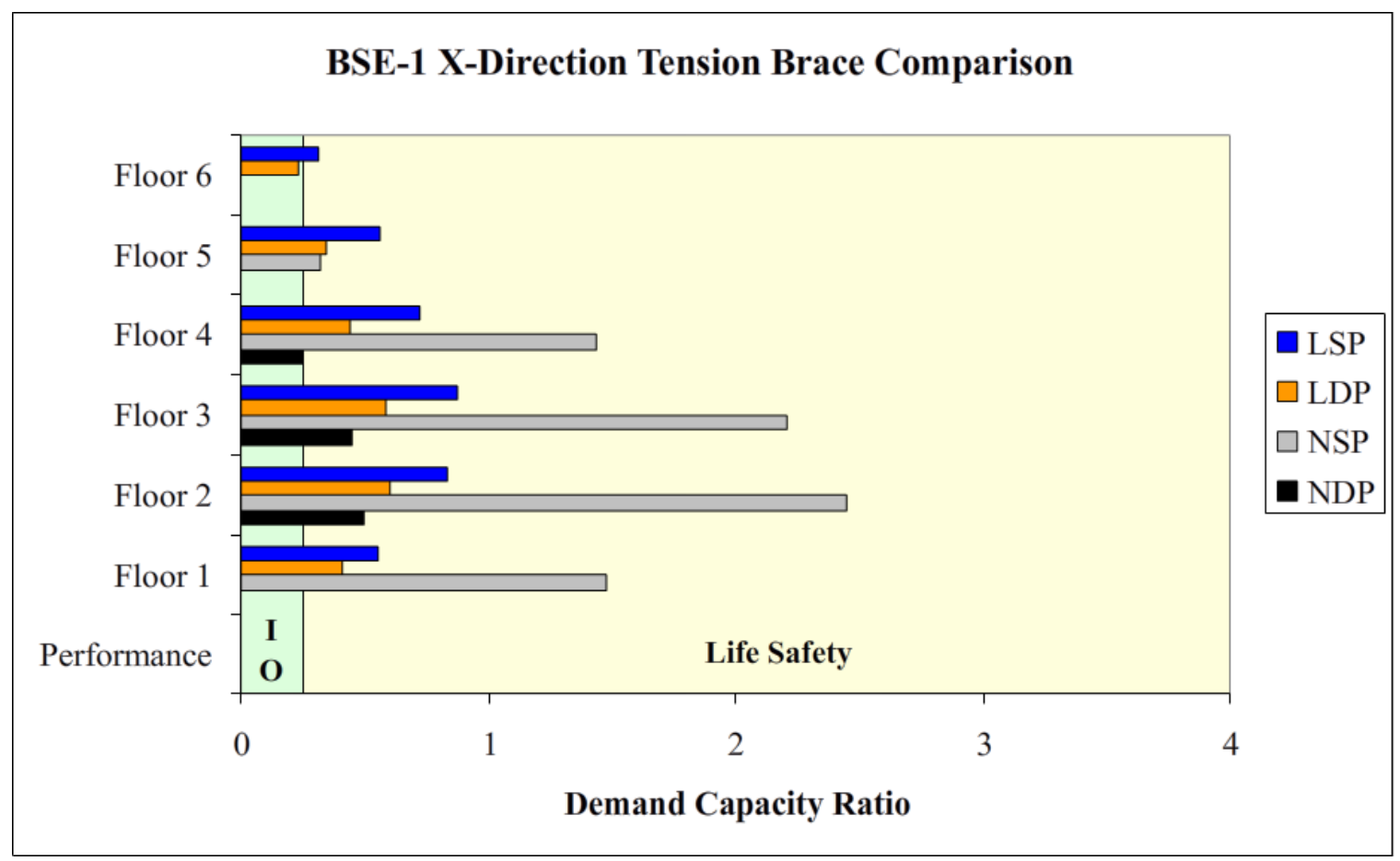

Figure II: BSE-1 X-Direction Tension Comparison of All Procedures

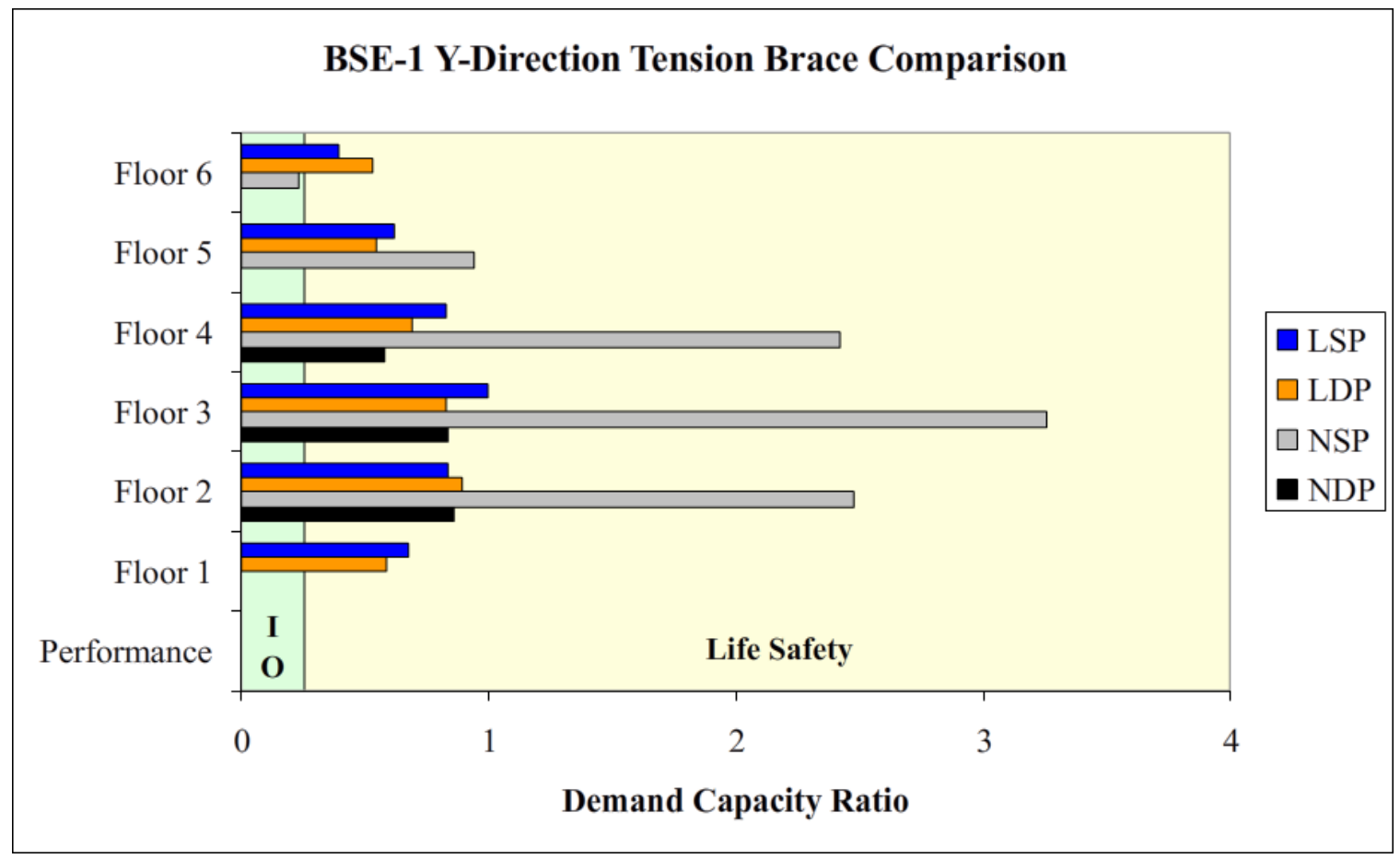

Figure JJ: BSE-1 Y-Direction Tension Comparison of All Procedures

Performance-Based Analysis of Steel Buildings: Special Concentric Braced Frame 


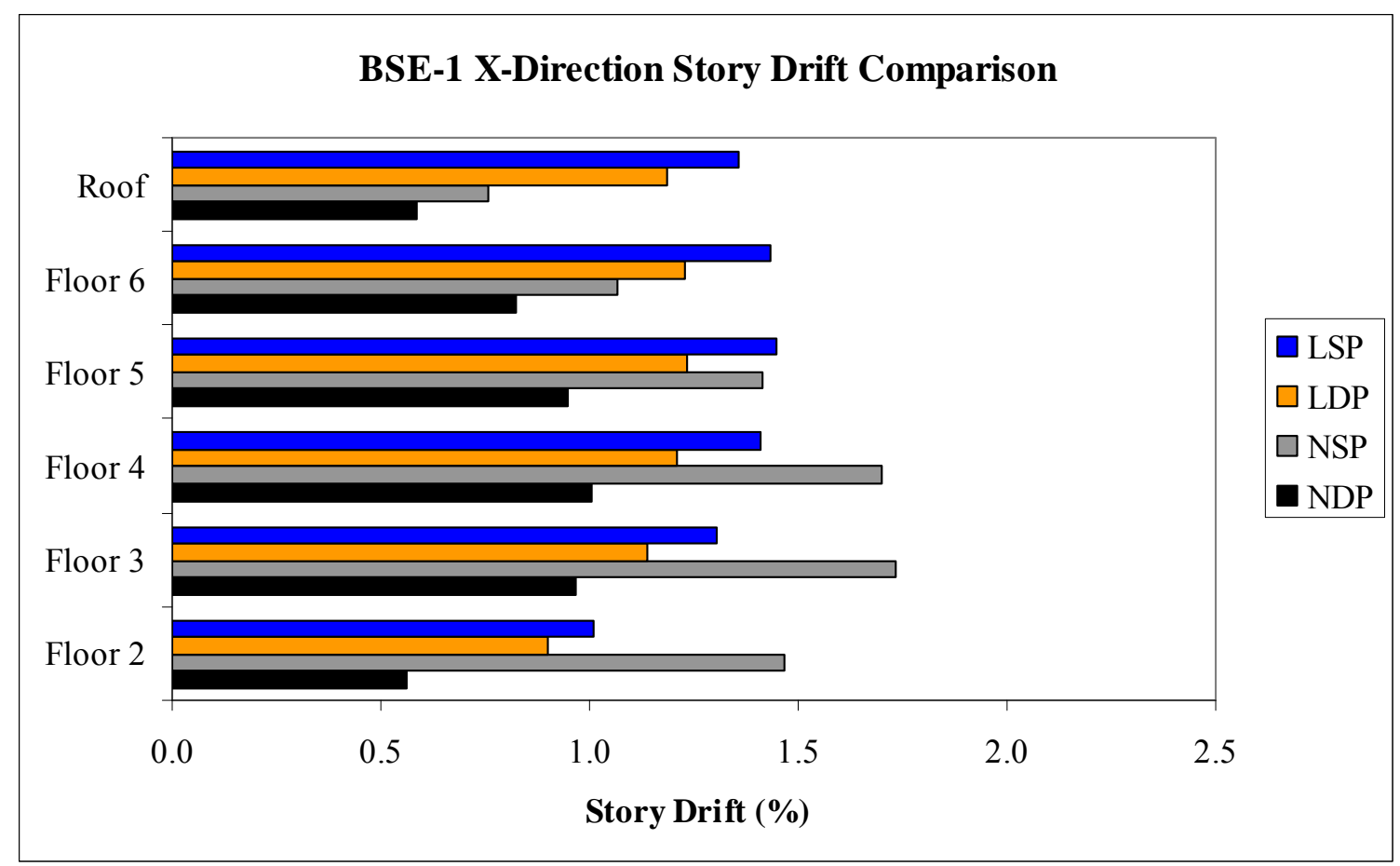

Figure KK: BSE-1 X-Direction Story Drift Comparison of All Procedures

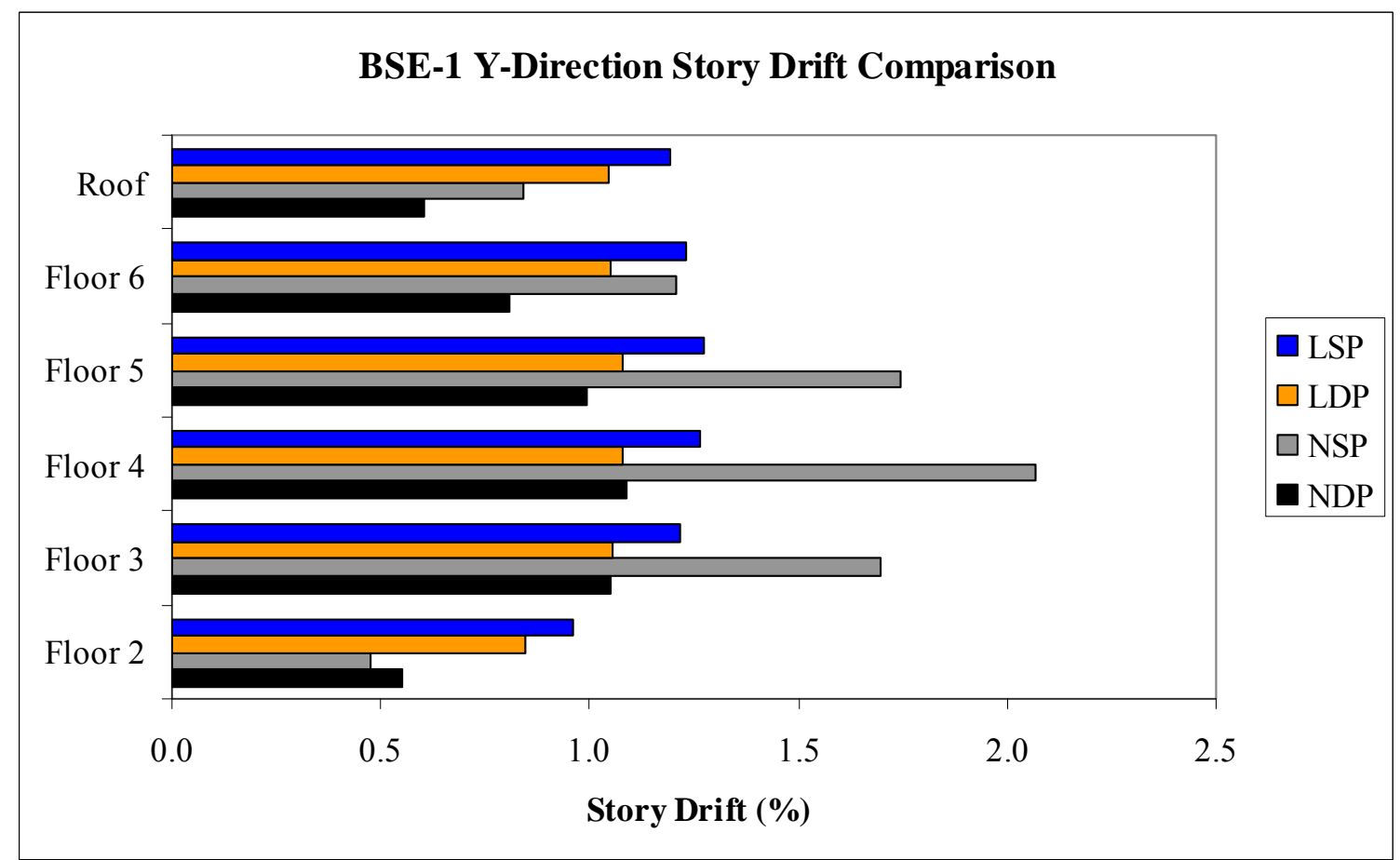

Figure LL: BSE-1 Y-Direction Story Drift Comparison of All Procedures

Performance-Based Analysis of Steel Buildings: Special Concentric Braced Frame 
Section C3.4.1 of ASCE 41-06 states that "the linear analysis procedures are intended to provide a conservative estimate of building response and performance in an earthquake," which is not the case here. The nonlinear procedures indicate more damage than the linear procedures, to the degree that some elements in the nonlinear analyses exceed the Life Safety, and even the Collapse Prevention acceptance limits.

The tension brace comparisons are not as similar to the compression results as expected. One or both of the linear procedures indicate the highest DCRs on some floors, and the NDP never resulted in a DCR larger than the linear procedures. The NSP shows significantly higher damage than the other procedures, which does follow the compression results. Despite this significant damage in the NSP, all procedures perform to the Life Safety limits. The tension DCRs relate closely to the floor drifts.

The drift comparison shows that on half of the floors, the linear static procedure had the largest drifts, while the remaining floors were governed by the nonlinear static procedure. The NDP typically has the smallest drift of the four procedures. The drifts of the linear procedures and the NDP is more in line with the ASCE 41-06 prediction of linear procedures being more conservative, but it indicates that the drift ratios do not directly relate to the brace damage. This is most likely a result of the nonlinear behavior of the braces. After a brace buckles, very small changes in floor drift correlate to large displacements in the brace hinge. This effect cannot be adequately represented in the linear procedures, so despite the more conservative drifts, the damage to the braces is under represented. 
The overall building performance for each procedure is summarized in Table J below.

\begin{tabular}{||c||c||}
\hline \multicolumn{1}{|c||}{ Procedure } & Performance Level \\
\hline \hline LSP & Life Safety \\
\hline LDP & Life Safety \\
\hline NSP & Collapse Prevention \\
\hline NDP & Limited Safety Range \\
\hline
\end{tabular}

Table J: BSE-1 Building Performance Summary

For a BSE-1 hazard level, the nonlinear procedures are more conservative than the linear procedures. The linear procedures definitively meet the Life Safety goal, while the nonlinear procedures have members that cross into the Collapse Prevention range.

The relative performance of the linear static procedure to the linear dynamic procedure was expected, as the base shear generated by the LDP was only $87 \%$ of the base shear calculated in the LSP. As would be expected, the reduction in base shear correlated to a decrease in member forces. This reduction is likely the result of the linear static equation approximating the total base shear as a function of only the first mode in each direction, while the linear dynamic procedure determines the base shear by combining twelve modes using a square-root sum of squares (SRSS) algorithm. This process results in a smaller base shear for the LDP.

The NSP had compression braces on multiple floors, and in both directions, exceed the Collapse Prevention limits, while the NDP only slightly exceeded Life Safety in one direction. This can be related to the maximum roof displacement in each procedure. The roof displacements are shown in Table $\mathrm{K}$ on the following page. 


\begin{tabular}{||c||c||c||c||c||c||}
\hline \multicolumn{7}{|c||}{ BSE-1 Roof Displacement (in.) } \\
\hline \hline Direction & $\begin{array}{c}\text { NDP } \\
\text { Min }\end{array}$ & $\begin{array}{c}\text { NDP } \\
\text { Average }\end{array}$ & $\begin{array}{c}\text { NDP } \\
\text { Max }\end{array}$ & $\begin{array}{c}\text { NSP } \\
\text { Target }\end{array}$ & $\begin{array}{c}\text { NSP } \\
\text { 150\% Target }\end{array}$ \\
\hline \hline X & 3.10 & 6.48 & 8.17 & 9.08 & 13.61 \\
\hline Y & 3.21 & 6.28 & 8.50 & 8.33 & 12.50 \\
\hline \hline
\end{tabular}

Table K: BSE-1 Roof Displacement Comparison

The table shows the minimum roof displacement of all seven ground motions, the average roof displacement for all seven ground motions, the maximum displacement occurring in one of the ground motions, and the nonlinear static target displacements. The NSP $150 \%$ target displacement is approximately twice the average displacement from all NDP ground motions, while the NSP target displacement more closely approximates the maximum displacement that occurred in one of the ground motions. The roof displacements explain the difference in performance between the nonlinear static and nonlinear dynamic procedures, and why the NSP predicts much more damage.

\subsubsection{Comparison of ETABS and PERFORM}

A nonlinear static procedure was performed in ETABS for the purpose of comparing the results to the PERFORM 3D NSP. The graphs on the following pages show a comparison between the data obtained from each software model. Only the results of the triangular load pattern are shown, as the uniform load pattern continued the same trends. The pushover curve for the $\mathrm{x}$-direction is shown in Figure MM and the $\mathrm{y}$ direction is shown in Figure NN. The compression DCRs are shown in Figure OO for the x-direction, and Figure PP for the y-direction. Figures QQ and RR show the tension DCRs for each respective direction, as do Figures SS and TT for the drift ratios. 


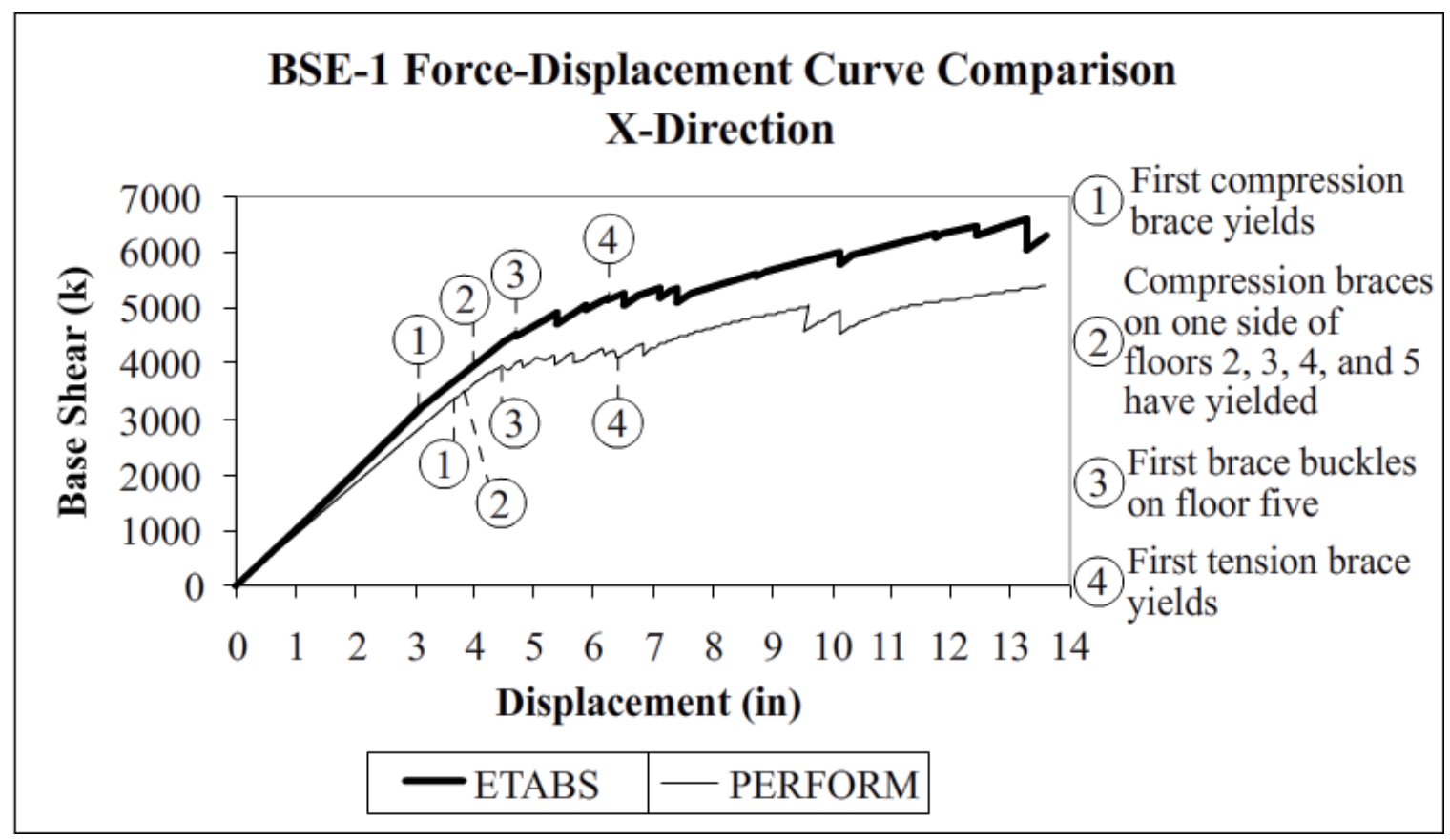

Figure MM: BSE-1 NSP X-Direction Pushover Curve Comparison

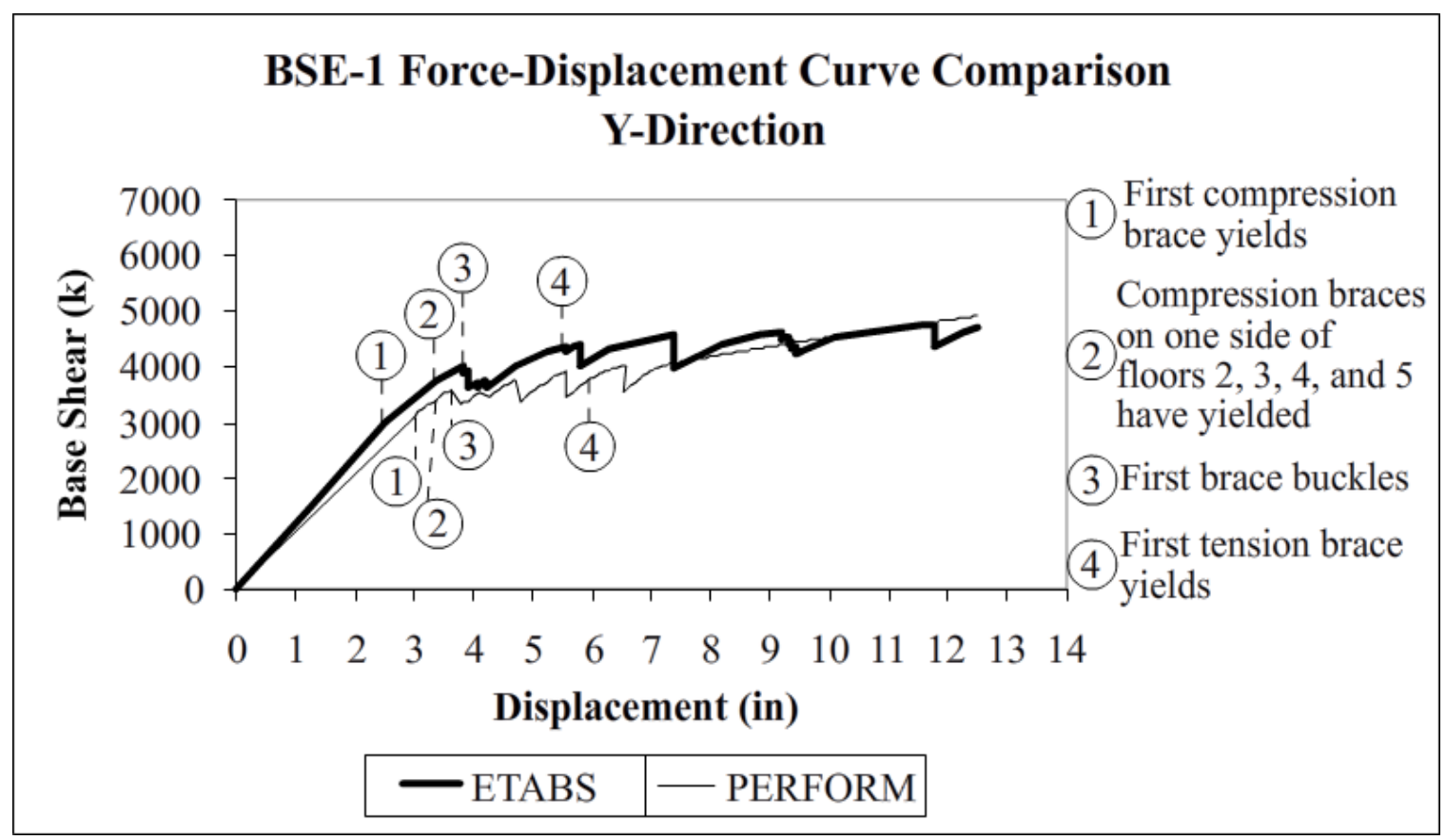

Figure NN: BSE-1 NSP Y-Direction Pushover Curve Comparison

Performance-Based Analysis of Steel Buildings: Special Concentric Braced Frame 


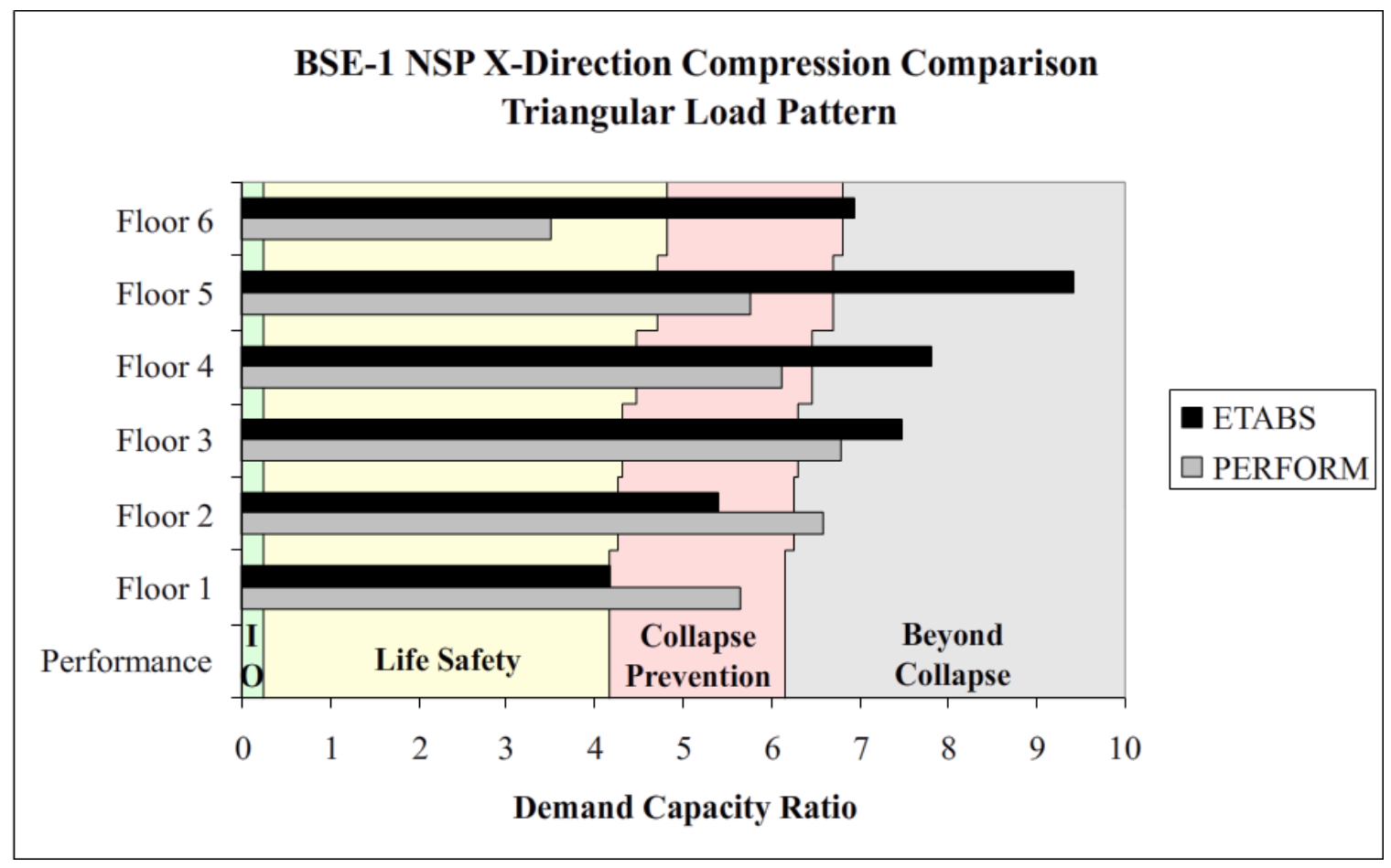

Figure OO: BSE-1 NSP X-Direction Compression Comparison

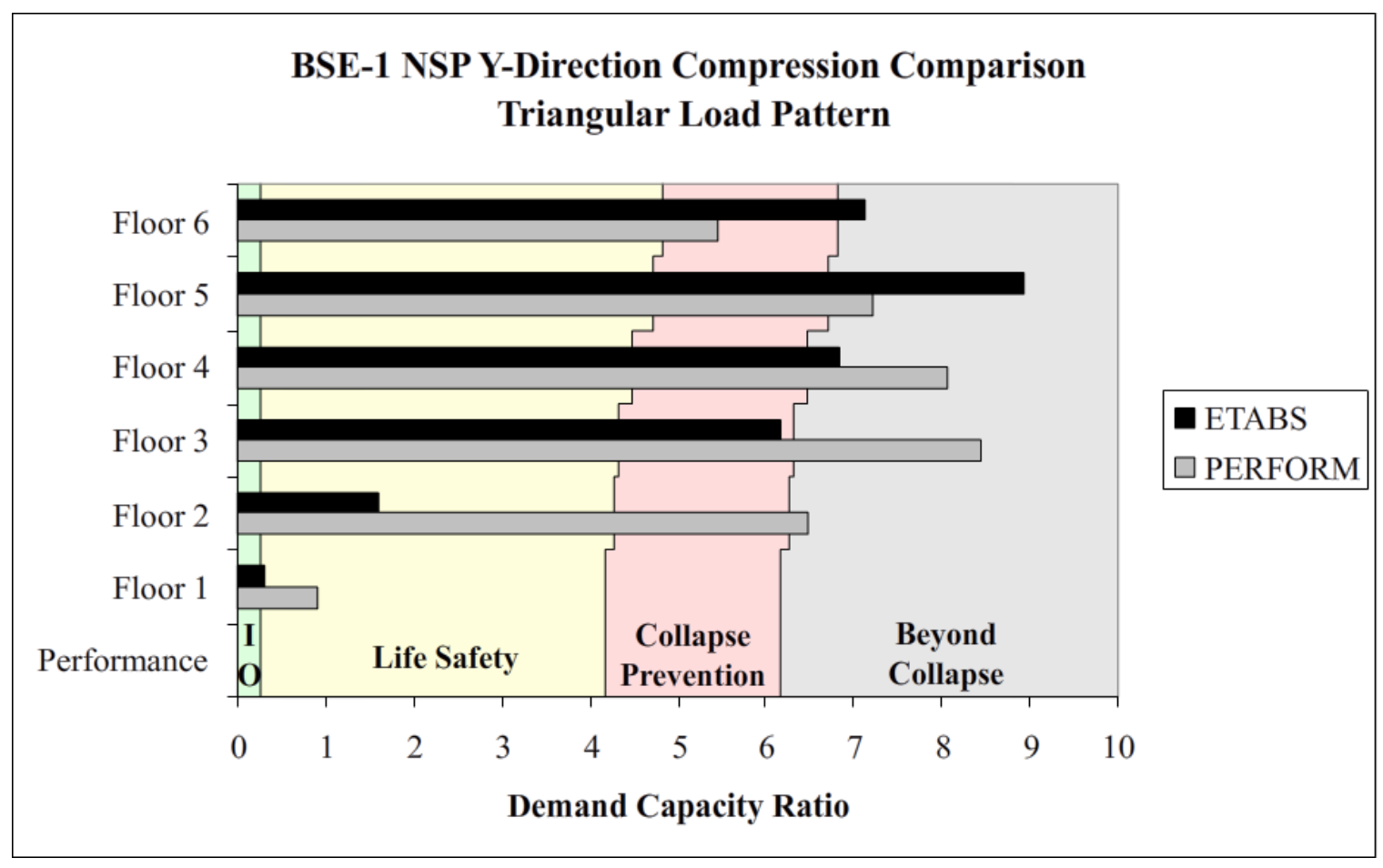

Figure PP: BSE-1 NSP Y-Direction Compression Comparison

Performance-Based Analysis of Steel Buildings: Special Concentric Braced Frame 


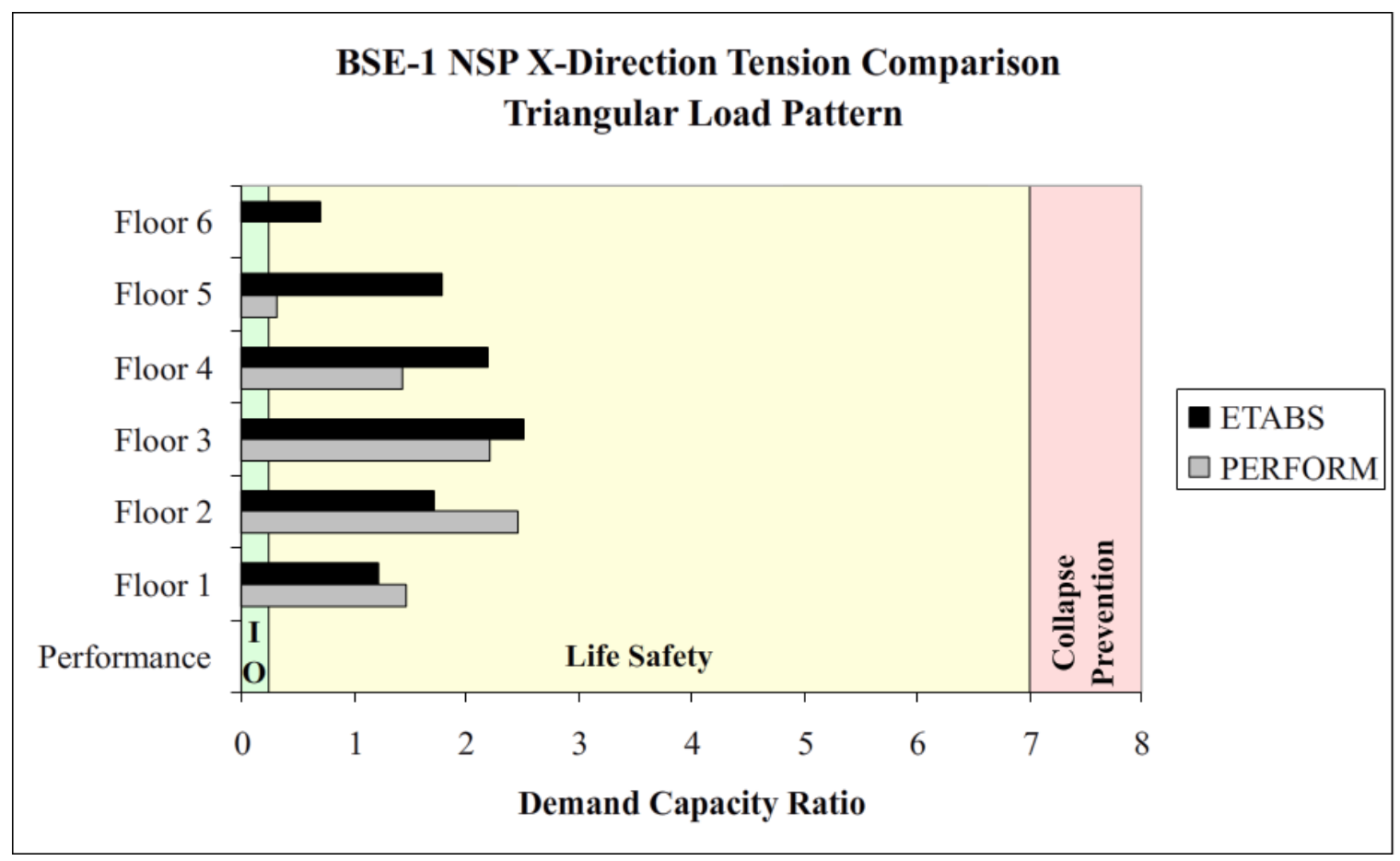

Figure QQ: BSE-1 NSP Y-Direction Tension Comparison

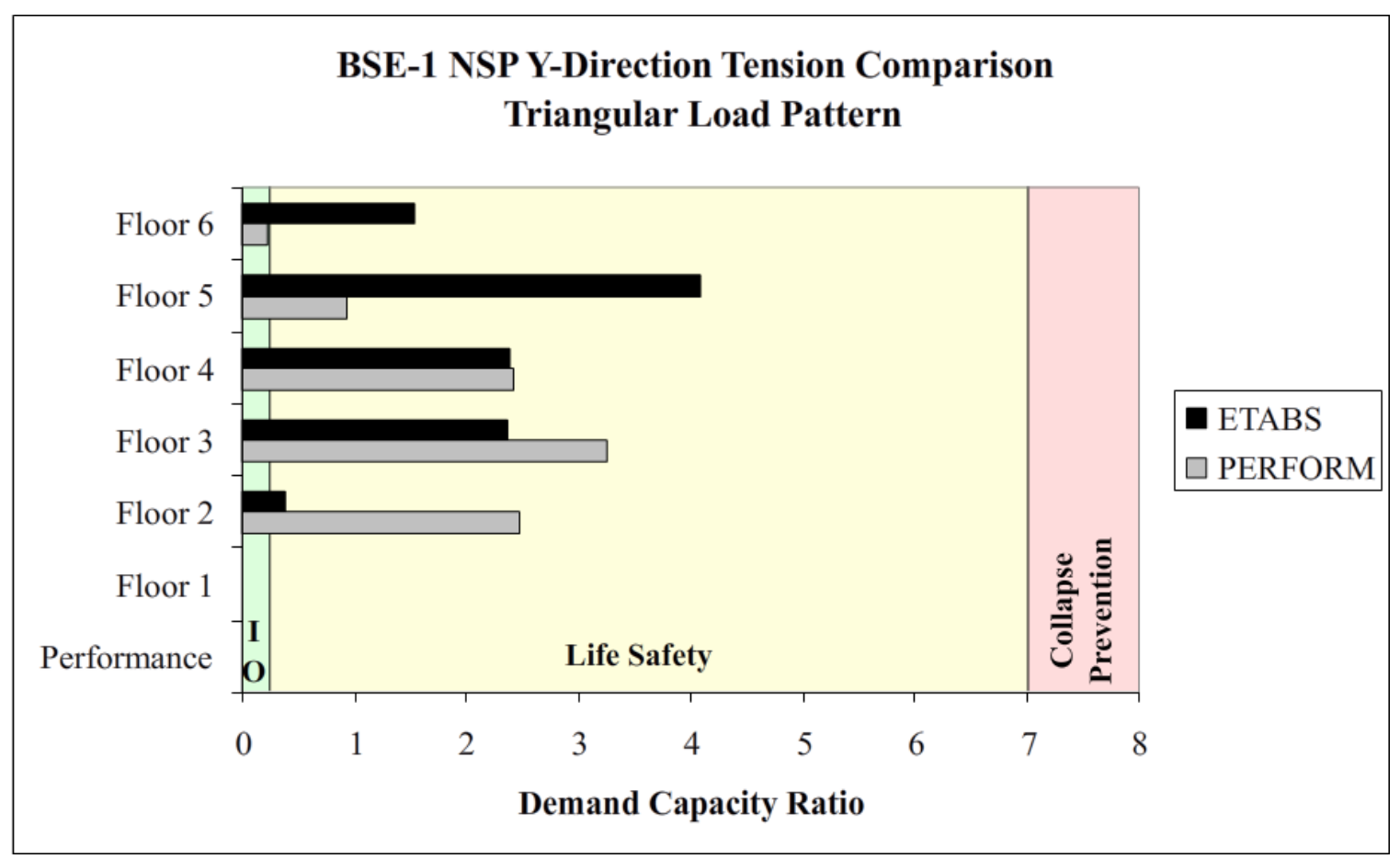

Figure RR: BSE-1 NSP Y-Direction Tension Comparison

Performance-Based Analysis of Steel Buildings: Special Concentric Braced Frame 


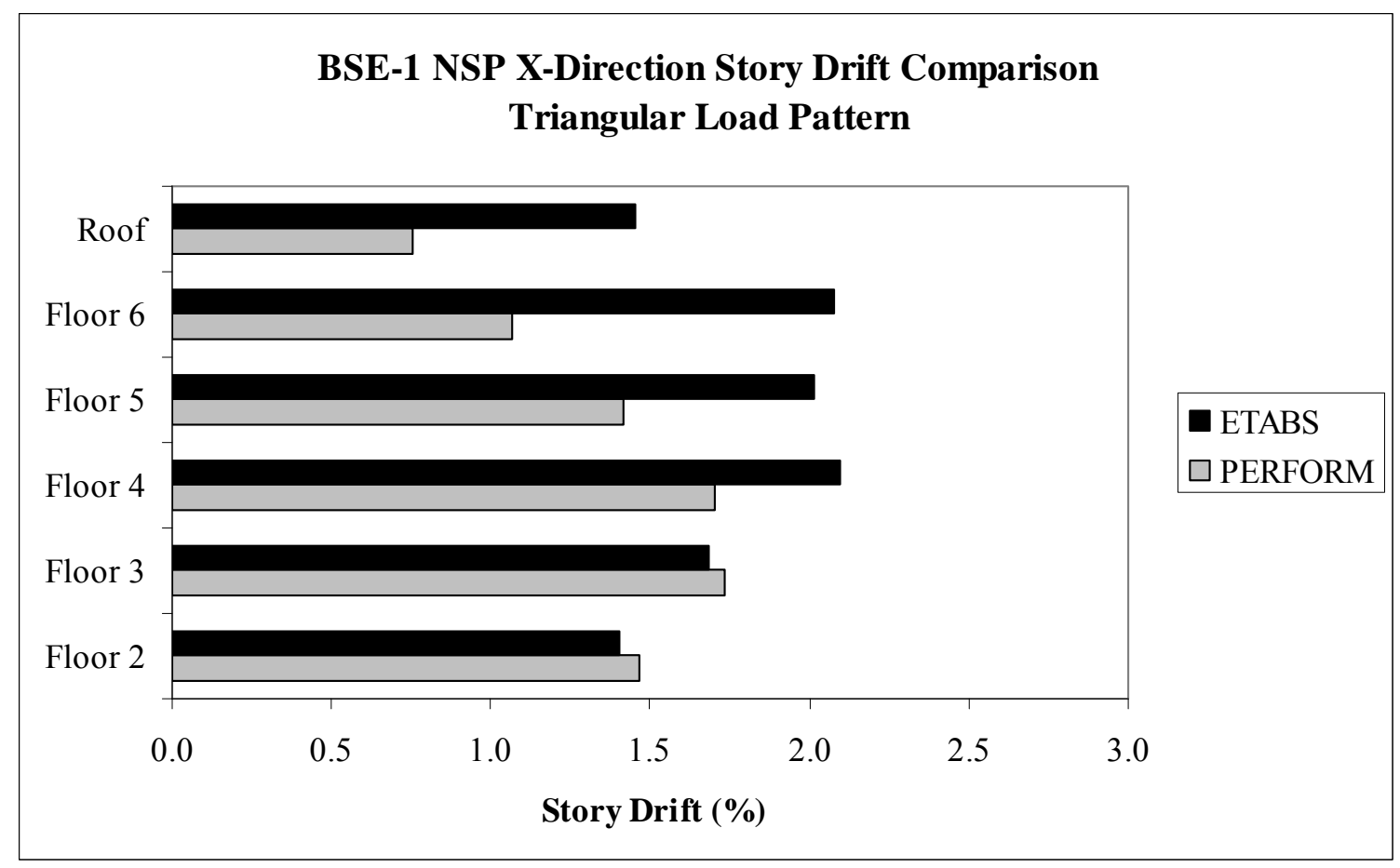

Figure SS: BSE-1 NSP X-Direction Drift Comparison

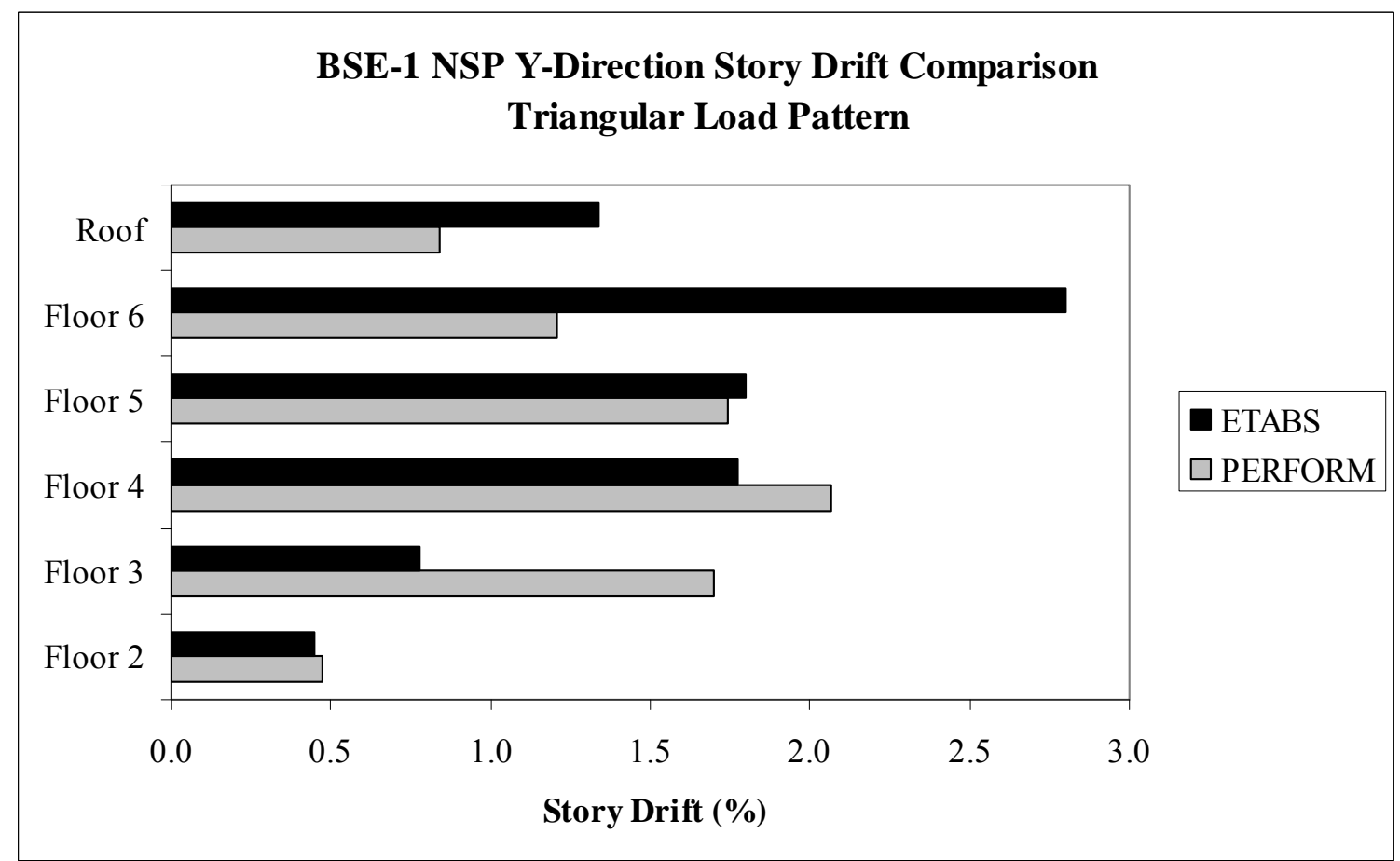

Figure TT: BSE-1 NSP Y-Direction Drift Comparison

Performance-Based Analysis of Steel Buildings: Special Concentric Braced Frame 
To examine possible differences between the two programs, a simple one-story, one-bay frame was constructed in both ETABS and PERFORM with a single brace spanning the full diagonal length of each side, and pinned connections at all joints. The resulting nonlinear pushover curves for the compression hinges, as well as the hinge model they were based on, are compared in Figure UU below.

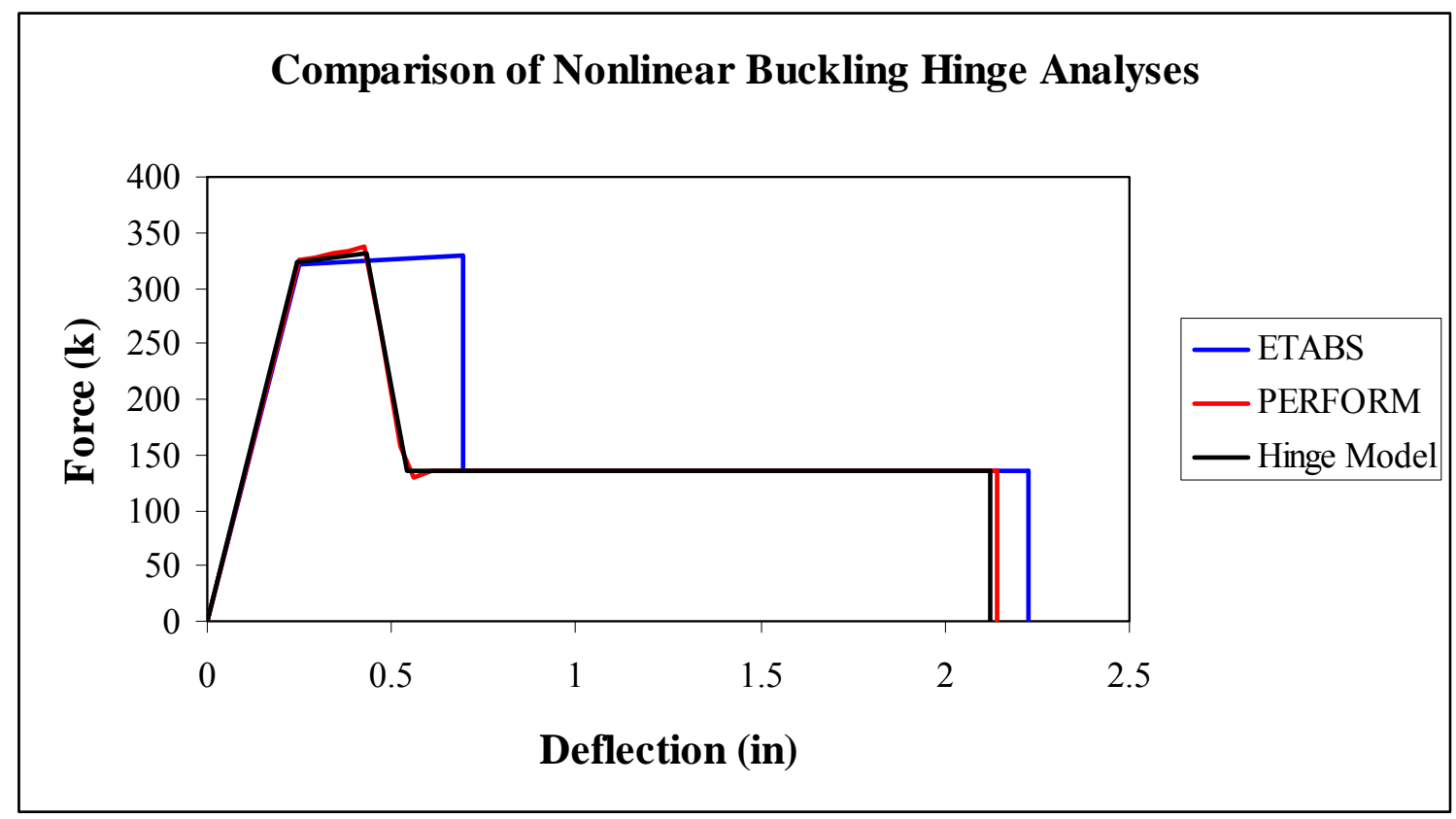

Figure UU: Nonlinear Compression Hinge Comparison

The pushover curves show that both programs have very similar initial stiffnesses and yield points, and that these match the hinge model. After the yield point however, differences between the two programs become apparent. PERFORM 3D follows the hinge model very closely with only minor variations in the post-yield stiffness and a slight dip in force after buckling. ETABS diverges from the hinge model by continuing in the post-yield range beyond the intended buckling displacement, while maintaining the designed buckling force. ETABS also failed to recreate the gradual slope in the post Performance-Based Analysis of Steel Buildings: Special Concentric Braced Frame 
bucking region, though this slope was only modeled to prevent convergence errors during the PERFORM 3D analysis. Both programs achieved the desired residual strength after the member buckled. This behavior applies to the tension hinges as well, which can be seen in the tension comparison graph located in the appendix.

For the actual building, the nonlinear force-displacement curves for both the $\mathrm{x}$ and y-directions show that the ETABS pushover had slightly larger initial stiffness than the PERFORM pushover, but both had a roughly similar stiffness after the buckling of the first brace. The hinge test model showed that braces will have similar elastic stiffnesses, so the difference between the elastic stiffnesses in the actual building is most likely caused by some other factor. Possible factors that could differ in each program include the lateral resistance of the gravity columns, and how each program models the springs placed at the beam-to-column connections. Further testing would need to be done to determine exactly what the cause of the disparity is.

For both programs, the first yield occurred in the same brace, and at similar base shears, though different displacements, which is a result of the variation in initial stiffness. The displacement associated with the buckling of the first brace occurred within $0.25 \mathrm{in}$. for each procedure, however, the force was about 500 kips less in the PERFORM analysis. The test model also showed a difference of about 25 in. for the buckling displacements, however, the buckling force was about the same. This would indicate that the gravity columns and/or connection springs are providing more lateral resistance in the ETABS model than the PERFORM 3D model. 
The DCR graphs of the compression braces, tension braces, and drift ratios show a consistent relationship between the PERFORM and ETABS output. The PERFORM results minimize the damage at the first floor while distributing the damage among the remaining floors, with a slightly higher concentration on the third floor. The ETABS results generally minimized the damage on the first and second floors, while concentrating the majority of the damage on the fifth floor. The most likely cause of the damage concentration in the fifth floor is the way in which ETABS redistributes the lateral force after the member has buckled. Clearly, the force is not redistributed as it is in PERFORM 3D, and the buckled member has no stiffness, so it continues to deform beyond what it should. The ETABS floor drifts mirror the damage in the braces, including the damage concentration at the fifth floor.

\subsection{BSE-2 Analysis Comparisons}

The basic safety earthquake 2 (BSE-2) hazard level has a design goal of Collapse Prevention for all procedures. As with the BSE-1 analyses, the results of the analysis procedures varied in the degree to which this goal was or was not achieved.

\subsubsection{Comparison of the Four Primary Analysis Procedures}

On the following pages, the DCRs for each analysis procedure are directly compared to one another. Figures VV and WW show the results for the compression braces in the $\mathrm{x}$ - and $\mathrm{y}$-directions respectively, while Figures $\mathrm{XX}$ and $\mathrm{YY}$ show the tension results for the $\mathrm{x}$ - and $\mathrm{y}$-directions respectively. Figures $\mathrm{ZZ}$ and AAA show a comparison of floor drift for each direction. 


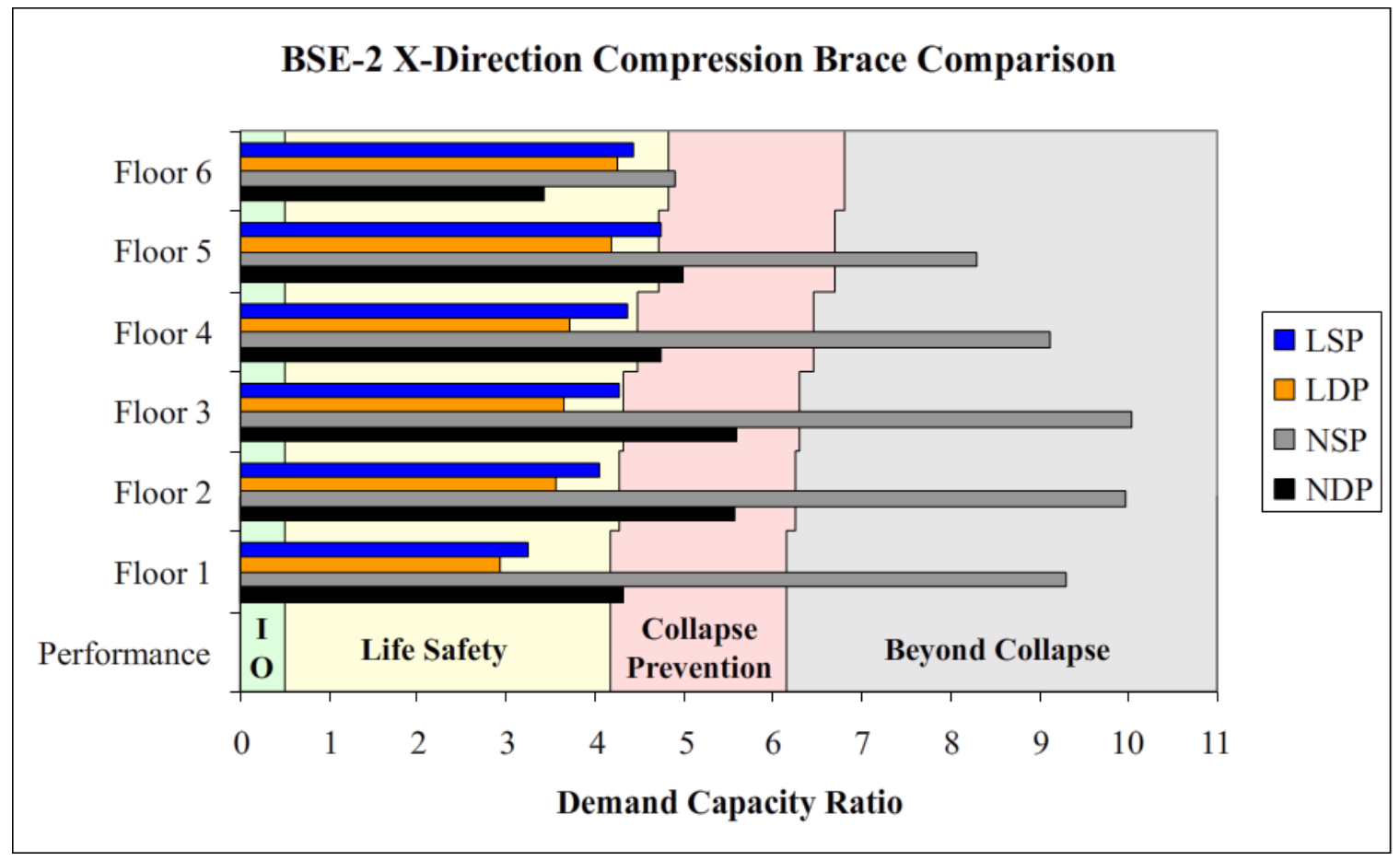

Figure VV: BSE-2 X-Direction Compression Comparison of All Procedures

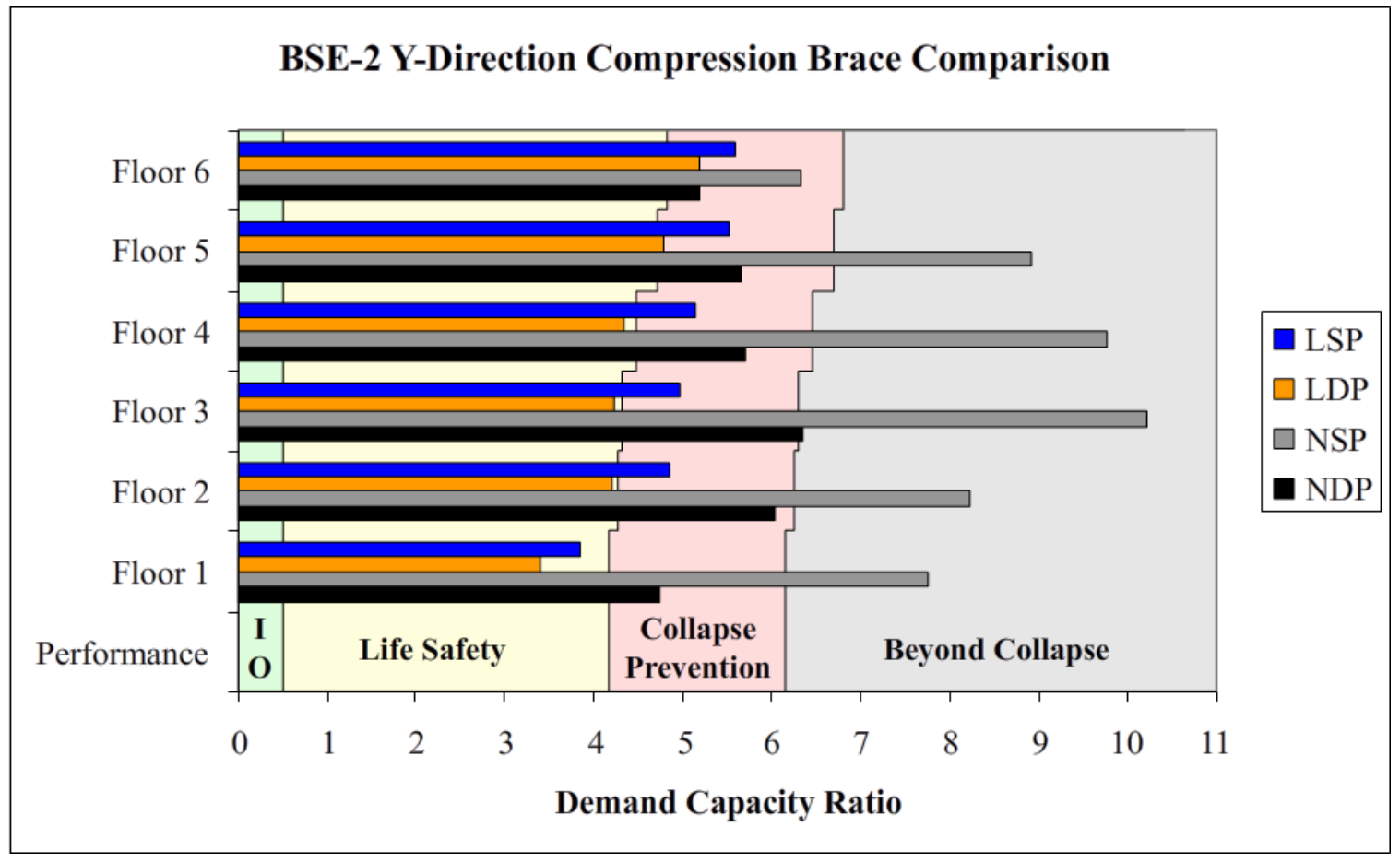

Figure WW: BSE-2 Y-Direction Compression Comparison of All Procedures

Performance-Based Analysis of Steel Buildings: Special Concentric Braced Frame 


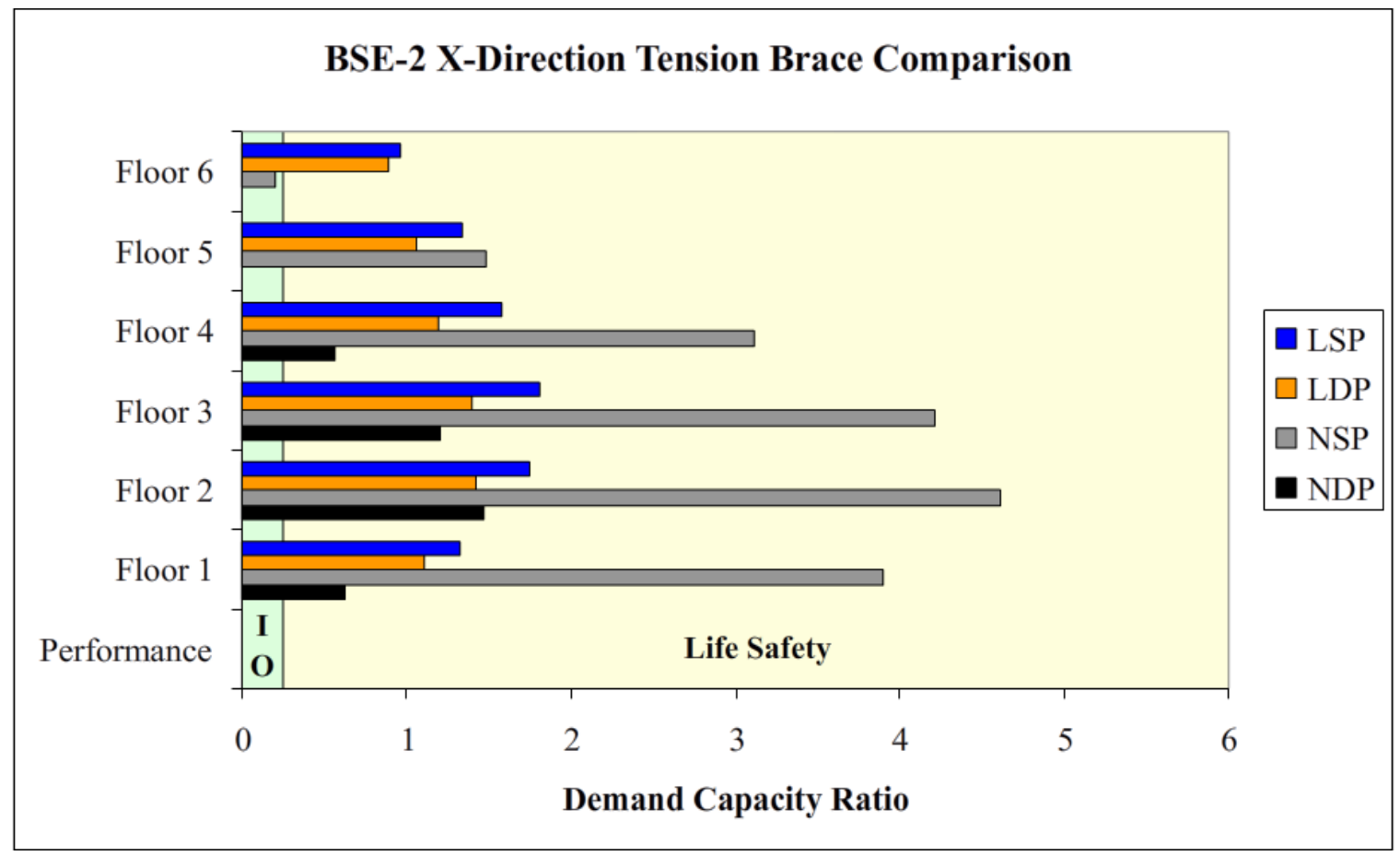

Figure XX: BSE-2 X-Direction Tension Comparison of All Procedures

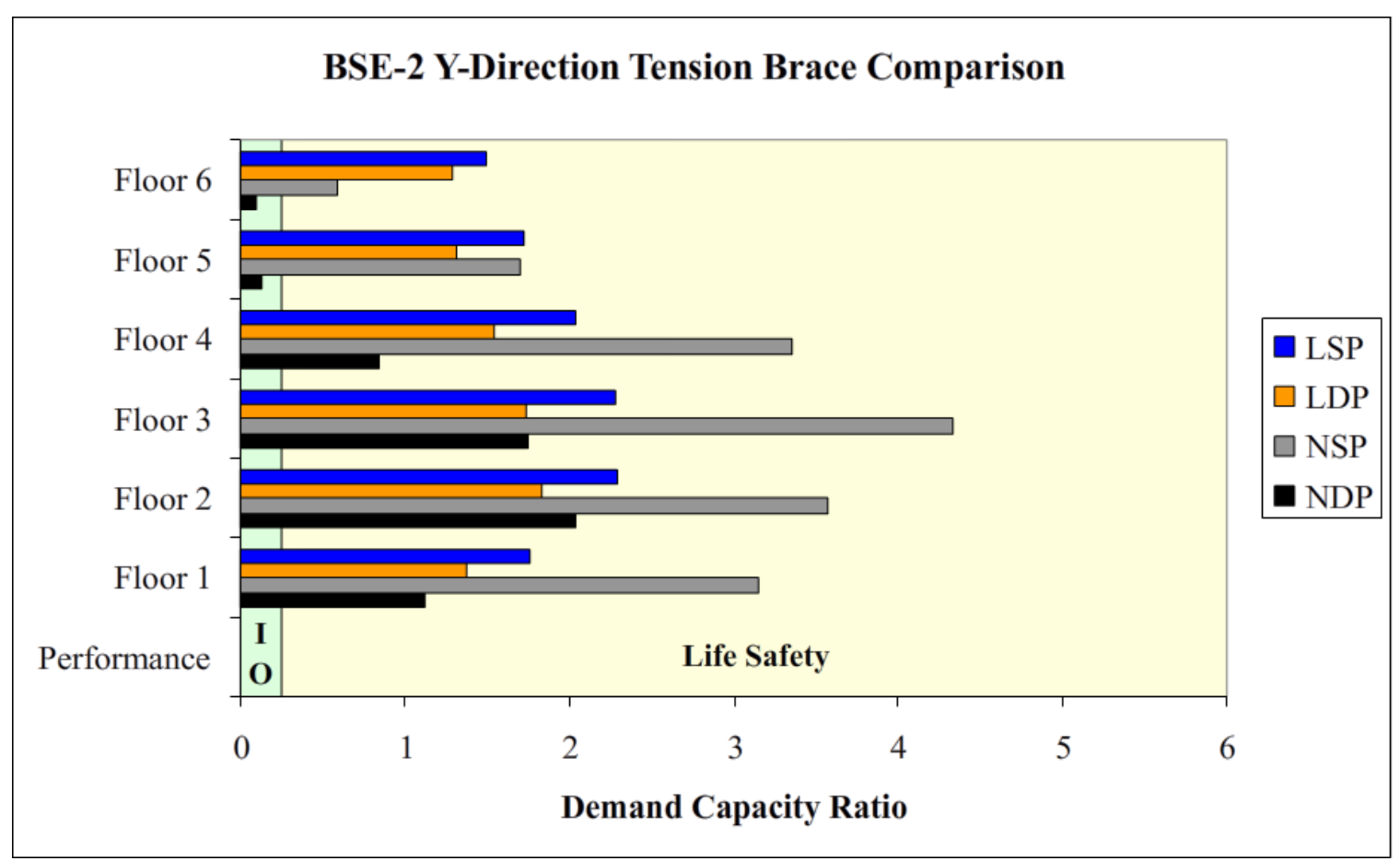

Figure YY: BSE-2 Y-Direction Tension Comparison of All Procedures

Performance-Based Analysis of Steel Buildings: Special Concentric Braced Frame 


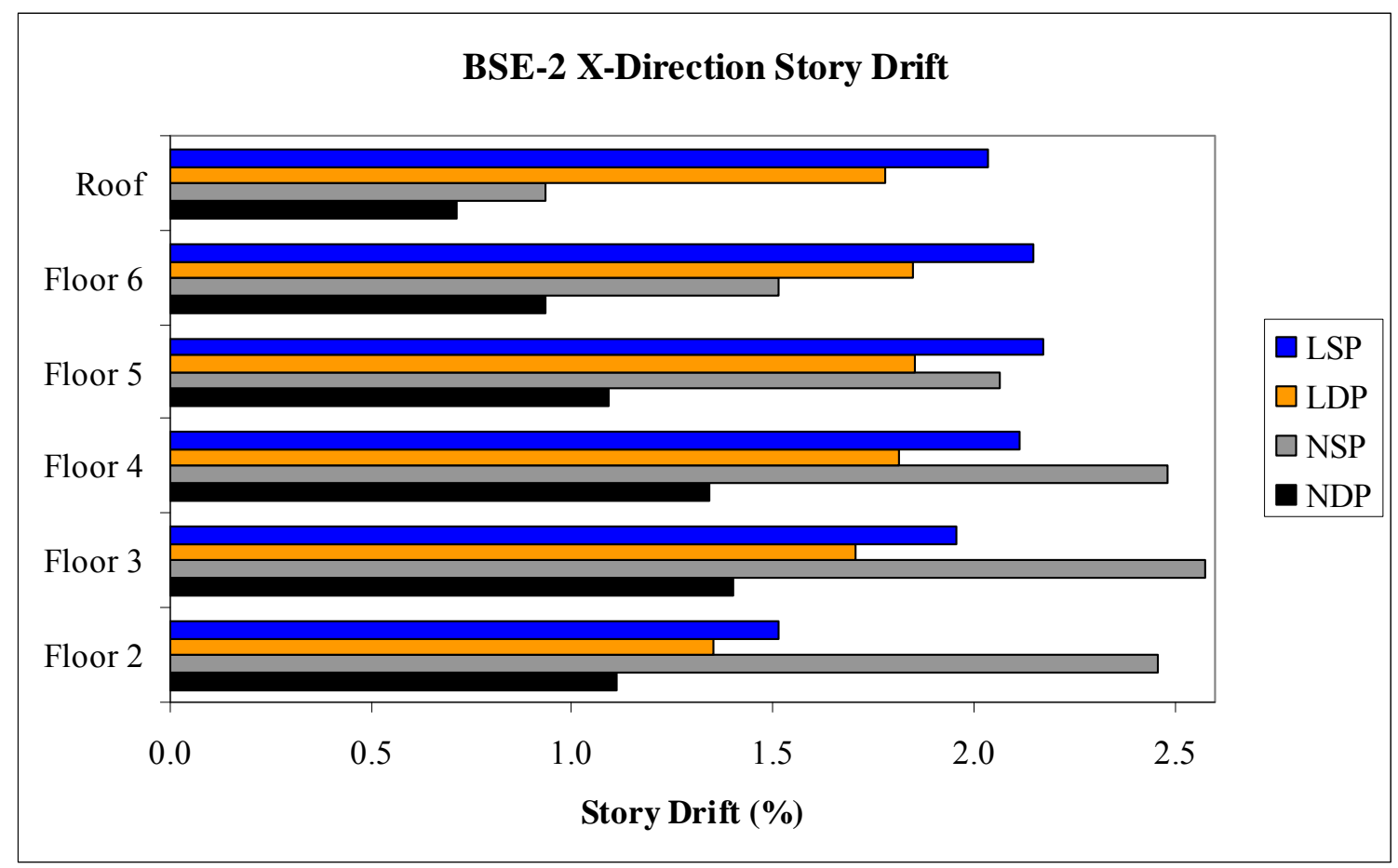

Figure ZZ: BSE-2 X-Direction Story Drift Comparison of All Procedures

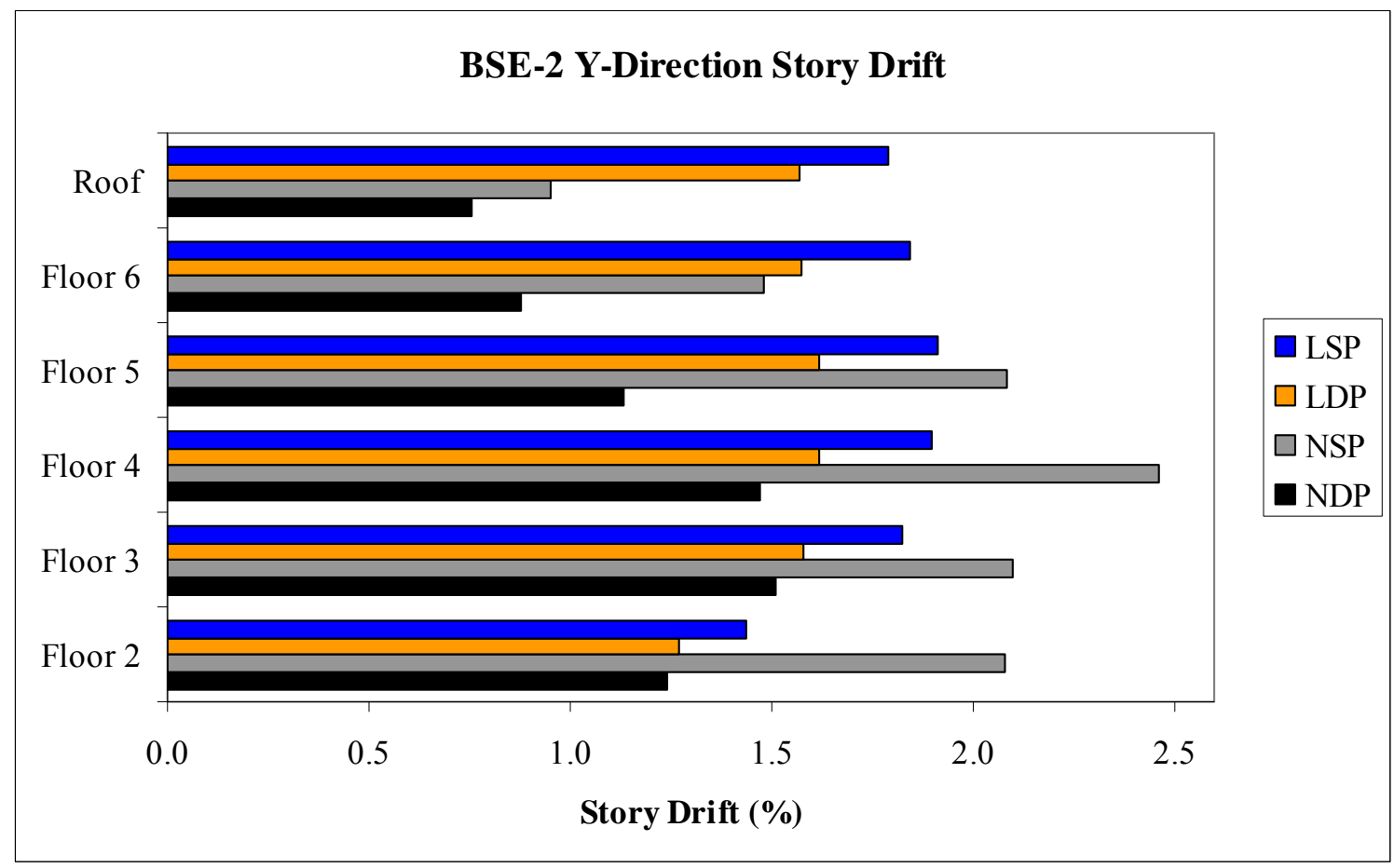

Figure AAA: BSE-2 Y-Direction Story Drift Comparison of All Procedures

Performance-Based Analysis of Steel Buildings: Special Concentric Braced Frame 
The compression results are similar to the BSE-1 results in that, once again, the nonlinear procedures govern the analysis, and in particular, the NSP shows the most damage, with most of the compression braces going significantly beyond the Collapse Prevention limits.

The tension brace comparisons indicate that the majority of the nonlinear damage occurred at the lower four floors, while the linear procedures distributed the damage more equally. As a result of this distribution, the linear static procedure resulted in the highest DCRs on the upper two floors, while the NSP resulted in highest DCRs on the lower four floors, and governed the tension results. As with the BSE-1 tension comparison, the NDP never produces the largest tension DCR. Although the NSP indicates increased damage, all of the tension braces perform to Life Safety.

The drift comparison is an extension of the tension results. The LSP typically results in the largest drift on the top two floors, and the NSP typically results in the largest drift on the bottom four floors. The NDP indicated the smallest drifts of the four procedures. As shown in the BSE-1 drifts, the drift ratios cannot be used to predict damage to the braces because the linear procedures do not adequately account for the large amount of damage that can accompany small displacements in buckled members.

The overall performance of each procedure is summarized in Table L on the following page. 


\begin{tabular}{||c||c||}
\hline \hline Procedure & Performance Level \\
\hline \hline LSP & Limited Safety Range \\
\hline LDP & Limited Safety Range \\
\hline NSP & Collapse Prevention \\
\hline NDP & Collapse Prevention \\
\hline
\end{tabular}

Table L: BSE-2 Building Performance Summary

A BSE-2 hazard level continues the trend established by the BSE-1 hazard. The NSP is the most conservative of the four, with a significant number of compression members performing beyond Collapse Prevention. The NSP is once again followed by the NDP, then the LSP, and finally the LDP indicates the least damage. The LSP and LDP can be said to perform within the Limited Safety Range, while the NDP and NSP fully cross over into the Collapse Prevention level. All procedures meet the performance goal of Collapse Prevention as a building system, even though some members in the NSP experience damage going beyond those limits.

\subsubsection{Comparison of ETABS and PERFORM}

An ETABS NSP was also performed for the BSE-2 target displacement to compare to PERFORM. The graphs on the following pages show a comparison between the data obtained from each software model. The pushover curve for the $\mathrm{x}$-direction is shown in Figure BBB and the y-direction is shown in Figure CCC. The compression DCRs are shown in Figure DDD for the x-direction, and Figure EEE for the y-direction. Figures FFF and GGG show the tension DCRs for each respective direction, as do Figures HHH and III for the drift ratios. 


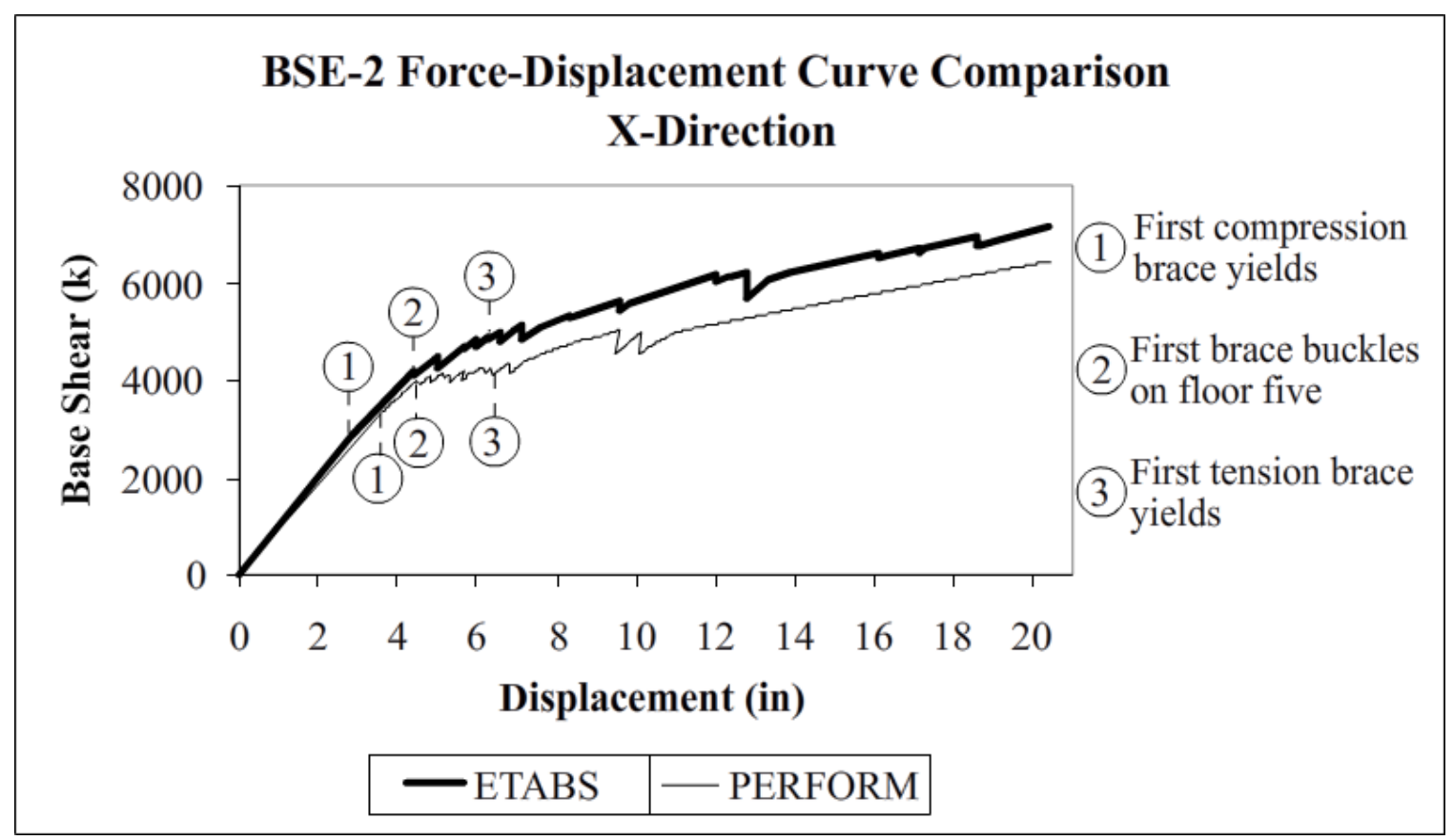

Figure BBB: BSE-2 NSP X-Direction Pushover Curve Comparison

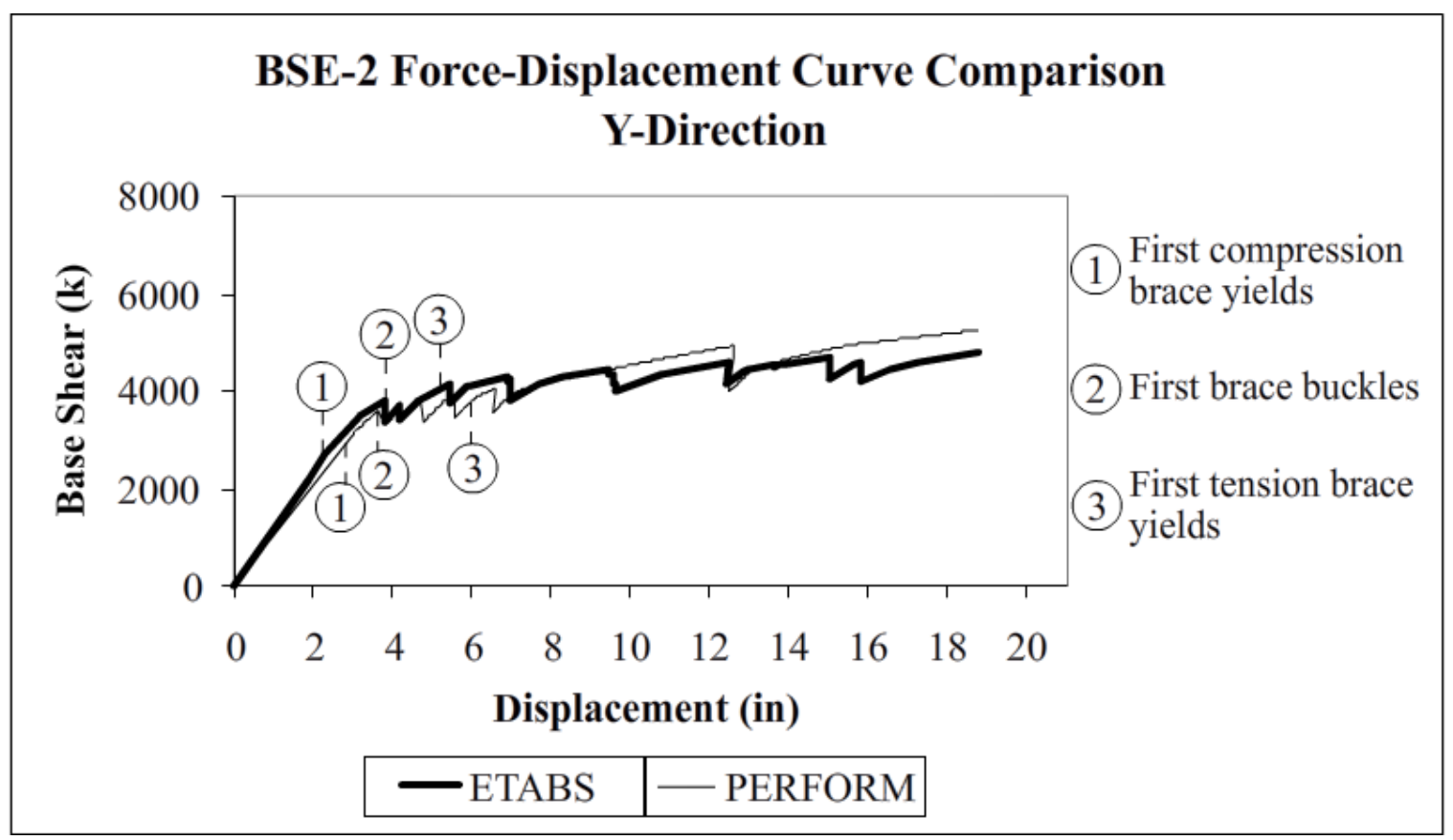

Figure CCC: BSE-2 NSP Y-Direction Pushover Curve Comparison 


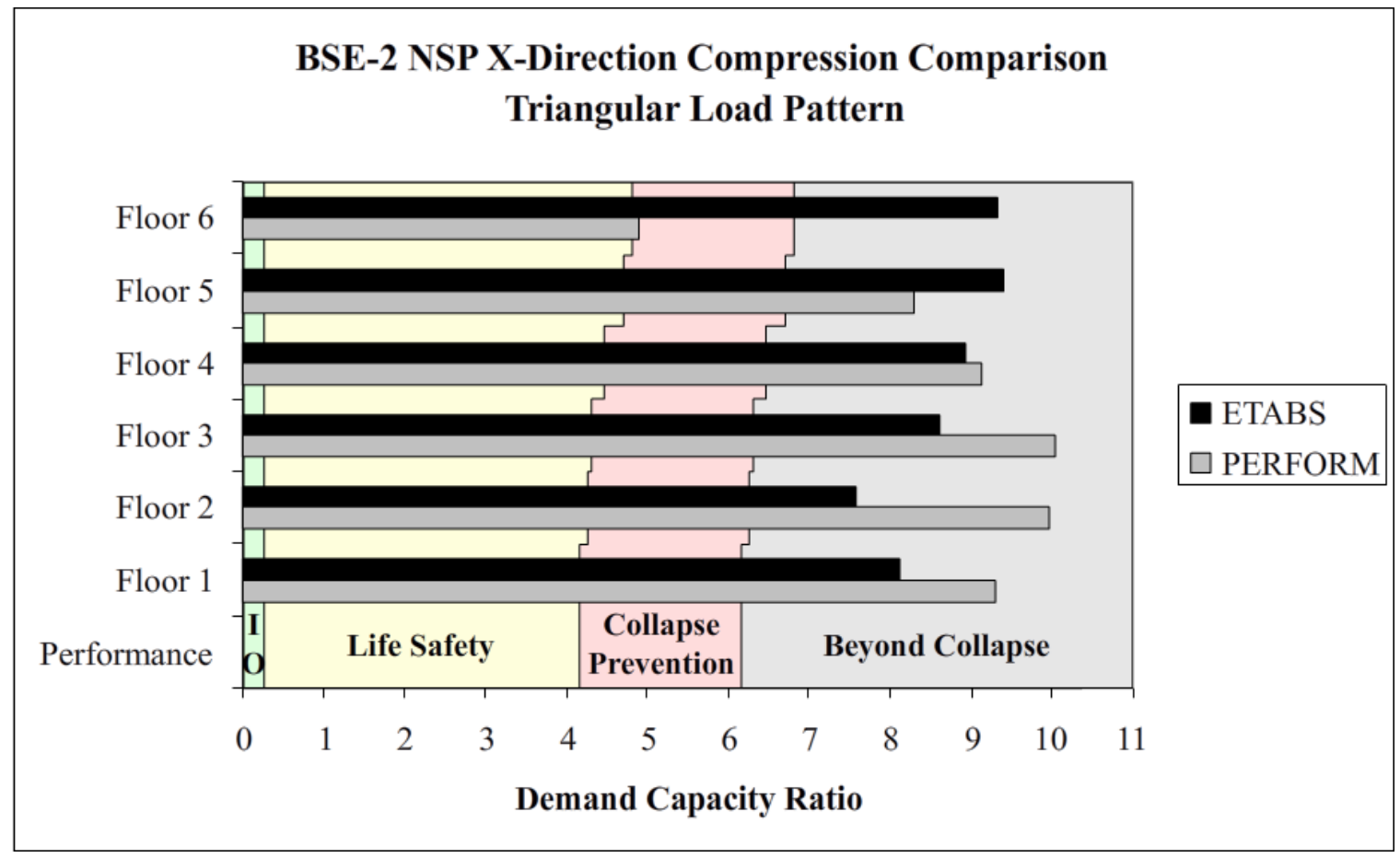

Figure DDD: BSE-2 NSP X-Direction Compression Comparison

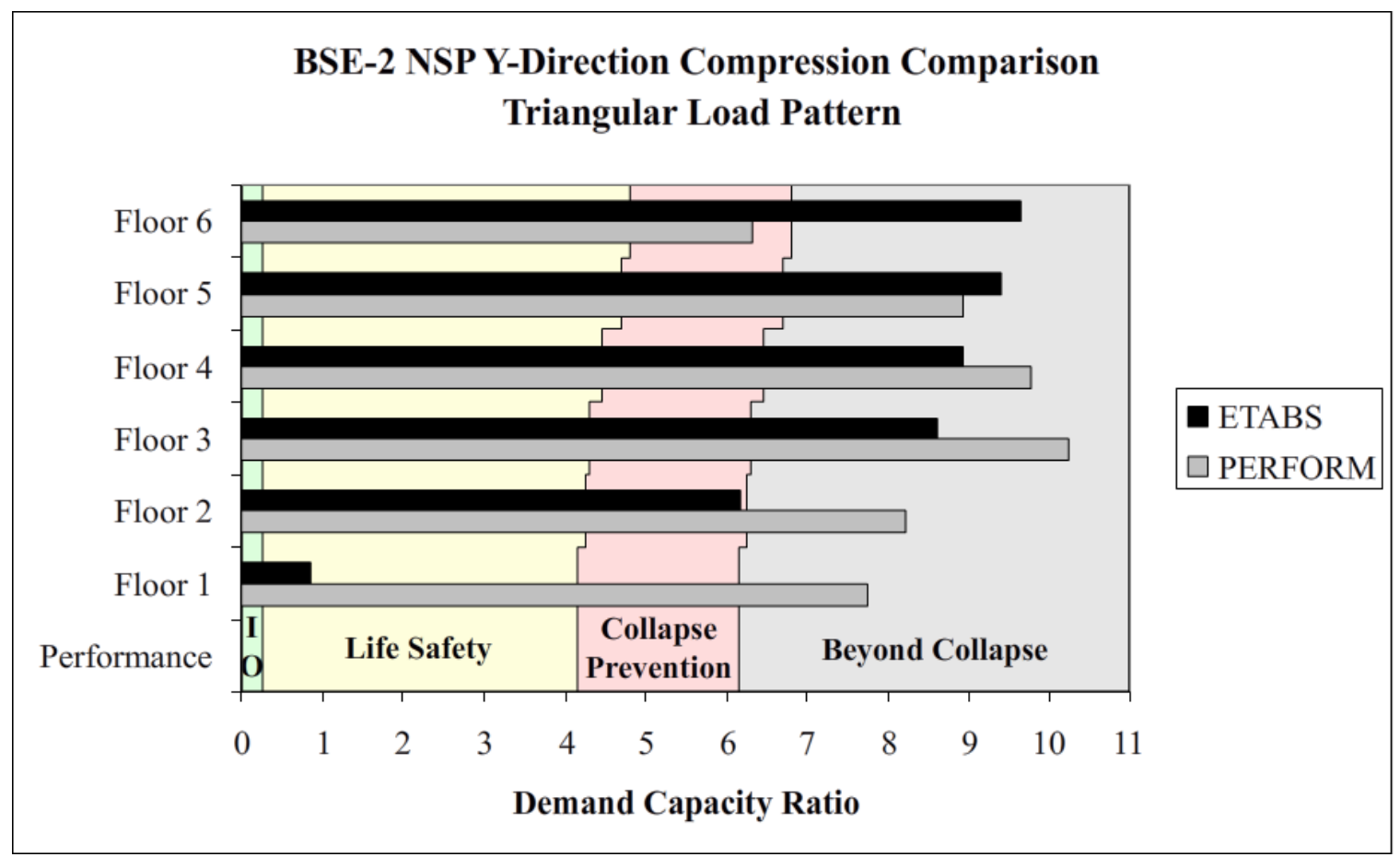

Figure EEE: BSE-2 NSP Y-Direction Compression Comparison

Performance-Based Analysis of Steel Buildings: Special Concentric Braced Frame 


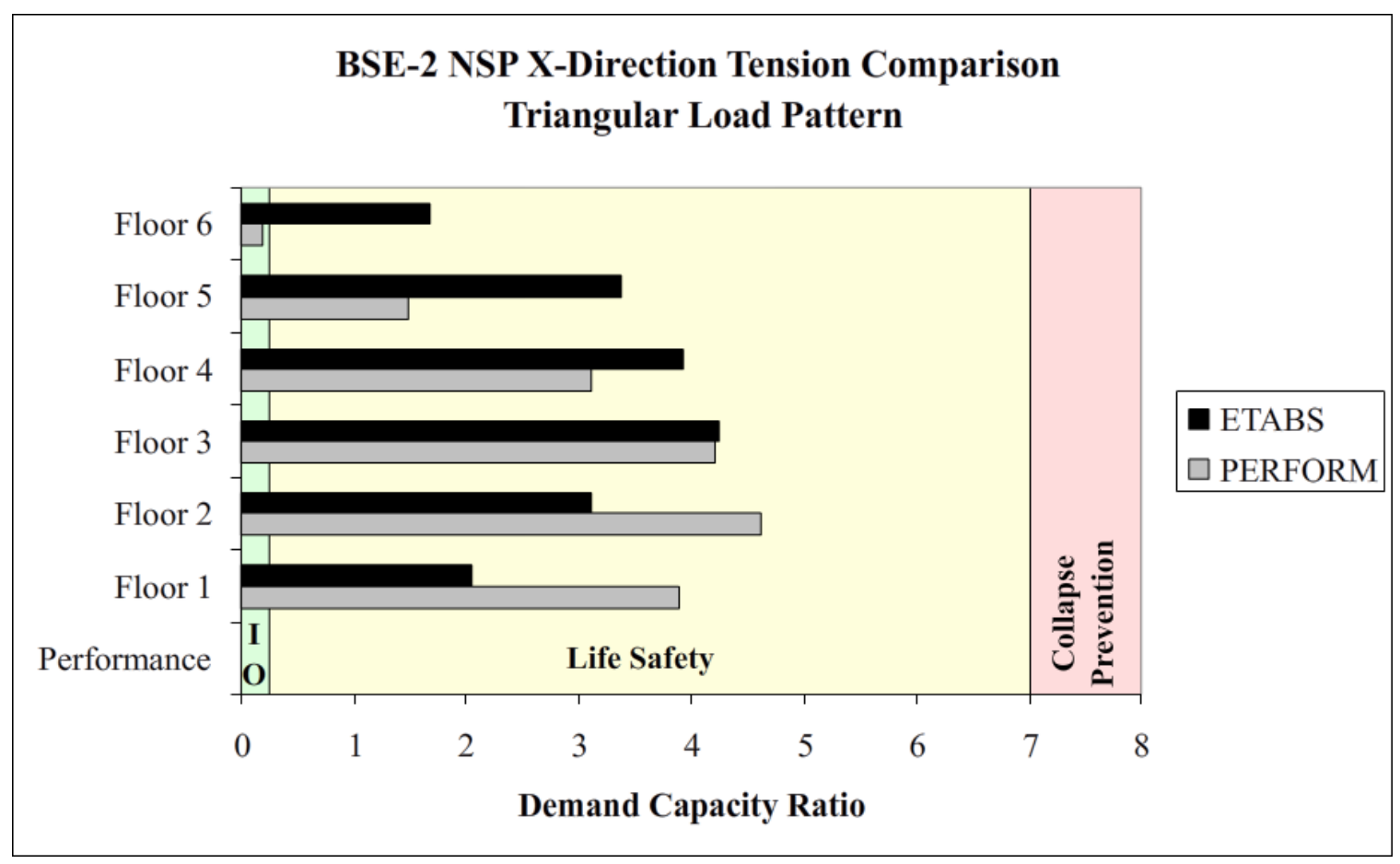

Figure FFF: BSE-2 NSP X-Direction Tension Comparison

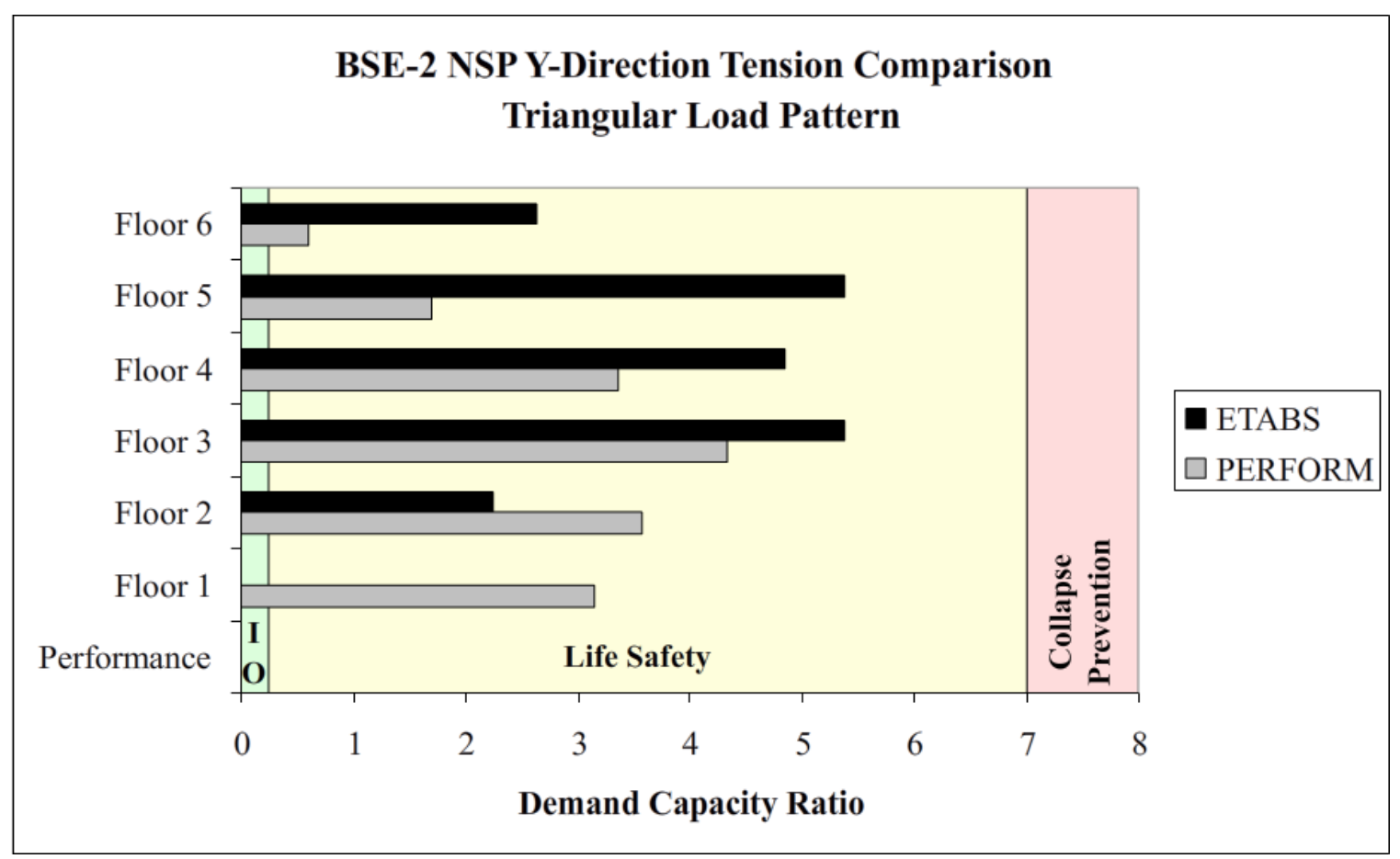

Figure GGG: BSE-2 NSP Y-Direction Tension Comparison

Performance-Based Analysis of Steel Buildings: Special Concentric Braced Frame 


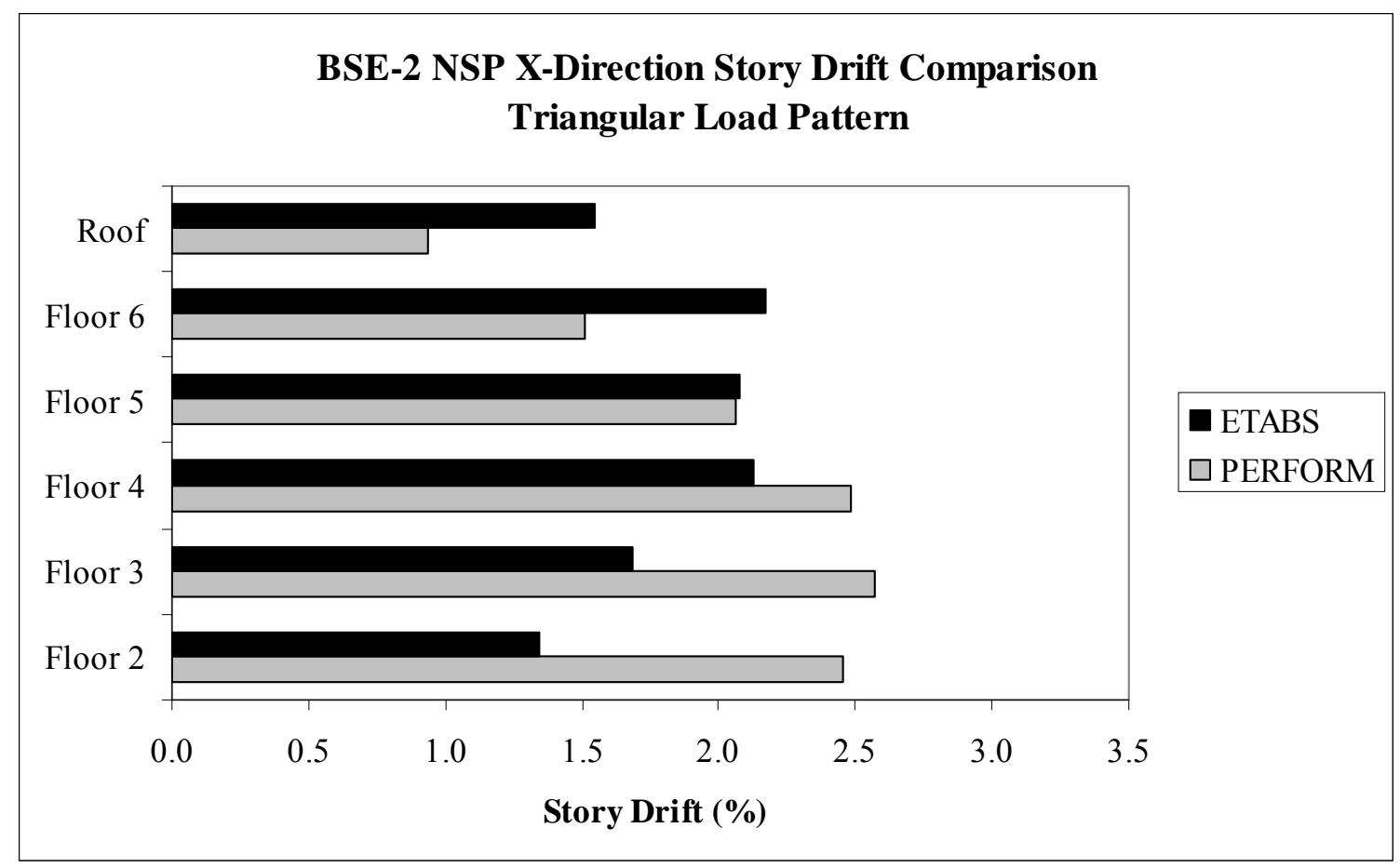

Figure HHH: BSE-2 NSP X-Direction Drift Comparison

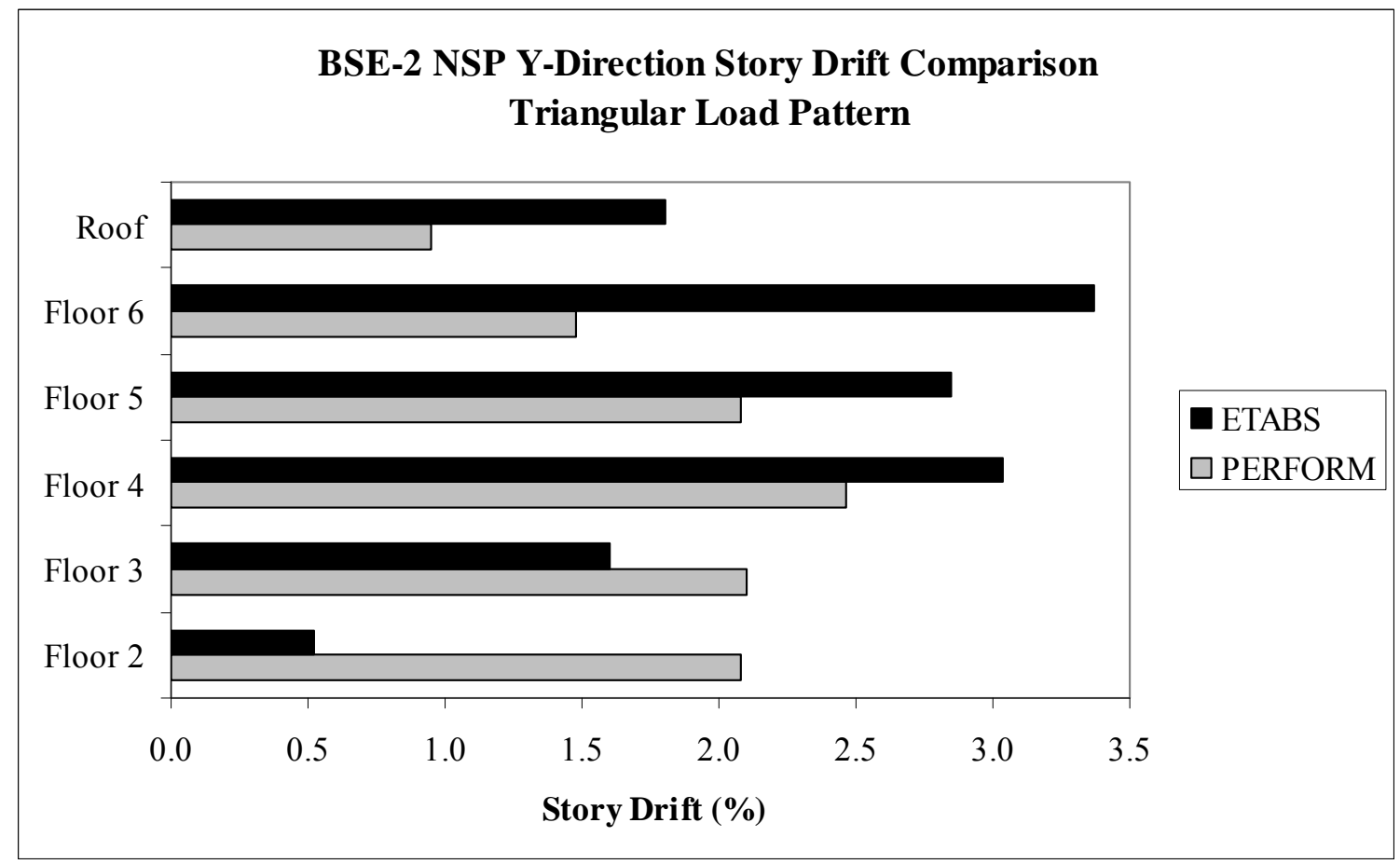

Figure III: BSE-2 NSP Y-Direction Drift Comparison

Performance-Based Analysis of Steel Buildings: Special Concentric Braced Frame 
The force-displacement curves remain fairly consistent after the BSE-1 target displacement. In the x-direction, the stiffnesses of each curve are similar, so the higher forces in the ETABS model remain constant. In the y-direction, the PERFORM model produces higher base shears after the BSE-1 target displacement due to the buckling of the several braces in the ETABS model. However, both models maintain relativly similar stiffnesses and base shears.

In the compression graphs, the trend from the BSE-1 analysis of ETABS indicating higher damage is not continued for the BSE-2 analysis. This is the result of the compression braces reaching the maximum deflections at most floors. Each analysis software package produces maximum limits higher than the modeled limit, but different from each other, as shown in the hinge comparison graph in section 7.1.2. This means that the graphs cannot be compared directly for which DCR is highest, but rather both perform similarly in that each of the braces reaches the maximum deformation possible for that software model. The differences in the maximum deflections are not very significant because both models produced DCRs that are substantially larger than the Collapse Prevention limits. The only significant difference between the models is that the braces on the first floor in the y-direction did not buckle in the ETABS model, while the braces did yield in the PERFORM model.

The x-direction tension and drift ratio graphs show a similar relationship in which the PERFORM values are slightly larger, primarily on the lower three floors. The ydirection shows the ETABS model concentrating the damage and drift at the upper floors as a result of the first-floor braces not buckling. 


\subsection{CONCLUSION}

This project subjected a special concentric braced frame building to two Basic Safety Earthquake (BSE) hazard levels, which enabled a performance-based evaluation of the ASCE 7-05 building design. In addition to examining the building performance level for the BSE-1 and BSE-2, this investigation also provided insight into the differences between the linear static procedure (LSP), linear dynamic procedure (LDP), nonlinear static procedure (NSP), and the nonlinear dynamic procedure (NDP) described ASCE 41-06. The project also explored the variations between ETABS and PERFORM when executing a nonlinear static procedure. This conclusion also includes a comparison between the results of this braced frame project, and the results of a companion project involving a similar building with a moment frame lateral system.

\subsection{Building Performance}

The building performance for each procedure was determined evaluating the performance of all components in the lateral resisting system. For a chevron braced frame, this included the braces acting in compression, as well as tension. A summary of each analysis and the resulting performance level is shown below in Table M.

\begin{tabular}{||c||c||c||}
\hline \multicolumn{3}{|c||}{ Building Performance } \\
\hline \hline Procedure & BSE-1 & BSE-2 \\
\hline \hline LSP & Life Safety & Limited Safety Range \\
\hline LDP & Life Safety & Limited Safety Range \\
\hline NSP & Collapse Prevention & Collapse Prevention \\
\hline NDP & Limited Safety Range & Collapse Prevention \\
\hline
\end{tabular}

Table M: Summary of Building Performance for All Analyses 
A performance level of Life Safety was determined if all components performed within the ASCE 41-06 Life Safety acceptance criteria. Procedures in which some members performed to Life Safety and others performed to Collapse Prevention were designated to be within the Limited Safety Range. ASCE 41-06 defines the Limited Safety Range as the "continuous range of damage states" between Life Safety and Collapse Prevention. Procedures in which compression braces performed past Collapse Prevention while the tension braces performed to Life Safety have been designated at the Collapse Prevention level.

The analyses for the BSE-1 hazard showed that the overall building performance conformed to Life Safety for the linear procedures, while the nonlinear dynamic procedure went beyond Life Safety and into the Limited Safety Range, and the nonlinear static procedure performed beyond the Limited Safety Range and into the Collapse Prevention level. The BSE-2 hazard level analyses continued the trend of the previous hazard level. The linear procedures went beyond Life Safety and into Limited Safety, while the nonlinear procedures went beyond Limited Safety and into Collapse Prevention.

There are several factors contributing to the variations in performance between each of the procedures. The linear dynamic procedure indicated less damage than the linear static procedure because the LDP base shear is $87 \%$ of the LSP base shear. The likely cause of this is static procedure approximating the total base shear as a function of the first mode, while the dynamic procedure determines the total base shear using an SRSS combination of the first twelve modes of the building. 
The linear procedures generally have lower demand-capacity ratios than the nonlinear procedures due to the deformation behavior of a buckling hinge. The linear procedures generally have larger drifts than the nonlinear procedures, as ASCE 41-06 predicts, but the braces have more damage in the nonlinear procedures. The increased damage in the nonlinear procedures is caused by the loss of stiffness after the brace buckles. The stiffness is reduced to zero in the post-buckled range, so the brace undergoes large deformations under relatively small forces. The acceptance criteria scaling factors of the linear procedures do not account for this damage relationship.

The reduction of the brace stiffness also resulted in damage concentrations during the NSP on the floors with the first buckling braces. The NSP is based on the roof of the building reaching a target displacement, so when the first brace buckled, the floor stiffness was reduced, and more of the target displacement was achieved by causing drift in the more flexible floor. The increased drift resulted in more brace deflection, which caused more damage to the braces. The damage concentrations can be seen in the compression braces on the third floor of the PERFORM BSE-1 analysis, and on the fifth floor of the ETABS BSE-1 analysis.

The nonlinear static procedure indicated more damage than the nonlinear dynamic procedure because of the NSP target displacement. The average roof displacement from the NDP was $50 \%$ of the NSP target displacement for the BSE- 1 , and $40 \%$ of the target displacement for the BSE-2. This reduction in roof displacement corresponds to a significant reduction in brace damage. 
Considering the variations in the damage shown by the four procedures, each analysis can have its advantages if performed for a similarly proportioned, regular, special concentric braced frame building. If the building passes a nonlinear static procedure, it will pass all other procedures, and can be used as a worst-case envelope, but the NSP has the potential to grossly overestimate the brace damage. The linear static or linear dynamic procedure can be used as a quick baseline value to create a best-case performance scenario for the other procedures, but both have the potential to underestimate the damage. The nonlinear dynamic procedure provides a middle range of damage compared to the other procedures. It includes nonlinear deformation effects of buckling members, while providing a more favorable prediction of maximum roof displacement. However, the NDP is more sensitive to the assumptions made while making the computer model, and takes significantly more time to perform an analysis.

There are some issues with ranking the performance of a building using ASCE 41-06. ASCE 41-06 provides only qualitative explanations for overall building performance, leaving the ultimate performance up to the subjective interpretations of the engineer or approval organization. In a system like a chevron configuration braced frame, the tension and compression braces meet the criteria for different performance levels, which results in the ultimate building performance being harder to quantify. A conservative, element-based approach would dictate that this building performed worse than if the lateral system is looked at as a whole. More definitive, quantitative global building evaluation procedures would make ASCE 41-06 less subjective. 
In general, no matter how the data is interpreted, the ASCE 7-05 design did not strictly meet the design goals of Life Safety for the BSE-1, and Collapse Prevention for the BSE-2 when looking at the nonlinear analyses. More investigations can be made into how best to improve the building performance, or the evaluation procedures in ASCE 4106.

\subsection{Areas of Future Study}

An issue of possible future study is the effect of including rigid-end-offsets on the braces, which would reduce the effective length. A preliminary calculation showed the capacity of the braces would increase between $6 \%$ and $12 \%$, but that strength increase would be accompanied by an increase in the stiffness of the building. To observe this stiffness increase, an analytical model was created in ETABS approximating the increased stiffness of the brace ends. This new, stiffer model reduced the building period by approximately $6 \%$, thereby increasing the base shear by $6 \%$. This is similar to the increase in capacity the braces would receive, so the net effect on the performance of the braces is minimal. However, more detailed brace ends might produce different results.

\subsection{ETABS vS. PERFORM}

Compared to PERFORM, ETABS consistently produced higher nonlinear displacement demands. ETABS also concentrated much more of the damage on a single floor, to the point of reaching the maximum hinge deformation limits in the BSE-1 analysis. The most likely cause of this behavior is the way the software processes the sudden loss of strength experienced when a member buckles, as well as the redistribution 
of forces away from the buckled member. For reference, the hinge comparison graph from Section 7.1.2 is reprinted in Figure TT on the following page.

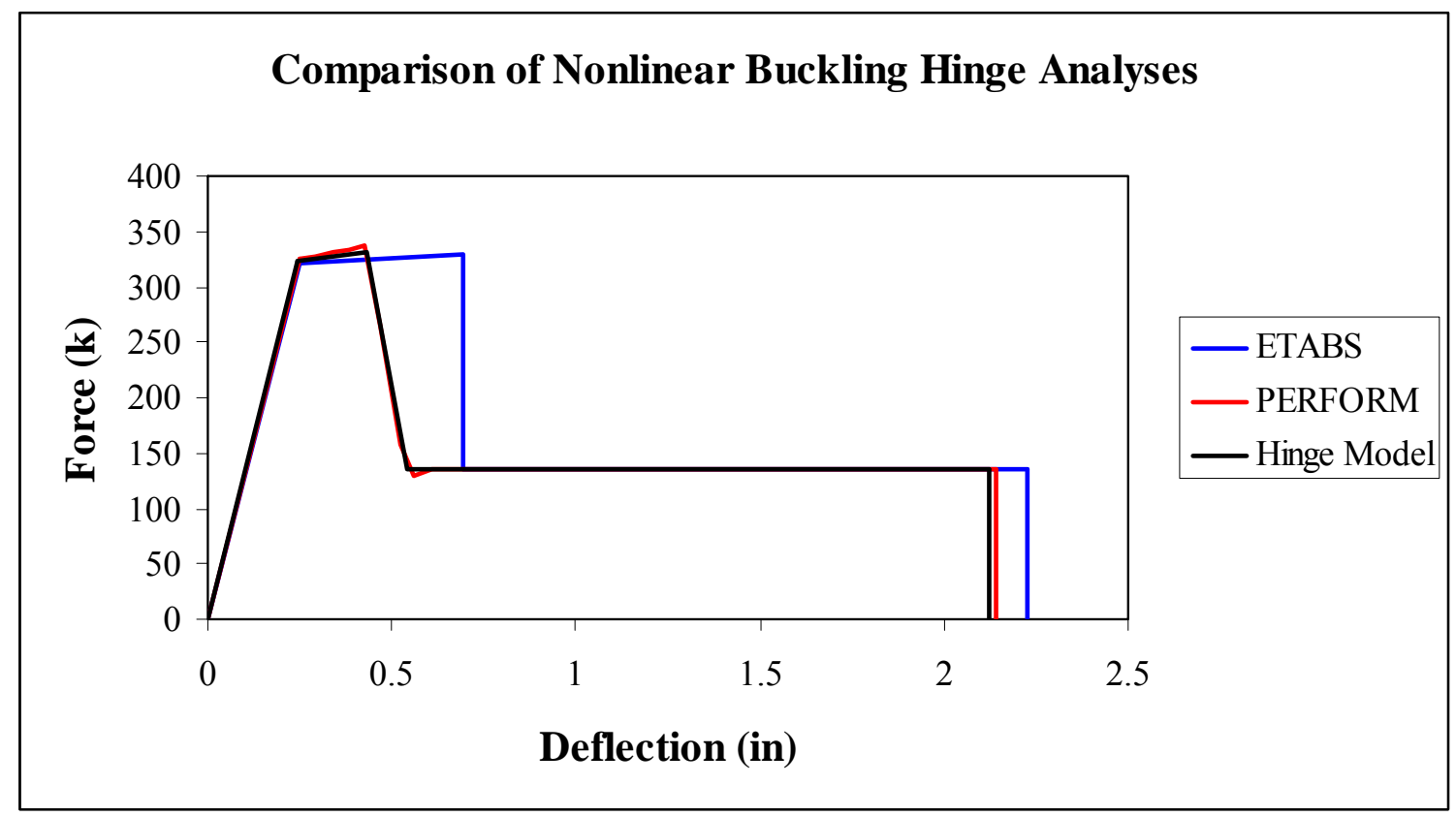

Figure TT: Nonlinear Compression Hinge Comparison

As the graph shows, the ETABS hinge has the same buckling force, but the displacement is increased. The ETABS hinge also neglects the gradual stiffness decrease after buckling, and instead instantly drops the force when the brace buckles, which is not what was modeled. This sudden drop is a possible cause of the damage concentrations, because there is no time to gradually transfer the load to the other braces.

\subsection{Comparison to Special Moment Frame Analysis}

The results for a similar performance-based analysis using a moment frame lateral system can be found in "Performance-Based Analysis of Steel Buildings" (Williams 2009). This research showed that a special moment frame (SMF) system performed as well or better than the ASCE 7-05 Life Safety design intent for the BSE-1 earthquake 
hazard. The relative performance of each procedure was also more in line with the ASCE 41-06 predictions, as the nonlinear procedures predicted less damage than the linear procedures. This differs from the special concentric braced frame (SCBF) analyses in which the nonlinear procedures predicted more damage than the linear counterparts. The likely cause of this discrepancy is the nonlinear hinge behavior for each building type. The bending hinges in the moment frame don't experience the sudden strength and stiffness loss of the buckling compression braces, which result in the increased damage.

Also of interest is the relative similarity between the maximum roof displacements that resulted from the NSP and NDP for the special moment frame analysis. The SMF NDP displacement was larger than the NSP displacement, with a difference of $9 \%$ between the two procedures. This is significantly higher than the $50 \%$ difference found in the braced frame analyses. A possible cause for this inconsistency is the way the target displacement equation was derived. FEMA 274 states that the equations were derived using "non-strength-degrading" single degree of freedom systems (FEMA 274, 3-24). When a brace buckles in the SCBF building, the strength drops suddenly, as shown in the NSP pushover curves. This sudden strength degradation could explain why the SCBF performs so poorly in the nonlinear static procedures, and the SMF performs as well as it does. 


\subsection{REFERENCES}

(ASCE 7-05) American Society of Civil Engineers. ASCE 7-05 Minimum Design Loads for Buildings and Other Structures. Reston, Virginia. 2006

(ASCE 41-06) American Society of Civil Engineers. ASCE 41-06 Seismic Rehabilitation of Existing Buildings. Reston, Virginia. 2007

(FEMA 274) United States. Federal Emergency Management Agency. FEMA 274: NEHRP Commentary on the Guidelines for the Seismic Rehabilitation of Buildings. Washington: FEMA, 1997.

(FEMA 351) United States. Federal Emergency Management Agency. FEMA 356: Recommended Seismic Evaluation and Upgrade Criteria for Existing Welded Steel Moment-Frame Buildings. Washington: FEMA, 2000.

(FEMA 440) United States. Federal Emergency Management Agency. FEMA 440: Improvement of Nonlinear Static Seismic Analysis Procedures. Washington: FEMA, 2005.

(Ghobarah 2001) Ghobarah, Ahmed. "Performance-Based Design in Earthquake Engineering: State of Development.” Engineering Structures. 23 (2001) 878-884.

(Hamburger 2008) Hamburger, Ronald. "Development of Next-Generation PerformanceBased Structural Design Criteria.” Building Safety Journal. April-May (2008) 3638

(Williams 2009) Williams, Matt. "Performance Based Analysis of Steel Buildings.” MS Thesis California Polytechnic State University, San Luis Obispo, 2009. Print. 


\subsection{APPENDIX}

The appendix includes all seven scaled ground motion graphs, a tension hinge comparison graph, typical hinge inputs for ETABS and PERFORM, hinge models for all braces, the MATLAB code used to scale the ground motions, and a list of acronyms.

\subsection{List of Acronyms}

AISC: American Institute of Steel Construction

ASCE: American Society of Civil Engineers

BSE: Basic Safety Earthquake

CP: Collapse Prevention

FEMA: Federal Emergency Management Agency

IO: Immediate Occupancy

LDP: Linear Dynamic Procedure.

LS: Life Safety

LSP: Linear Static Procedure.

MCE: Maximum Considered Earthquake

NDP: Nonlinear Dynamic Procedure.

NSP: Nonlinear Static Procedure.

PBD: Performance Based Design

SRSS: Square Root Sum of Squares 

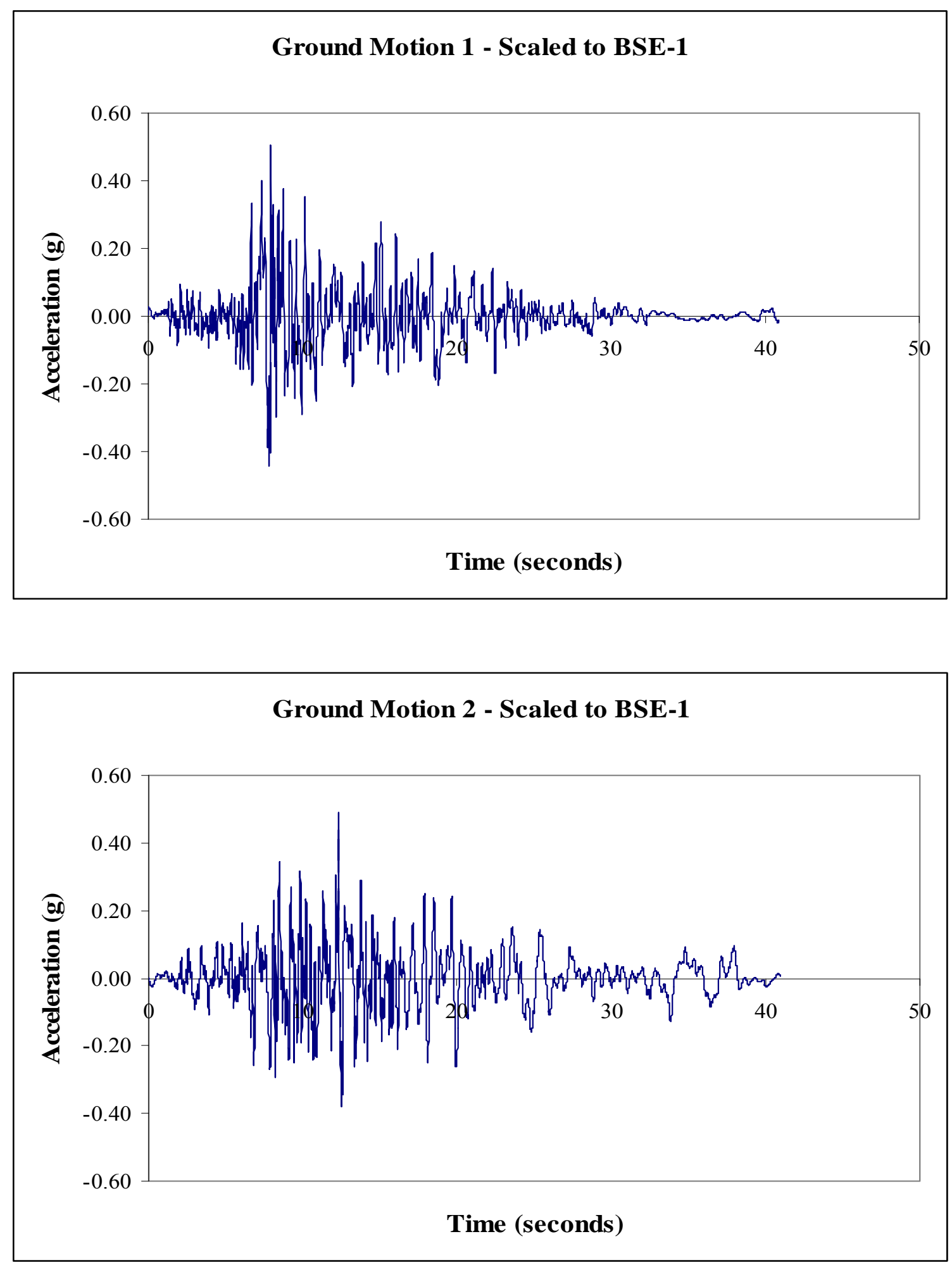

Performance-Based Analysis of Steel Buildings: Special Concentric Braced Frame 

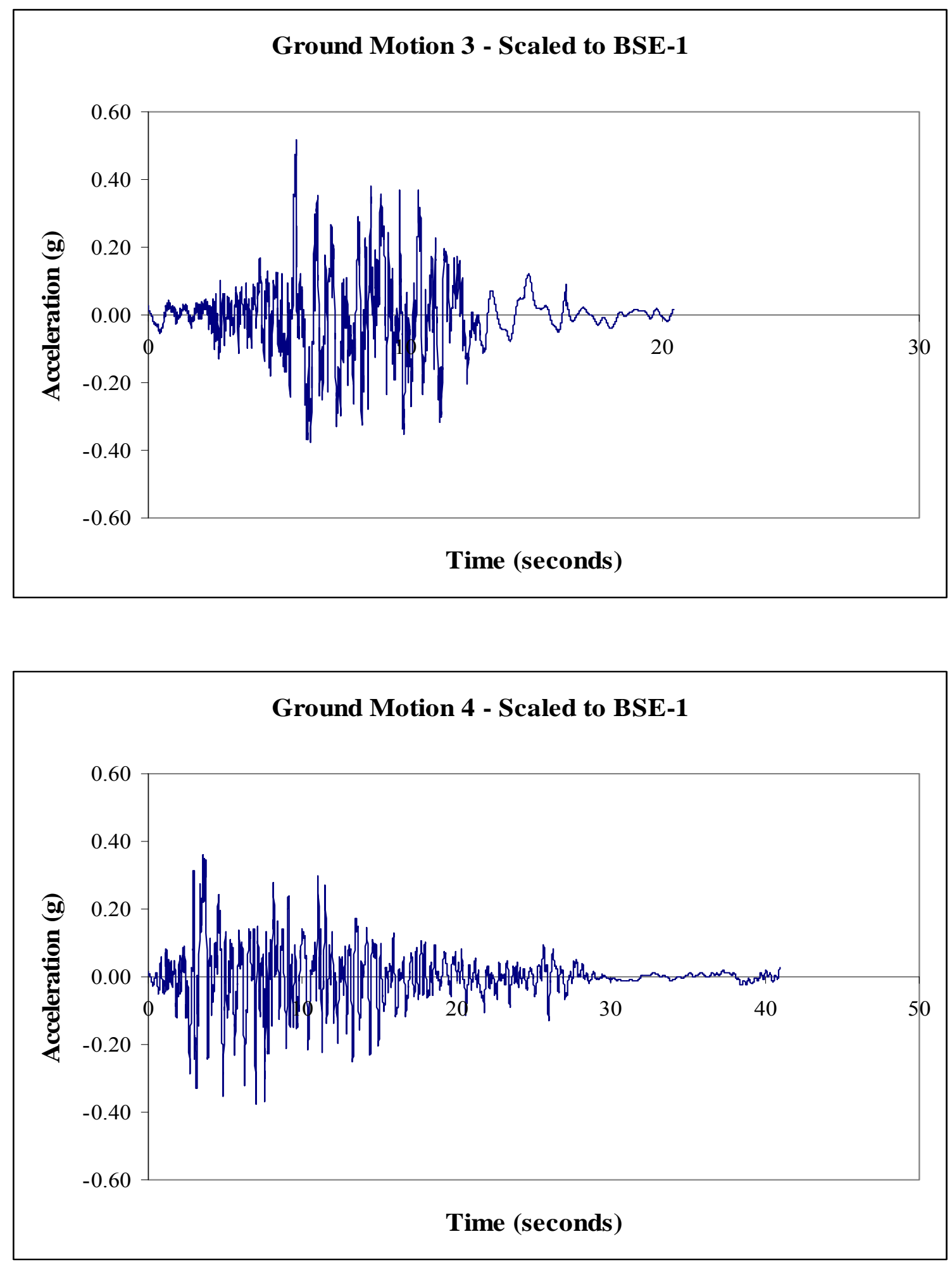

Performance-Based Analysis of Steel Buildings: Special Concentric Braced Frame 

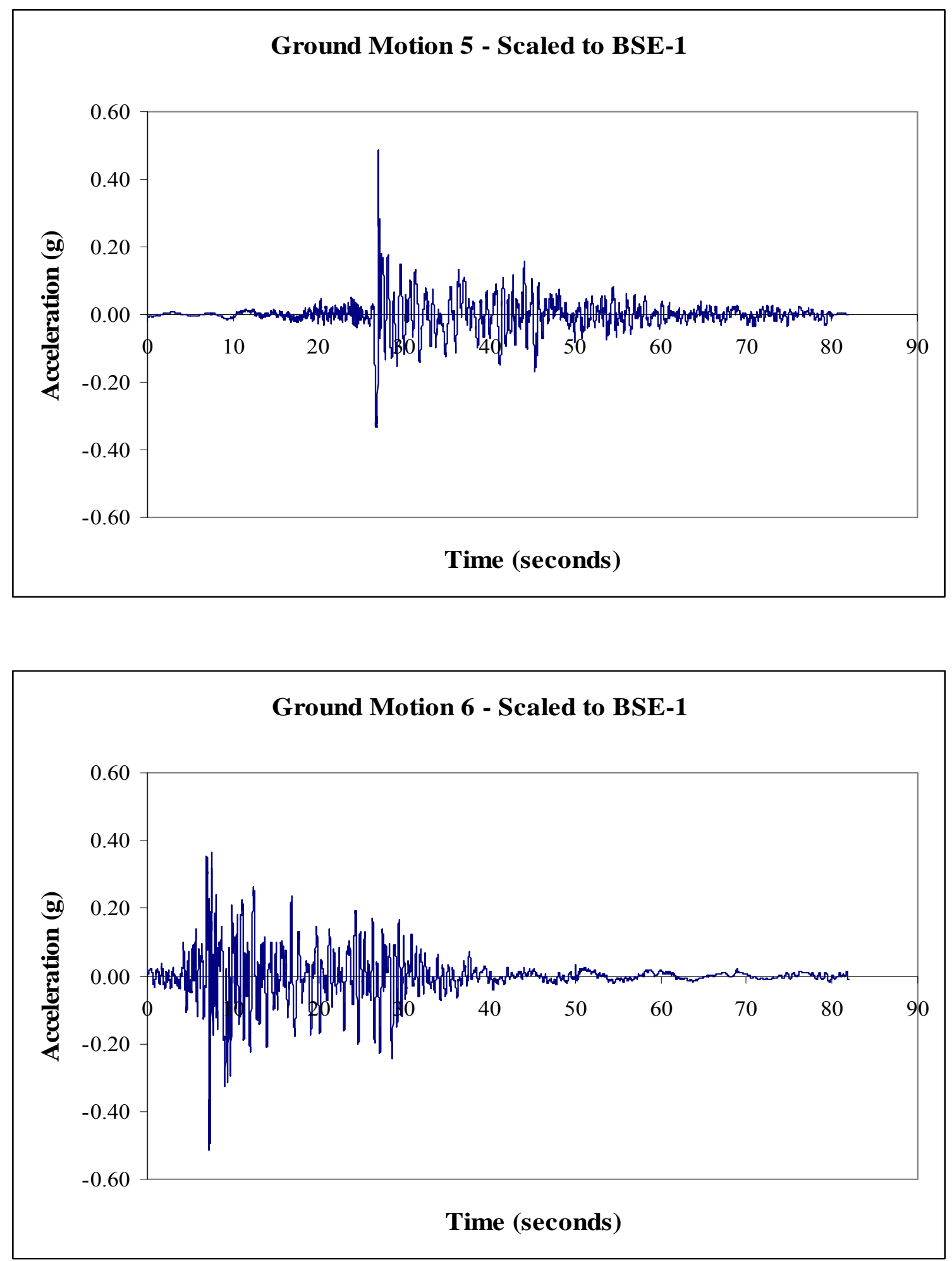

Performance-Based Analysis of Steel Buildings: Special Concentric Braced Frame 

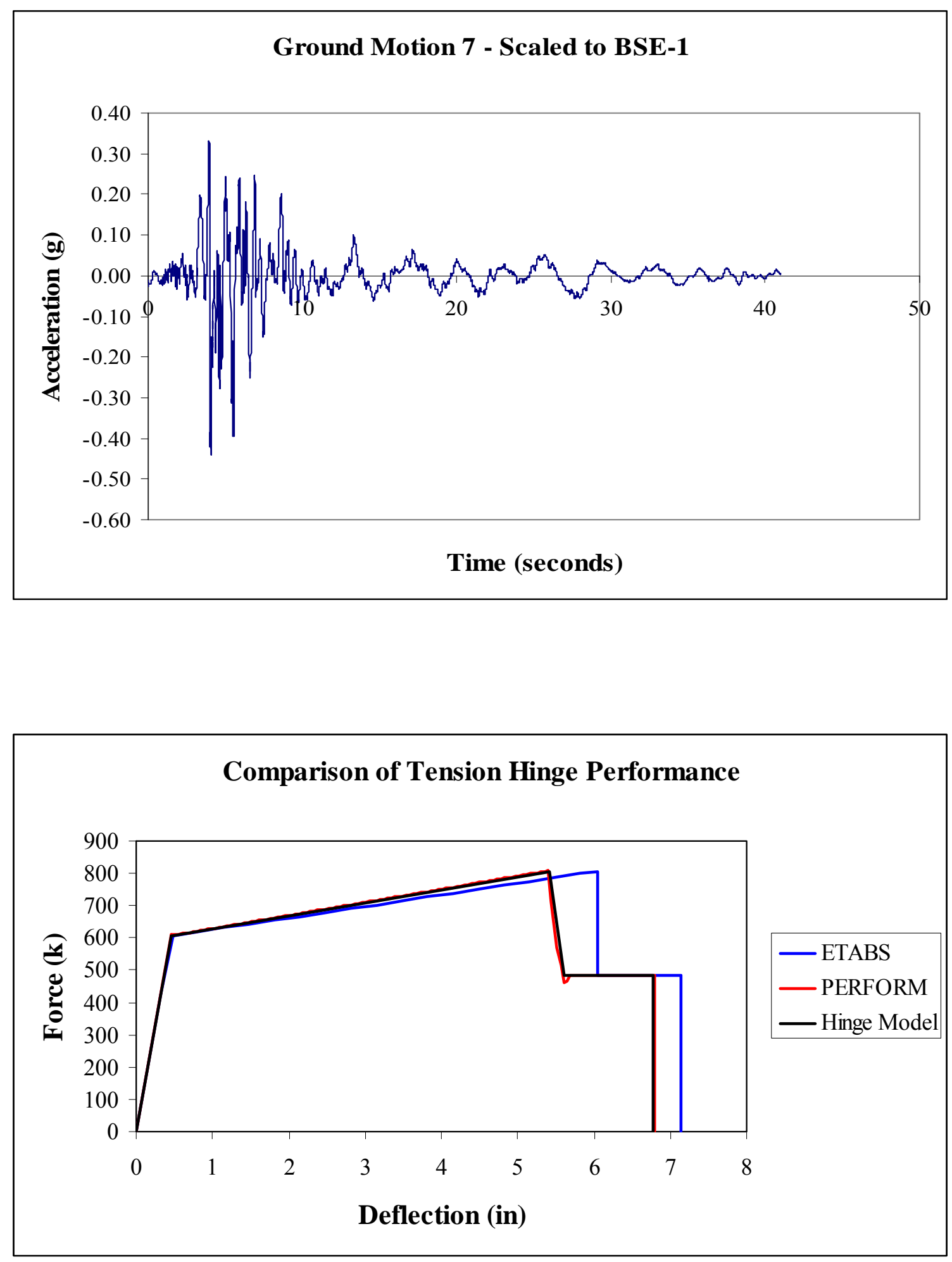

Performance-Based Analysis of Steel Buildings: Special Concentric Braced Frame 


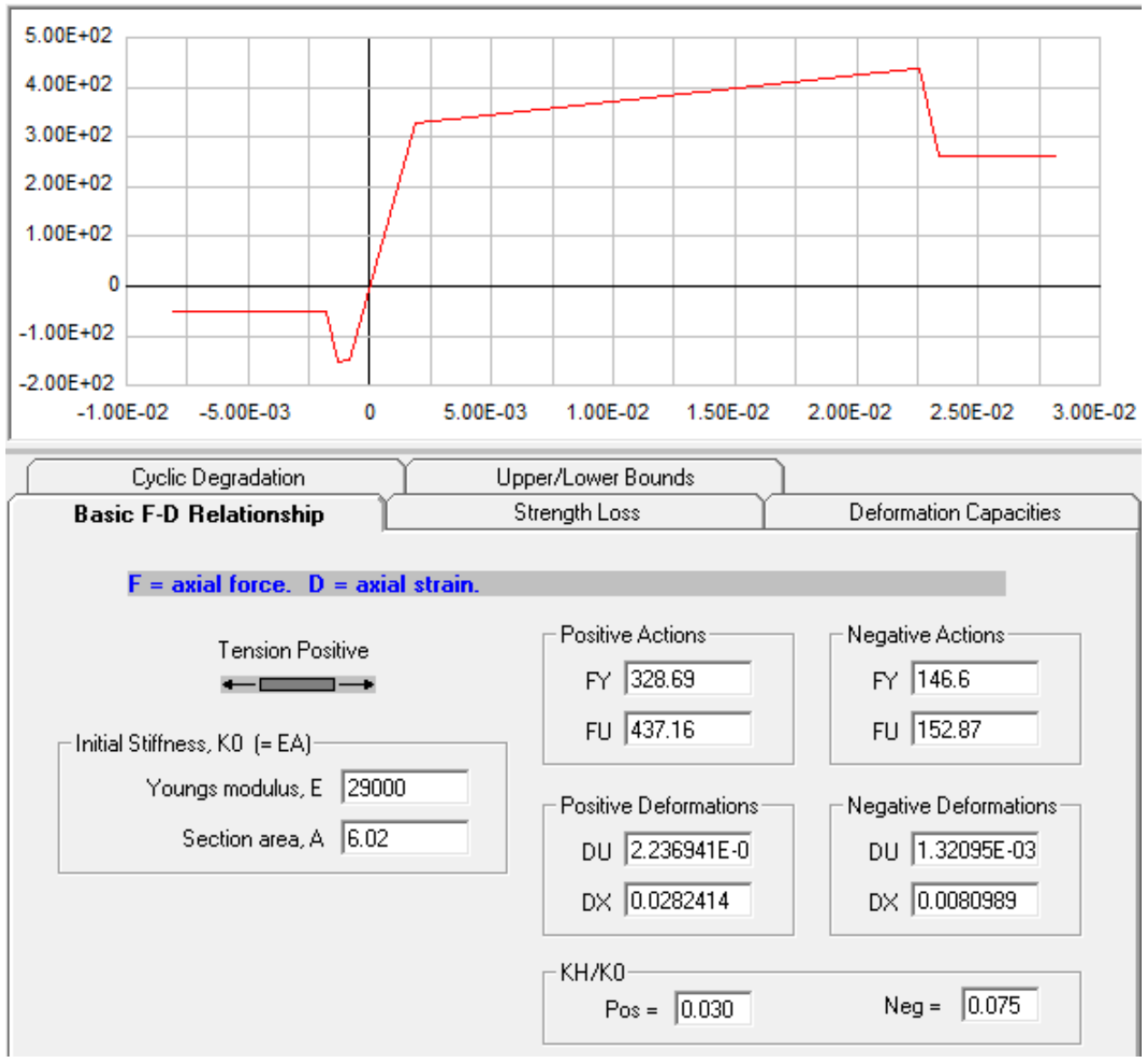

\section{Typical PERFORM Hinge}

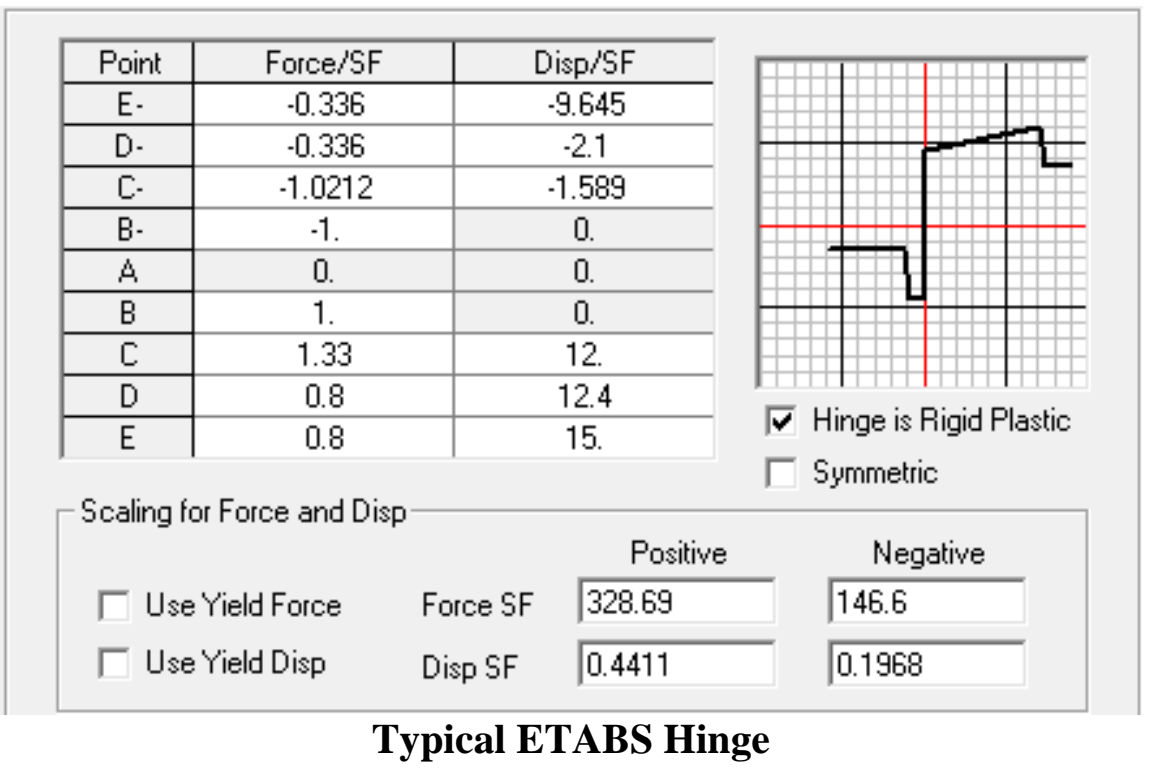

Performance-Based Analysis of Steel Buildings: Special Concentric Braced Frame 

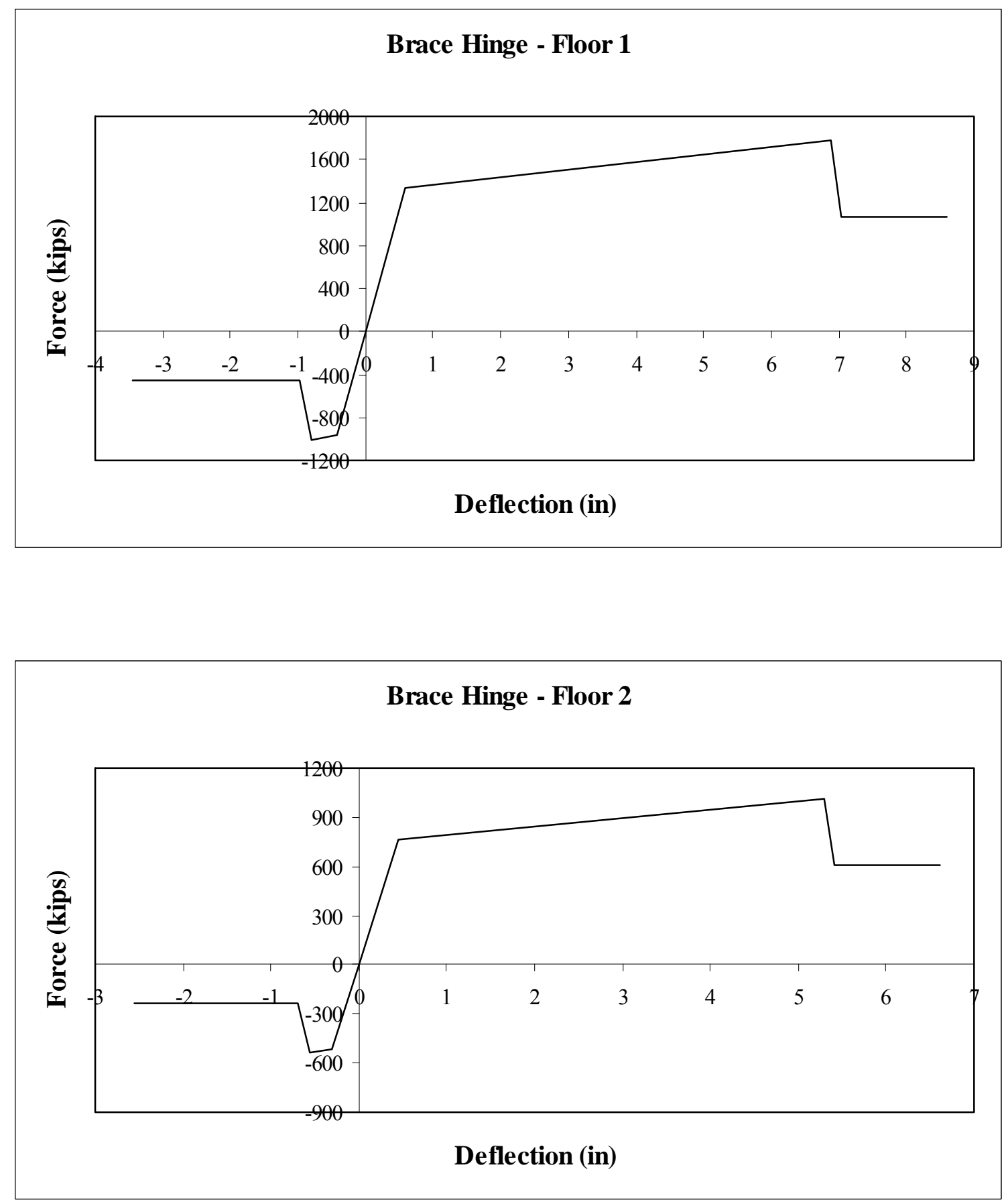

Performance-Based Analysis of Steel Buildings: Special Concentric Braced Frame 

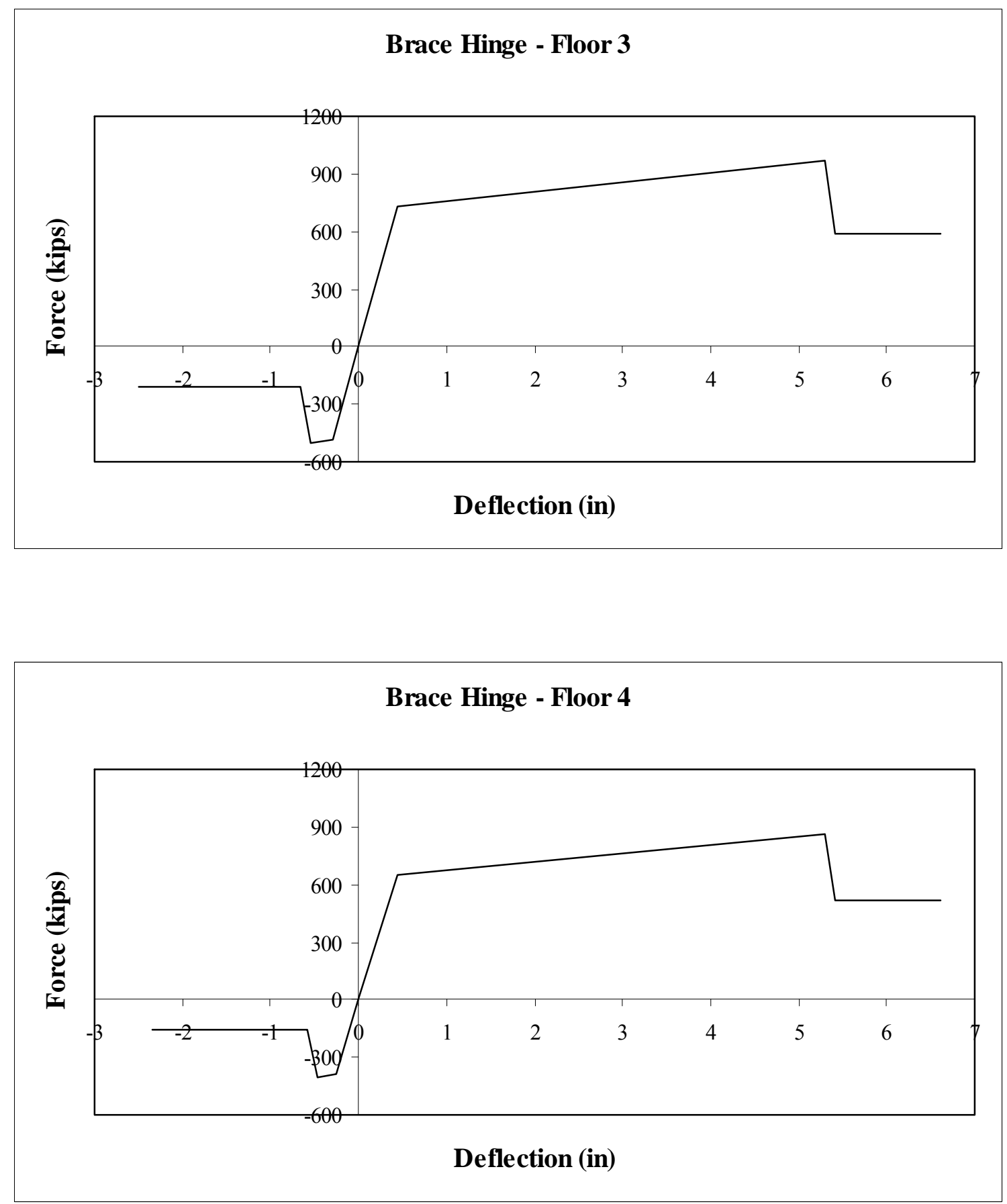

Performance-Based Analysis of Steel Buildings: Special Concentric Braced Frame 

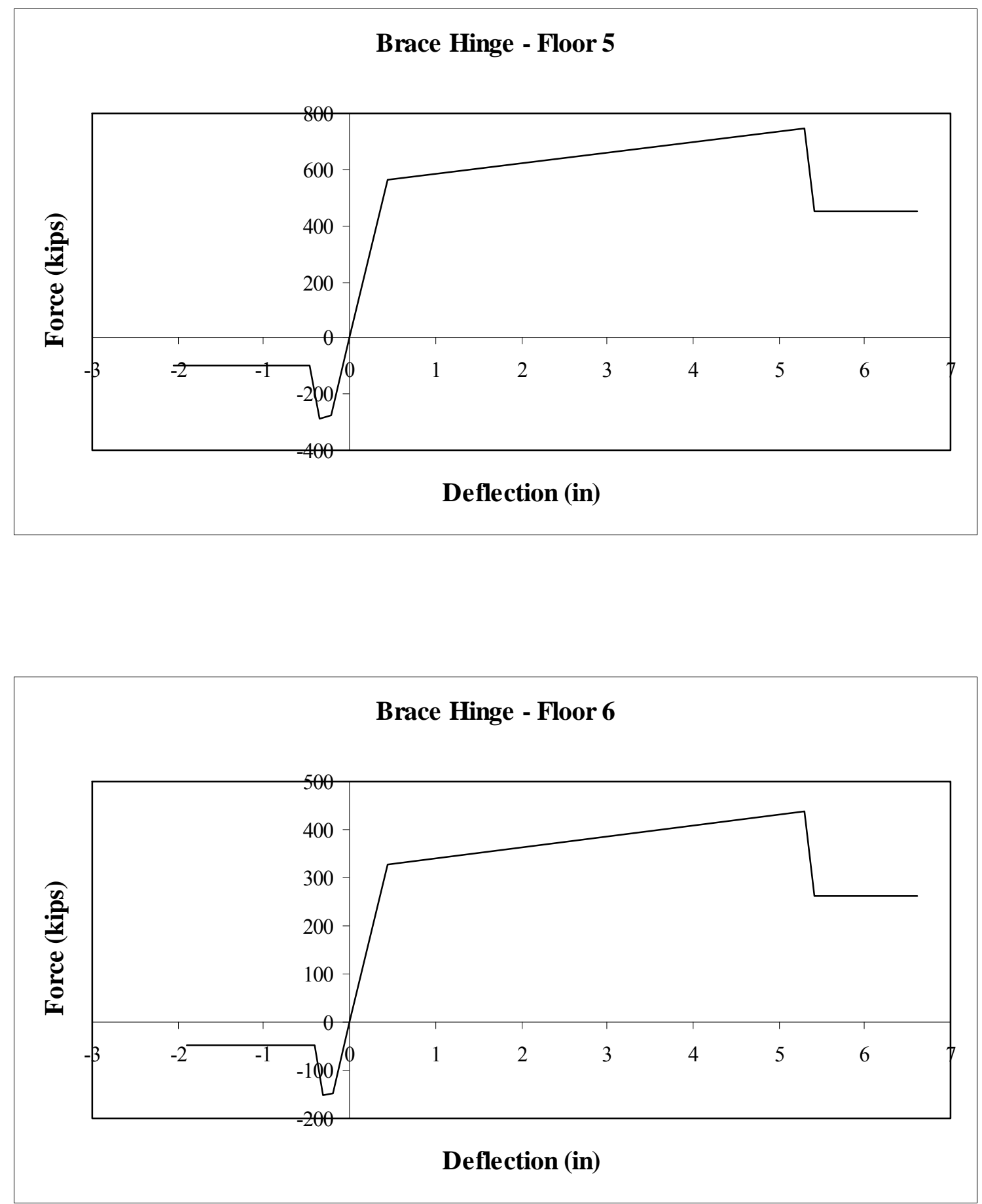

Performance-Based Analysis of Steel Buildings: Special Concentric Braced Frame 


\section{MATLAB Scaling Program}

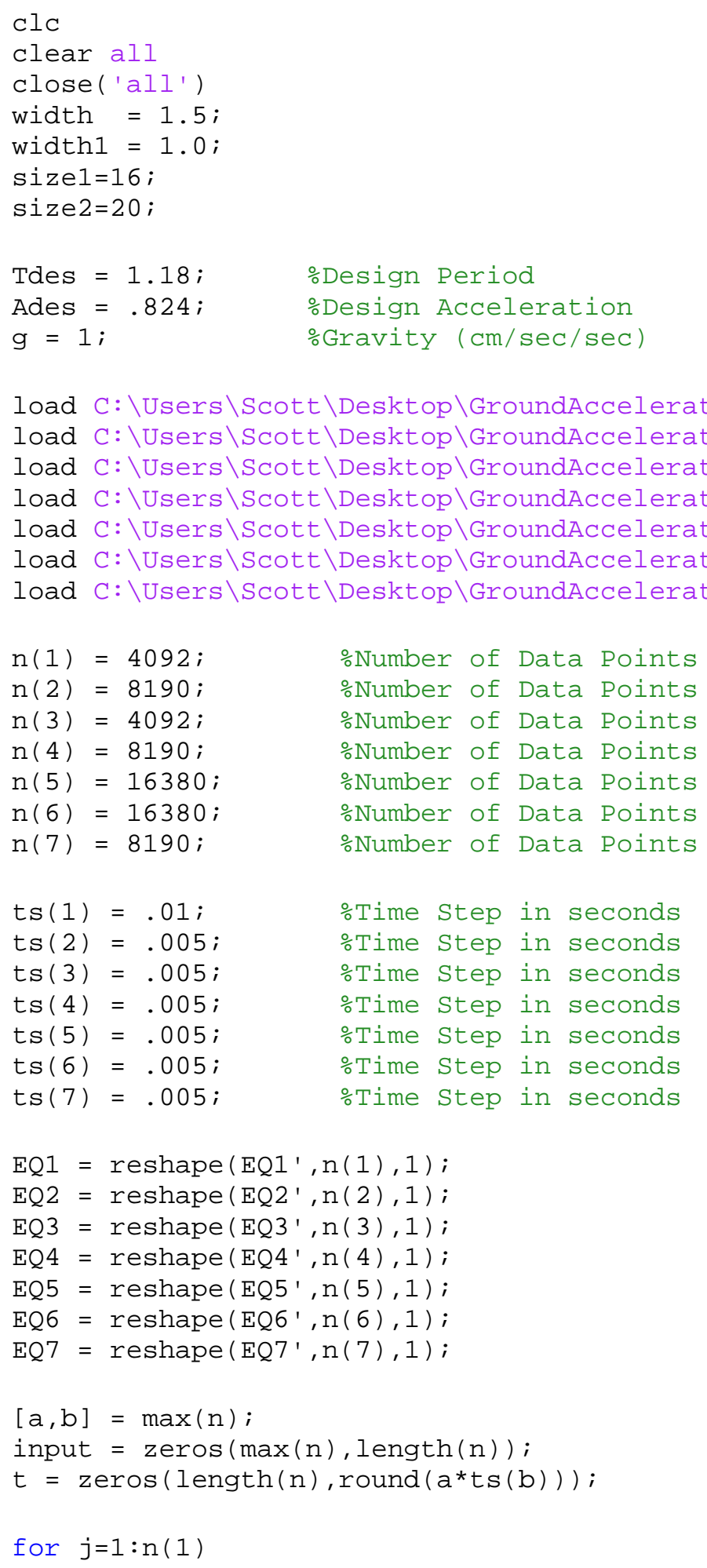




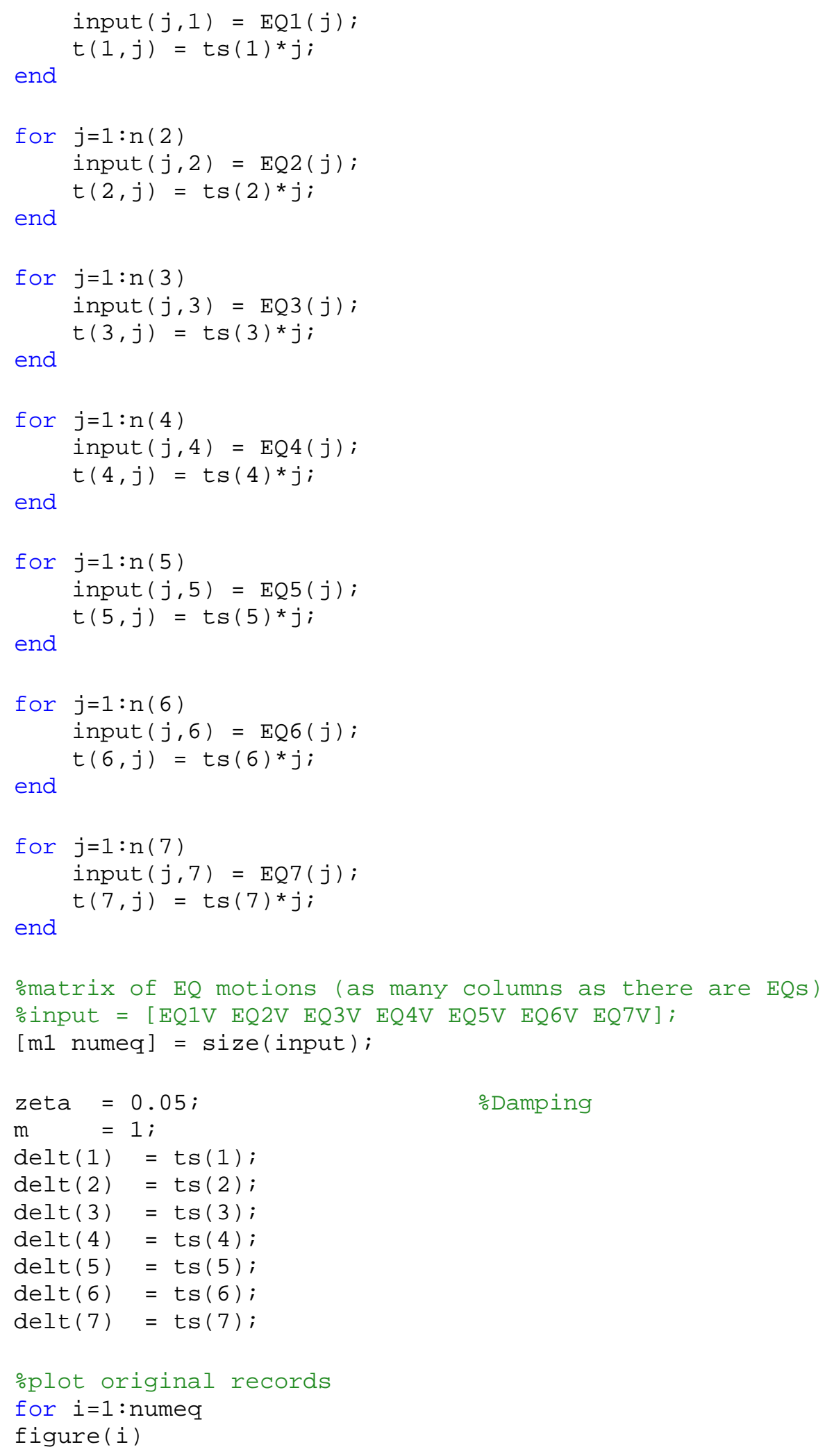

Performance-Based Analysis of Steel Buildings: Special Concentric Braced Frame 


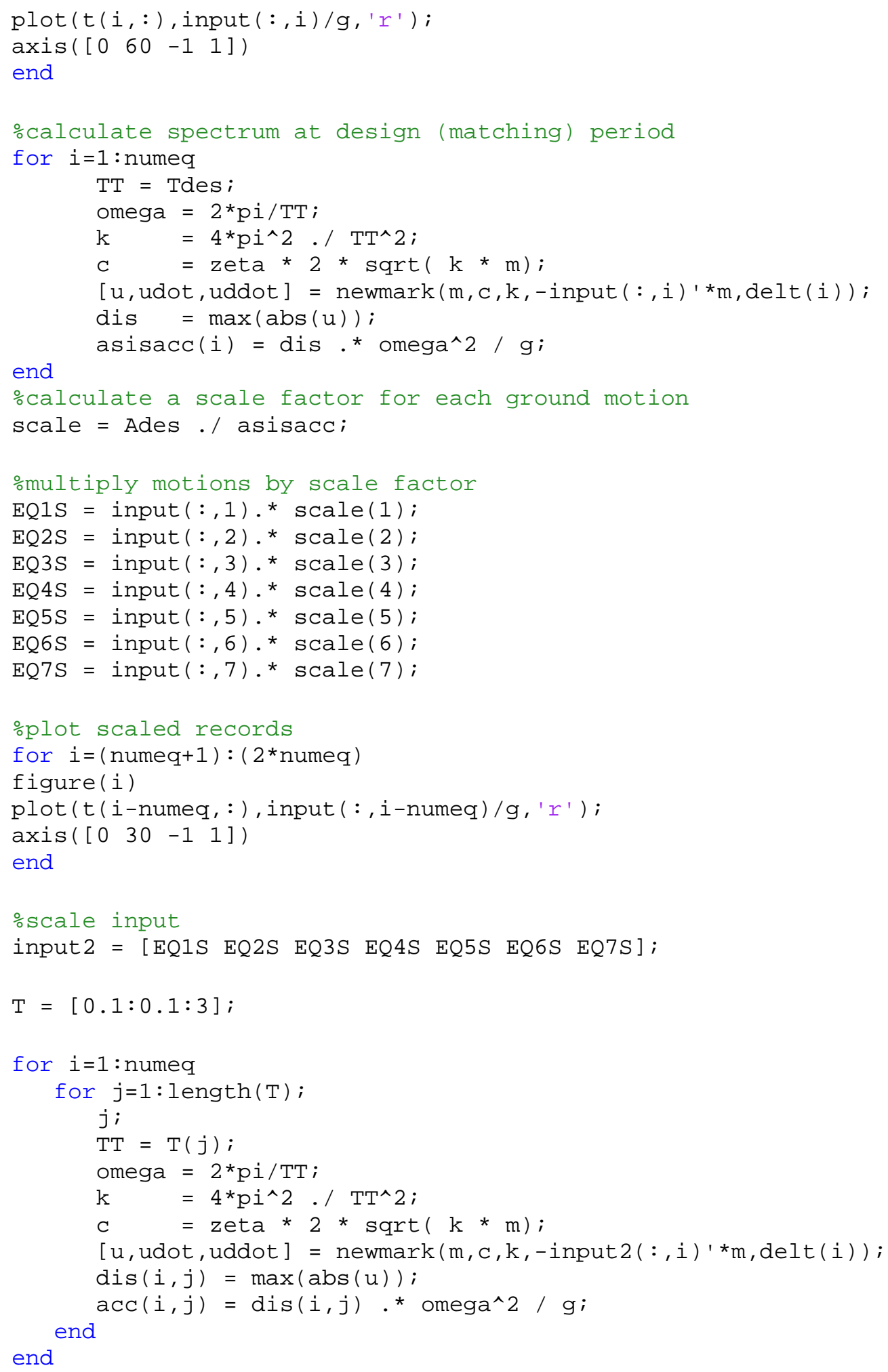

Performance-Based Analysis of Steel Buildings: Special Concentric Braced Frame 


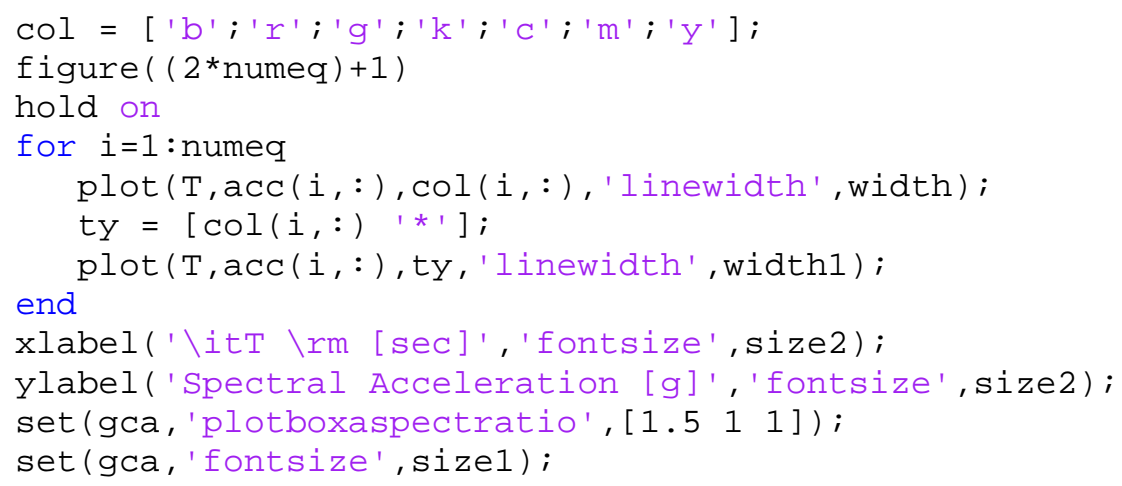

\section{MATLAB Newmark Sub-Program}

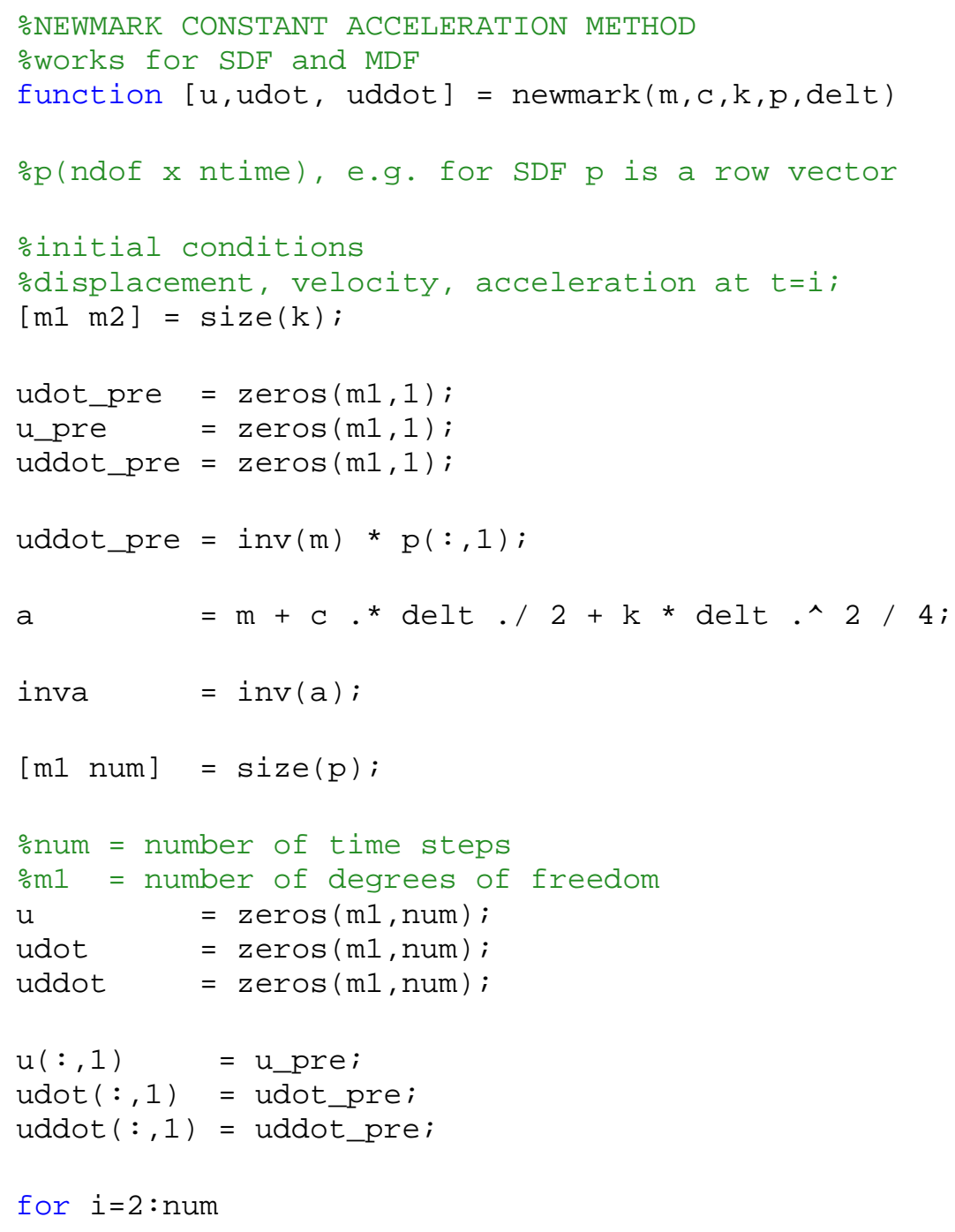

Performance-Based Analysis of Steel Buildings: Special Concentric Braced Frame 


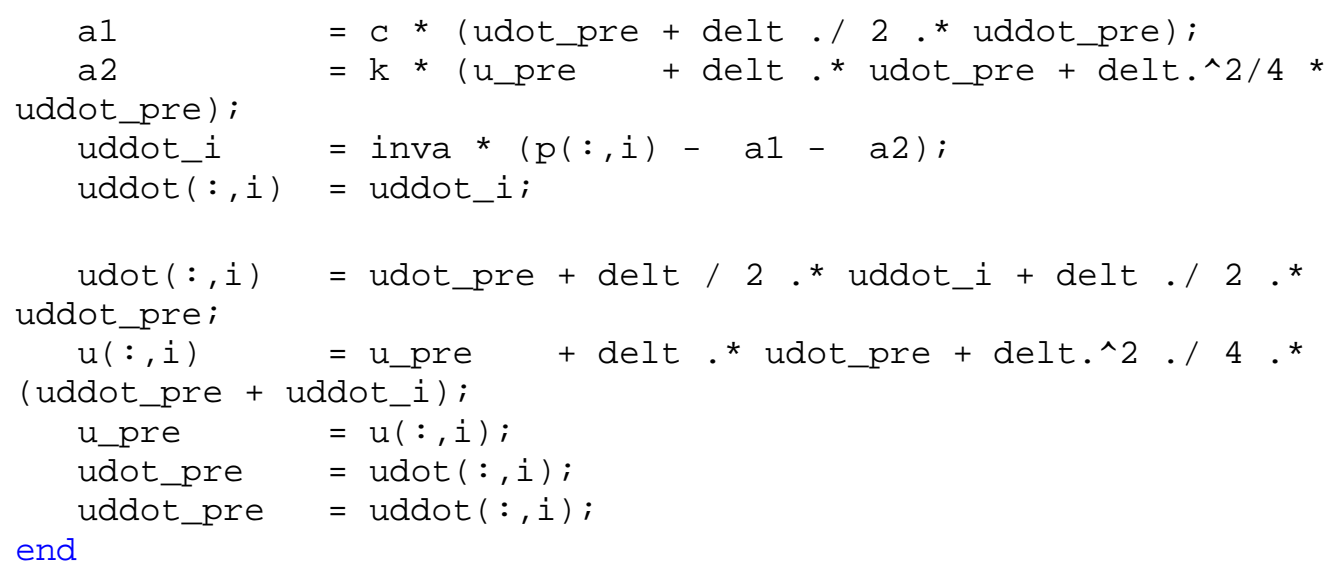

